\title{
"ESTUDO CEFALOMÉTRICO DO POSICIONAMENTO DENTÁRIO EM JOVENS BRASILEIROS FEODERMAS, COM OCLUSÃO NORMAL"
}

EDUARDO JACOMINO FRAJNCO

Dissertação apresentada à Faculdade de Odontologia de Bauru da Universidade de São Paulo, como parte dos requisitos para obtenção do Título de Mestre em Odontologia, área de Ortodontia. 



\section{“ESTUDO CEFALOMÉTRICO DO POSICIONAMENTO DENTÁRIO EM JOVENS BRASILEIROS FEODERMAS, COM OCLUSÃO INORMAL"}

EDUARDO JACOMINO FRANCO

Dissertação apresentada à Faculdade de Odontologia de Bauru da Universidade de São Paulo, como parte dos requisitos para obtenção do Título de Mestre em Odontologia, área de Ortodontia.

Orientador: Prof. Dr. Arnaldo Pinzan 
Franco, Eduardo Jacomino

F848e Estudo Cefalométrico do posicionamento dentário em jovens brasileiros feodermas, com "oclusão normal".

Eduardo Jacomino Franco. -- Bauru, 2006.

xvii, 128 p. : il. ; $30 \mathrm{~cm}$.

Dissertação (Mestrado) -- Faculdade de

Odontologia de Bauru. Universidade de São Paulo.

Orientador: Prof. Dr. Arnaldo Pinzan

Autorizo, exclusivamente pra fins acadêmicos e científicos, a reprodução total ou parcial desta tese, por processo fotocopiadores e/ou meios eletrônicos.

Assinatura do autor:

Data:

Comitê de Ética da FOB-USP

Protocolo n. ${ }^{0}: 30 / 2005$

Data: $25 / 05 / 05$ 


\section{EDUARDO J ACOMI NO FRANCO}

17 de março de 1980

Filiação

1998-2002

2003-2003

2003-2006

2004-2006

Associações
Nascimento - BAURU- SP

Eduardo Batista Franco

Regina Célia Jacomino Franco

Curso de Graduação em Odontologia pela Faculdade de Odontologia de Bauru Universidade de São Paulo.

Curso de Aperfeiçoamento em Ortodontia Preventiva e Interceptiva I na PROFIS Bauru.

Curso de Aperfeiçoamento em Ortodontia na ACOPEN - Bauru.

Curso de Pós-graduação em Ortodontia, em nível de Mestrado, pela Faculdade de Odontologia de Bauru - Universidade de São Paulo.

APCD- Associação Paulista de CirurgiõesDentistas.

SBPQO- Sociedade Brasileira de Pesquisa Odontológica. 



\section{DEDICO ESTE TRABALHO}

\section{DEUS}

A Deus dedico este trabalho pois, quando enfraqueci, o Senhor me mostrou que "Tudo posso naquele que me fortalece".

Porque, quando me preocupei, o senfor disse:

"Confiai-me todas as suas preocupações".

Porque, quando me senti desorientado, o Senhor disse:

"Eu guiarei seus passos".

Porque ama a mim e a cada um de nós.

Porque, quando tudo é feito em nome de Deus, o universo conspira em nosso favor. 



\section{MĨ̃E}

À minha mãe querida, que sempre renunciou à si própria pela total dedicação aos filhos, que com simplicidade deu-lhes retidão e os fizeram possuir luz própria, para que caminhassemos em busca dos nossos objetivos.

Com muito amor, dedico este trabalho.

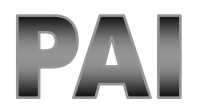

Por me apoiar em algumas das minhas decisões e me ensinar os verdadeiros valores da vida. Seus ensinamentos abriram as portas para um caminho iluminado. Pude crer que, com determinação, honestidade e amor, posso transformar meus desejos em algo real. Orgulho-me de ser seu filho e eterno aluno. Admiro-o como Professor e Educador, pois o verdadeiro homem que ensina não é aquele que repassa somente os seus confecimentos e sim o que busca transformar os que o cercam, vislumbrando que, ao retornarem, serão capazes como ele.

Ao meu pai professor, dedico este trabalho...

\section{ERIC}

Ao meu irmão querido, que sempre me incentivou com seu exemplo de inteligência e força de vontade, principalmente para o meu crescimento pessoal e profissional. 



\section{ANGÉLICA}

Pela amizade e consideração sempre demonstradas, fortalecendo os laços familiares juntamente com o Eric e o Vinícius.

\section{VINícIUS}

Ao meu sobrinho com carinho especial, que sua vinda possa trazer novas alegrias e emoções à nossa família.

\section{Vó JANDIRA}

Exemplo de luta e dedicação. Sua vivacidade incentiva a todos que a cercam.

\section{RAQUEL}

Pela cumplicidade, amizade, carinfo e amor dedicados ao longo destes anos. Ao seu lado encontrei tranquilidade para desfrutar os momentos mais alegres. Superamos, juntos, todas as dificuldades.

Um beijo e muito obrigado.

Aos meus familiares e amigos que sempre me apoiaram ao longo desta caminhada. Fico grato pela consideração e incentivo. Agradeço pelos momentos de alegria e descontração. Transmitiram-me o sentimento de que existe vida além do mestrado. 



\section{AGRADECIMENTO ESPECIAL}

\section{Profi Dr. Arnaldo Pinzan}

Que acreditou na possibilidade de chegar a termo a hipótese inicial deste trabalho, confiando-me a responsabilidade de sua excecução, so6 suas diretrizes, permitiu materializar o que impulsiona os verdadeiros orientadores, a busca constante por respostas às suas interrogações.

O meu reconhecimento. 



\section{AGRADECIMENTO ESPECIAL}

Aos docentes da disciplina de Ortodontia, Professores Doutores Décio Rodrigues Martins, Guilherme Janson, Marcos Roberto de Freitas e Renato Rodrigues de Almeida pelos valiosos ensinamentos.

Aos Professores do Departamento de Dentística, pela convivência fraterna, desde a minha infância, induzindo-me a valorizar o ensino e a docência.

Ao Professor Rafael Mondelli, que me orientou em minha primeira pesquisa de iniciação científica e sempre demonstrou sua amizade sincera durante o período de graduação e pós-graduação, nesta faculdade.

Ao Professor José Roberto Pereira Lauris, pela objetividade na conferência da análise estatística e valiosa consultoria na interpretação dos dados coletados.

Aos Professores do curso de ortodontia preventiva da PROFIS, Em especial, Dr. Omar Gabriel e Patrícia Freitas, pela oportunidade, amizade e conhecimentos transmitidos. 



\section{AGRADECIMENTO ESPECIAL}

Ao Tio Gastão, pelo exemplo de simplicidade, amizade e solidariedade que sempre demonstrou com a minha família.

Ao Dr. Adriano Mondelli, pelos ensinamentos e oportunidades oferecidos como sinônimo de amizade ao longo desses anos. Sempre vou lembrar da felicidade demonstrada ao receber os amigos em sua casa.

Obrigado por abrilhantar minha vida profissional e confiar em mim.

Aos meus amigos Adilson e Ana Raquel, Pelos ensinamentos que engrandeceram meu potencial acadêmico ao longo da minha vida nesta Faculdade

Aos colegas do doutorado antigo: em especial, Leniana, Karina Lima e Karina Freitas, que sempre dividiram suas experiências com serenidade e carinho. 



\section{AGRADECIMENTO ESPECIAL}

Ao meu grande amigo Rodrigo Cançado. Sinônimo de superação, na vida e dedicação plena aos estudos e ensinamentos no contexto da ortodontia. Agradeço todo o seu apoio e confiança.

À Analu, pelo incentivo e receptividade. Agradeço por me ajudar nas correções dos traçados cefalométricos.

À Marta, da Saúde Coletiva, pela disponibilidade na fase de visitação da escola Casa do Garoto.

À Karin, pela disponibilidade e amizade durante a fase de montagem da amostra.

Aos Funcionários da Dentística, Nelson, Dito e Junior, que me auxliaram ativamente na confeç̧ão dos modelos de gesso durante a etapa da montagem da amostra.

Obrigado pela paciência, atenção, amizade e momentos de descontração, ao longo desses anos. 



\section{AGRADECIMENTO ESPECIAL}

À funcionária Zuleica, que sempre me ajudou durante a realização deste trabalho, viabilizando a salinha e o consultório da Dentística para o desenvolvimento da avaliação clínica dos pacientes.

À Elisabeth, pelo apoio durante a graduação e pós-graduação. Agradeço, pela disponibilidade e auxílio para consignação deste trabalho.

Ao funcionário Roberto, do Departamento de Radiologia, que colaborou, diretamente, com as tomadas radiográficas deste trabalho.

Obrigado pela atenção e disponibilidade.

Aos funcionários do departamento de Ortodontia, Verinha, Neide, Cristina, Luciana, Daniel(Bonné), Danilo e Sérgio. Pelo convívio diário aos longo destes dois anos de mestrado. 



\section{AGRADECIMENTO ESPECIAL}

Aos funcionários da biblioteca da FOB-USP, pelo auxílio nas buscas de artigos e formatação deste trabalho. Em especial, Ademir, Monica, Valéria, Maria Helena, Rita, Cesar e Marcelo.

Aे turma de doutorado da Ortodontia, pela amizade e convivência. Sempre dividiram suas experiências com serenidade e carinho.

Em especial à Lívia, pelas considerações que enalteceram este trabalho.

Meu reconhecimento...

Aे turma de mestrado, pela amizade e carinho demonstrados durante o curso. Aprendi a entender os pensamentos, expressões, sentimentos de cada um de vocês. Afinal, todos nós somos diferentes, pensamos diferente e agimos diferente.

Podem contar sempre comigo.

Obrigado, O futuro nos espera...

Aे CAPES, pela concessão da bolsa de estudos durante toda a realização deste Mestrado. 



\section{SUMÁRIO}

LISTA DE FIGURAS..........................................................................XIV

LISTA DE TABELAS ........................................................................XVI

RESUMO ........................................................................................XVII

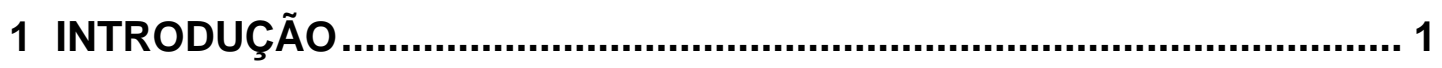

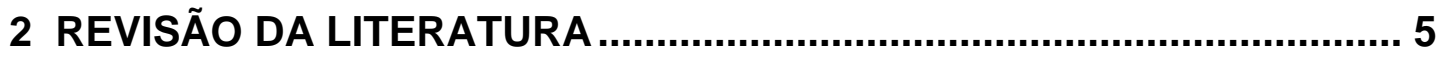

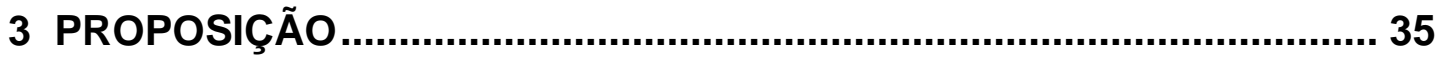

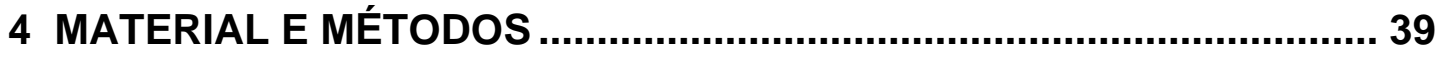

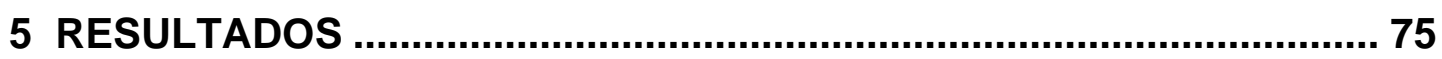

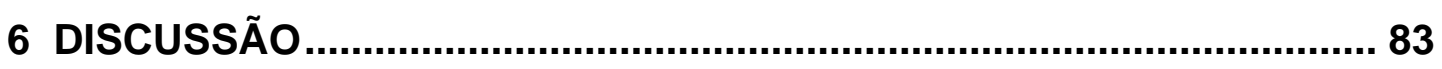

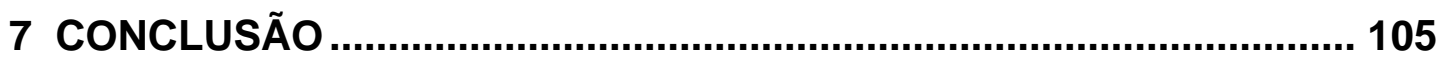

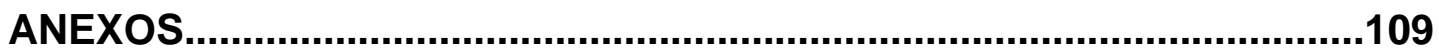

REFERÊNCIAS BIBLIOGRÁFICAS............................................... 113

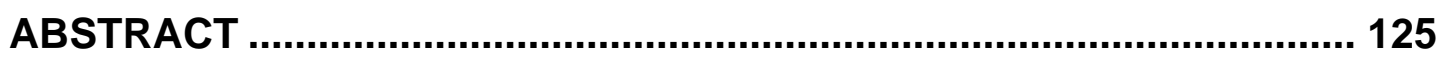

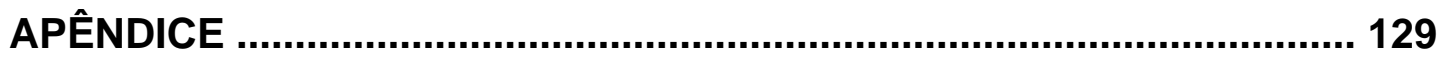





\section{LISTA DE FIGURAS}

FIGURA 1- Fotos extrabucais. Jovem feoderma do gênero masculino .43

FIGURA 1.1- Fotos extrabucais frontal e lateral, representando a amostra de indivíduos feodermas, do gênero masculino. 45

FIGURA 1.2- Fotos extrabucais frontal e lateral, representando a amostra de indivíduos feodermas, do gênero masculino. 47

FIGURA 2- $\quad$ Fotos intrabucais. Determinação das características oclusais em um jovem do gênero masculino, com "oclusão normal"

FIGURA 3- Fotos extrabucais. Jovem feoderma do gênero feminino...... .51

FIGURA 3.1- Fotos extrabucais frontal e lateral, representando a amostra de indivíduos feodermas, do gênero feminino .53

FIGURA 3.2- Fotos extrabucais frontal e lateral, representando a amostra de indivíduos feodermas, do gênero feminino.

FIGURA 4- Fotos intrabucais. Determinação das características oclusais em uma jovem do gênero feminino, com "oclusão normal".

FIGURA 5- Telerradiografias em norma lateral.

FIGURA 5.1- Desenho das estruturas anatômicas. 

FIGURA 5.2- $\quad$ Pontos Cefalométricos................................................66

FIGURA 5.3- $\quad$ Representação das linhas e planos.................................68

FIGURA 5.4 - $\quad$ Componente dentoalveolar anterior superior....................70

FIGURA 5.5 - $\quad$ Componente dentoalveolar anterior inferior.....................72 



\section{LISTA DE TABELAS}

TABELA 1- Avaliação do erro intra-examinador. Resultado do teste $t$ dependente (erro sistemático) e do erro casual 78

TABELA 2- Análise estatística das médias das idades em ambos os gêneros 79

TABELA 3- Análise descritiva da amostra, com os valores das médias e desvios-padrão em jovens brasileiros feodermas. 80

TABELA 4- Análise estatística do teste "t" independente para o dimorfismo entre os gêneros, em jovens brasileiros feodermas 81

TABELA 6.1- Médias observadas em jovens brasileiros feodermas, comparativamente às obtidas em melanodermas por MEDEIROS, com relação ao posicionamento dentário, na faixa etária de 12 a 14 anos de idade. .94

TABELA 6.2- Valores médios entre o posicionamento do incisivo inferior nos diferentes grupos étnicos para a variável Linha I, de acordo com diferentes autores.

TABELA 6.3- Médias das variáveis dentárias em jovens brasileiros leucodermas e feodermas na faixa etária de 12 a 14 anos de idade 96 



\section{RESUMO}





\section{RESUMO}

Com o propósito de apresentar um padrão cefalométrico específico para os jovens brasileiros feodermas, este estudo objetivou obter os valores médios de normalidade para algumas das variáveis cefalométricas dentárias e verificar a presença de dimorfismo entre os gêneros. A amostra constituiu-se de 40 telerradiografias, em norma lateral, sendo 20 do gênero masculino, com idade média de 13,25 anos (idade mínima de 12,20 anos e máxima de 14,30 anos), e 20 do gênero feminino, com idade média de 13,10 anos (idade mínima de 12,00 anos e máxima de 14,21 anos), obtidas em jovens brasileiros, feodermas (mulatos ou pardos), não submetidos ao tratamento ortodôntico e que apresentavam "oclusão normal". As variáveis cefalométricas dentárias foram determinadas de acordo com as análises de DOWNS, STEINER, RIEDEL, TWEED, McNAMARA, RICKETTS. Os valores foram submetidos à análise estatística pelo teste "t" independente para comparar as variáveis entre os gêneros. De acordo com os resultados e a metodologia aplicada, pode-se concluir que os incisivos superiores e inferiores apresentaram-se protruídos e inclinados para vestibular. Não ocorreu diferença estatística significante entre os gêneros para as treze variáveis dentárias avaliadas.

Palavras-chave: Grupos étnicos, Cefalometria, Incisivos. 


$$
\text { 1. INTRODUÇÃ̃o }
$$





\section{INTRODUÇÃO}

Dentro do contexto populacional pode-se observar uma intensa variação quanto aos grupos étnicos, principalmente nos grandes centros urbanos, trazendo a necessidade de reconhecer que um único padrão de estética facial pode não ser apropriado para as decisões de diagnóstico e plano de tratamento em indivíduos de várias origens étnicas, que migraram para distintas regiões geográficas ${ }^{19,26,68}$.

No Brasil, a miscigenação entre o colonizador português, o indígena e o negro resultou na formação de uma população diversificada, sendo que uma parcela significante da população brasileira foi consignada do relacionamento de branco-negro (mulato), branco-índio (caboclo), negro-índio cafuzo). Cada um dos três grupos básicos (índio, branco e negro) está longe de representar uma etnia pura. Torna-se importante identificar as características da população brasileira, analisando os aspectos somáticos respectivos ${ }^{66}$.

A importância em estudar os componentes esqueléticos e dentários da face e relacioná-los com as características normais e individuais nos diversos grupos étnicos, com diferentes influências culturais e sociais, está fundamentada no questionamento das limitações do tratamento ortodôntico e suas implicações clínicas, principalmente quando as mecânicas comprometem a estética facial $^{8,10,23-26,30,34,37,44,45,77}$. Os valores normativos das grandezas cefalométricas, que são específicos, para diferentes grupos étnicos, devem ser interpretados para complementarem o diagnóstico e o plano de tratamento, de acordo com as necessidades e expectativas individuais do paciente ${ }^{2,74}$. A literatura ressalta a carência de estudos cefalométricos, referentes às diferenças da morfologia facial entre os grupos étnicos ${ }^{2,8,24,25,42,51,68}$. A 
aplicabilidade das características dos padrões faciais, esqueléticos e tegumentares também deve ser determinada para o estabelecimento de um diagnóstico e planejamento no tratamento das más oclusões, objetivando as relações normais oclusais, funcionais e esqueléticas. Desta maneira, os estudos cefalométricos e oclusais visam promover correções ortodônticas estáveis, com um posicionamento dentário ideal.

Portanto, em função da ausência de trabalhos específicos em indivíduos feodermas (pardos ou mulatos), este estudo foi idealizado para comparar as normas cefalométricas existentes para o posicionamento ideal dos incisivos superiores e inferiores, em indivíduos leucodermas, preconizados por DOWNS ${ }^{33}$, STEINER $^{85}$, TWEED $^{91-93}$, MCNAMARA $^{65}$, RICKETTS $^{78}$. 
2- REVISÃO DE LITERATURA 



\section{REVISÃO DE LITERATURA}

A pesquisa literária, apresentada a seguir, incluiu os tópicos:

- Raça ou etnia;

- Considerações históricas etnológicas no Brasil;

- Cefalometria: sua importância e aplicabilidade na atualidade;

- Crescimento e desenvolvimento craniofacial;

- Mecanismos de compensação dentária;

- Avaliação das variáveis cefalométricas nos diferentes grupos étnicos;

- Relação dentária X bases ósseas: influências na harmonia facial dos diferentes grupos étnicos.

\section{1- Raça ou etnia}

Como os termos "RACIAL" e "ÉTNICO" podem induzir interpretações dúbias, foi utilizada a classificação de CUVIER, citada por ÁVILA ${ }^{6}$, que evidencia os três grupos raciais principais de acordo com os critérios de diferenciação relacionados à coloração da pele humana, ou seja:

- A raça branca apresenta uma classificação em relação a cor da pele como LEUCODERMA.

- A raça amarela apresenta uma classificação em relação a cor da pele como XANTODERMA.

- A raça negra apresenta uma classificação em relação a cor da pele como MELANODERMA. 
O significado de grupo étnico está intimamente relacionado às condições de cultura e integração sociopolítica dos integrantes de cada população, tanto no que se refere ao idioma, como nos costumes e modo de viver. Assim, entende-se como grupo étnico uma população entre diversas populações, constituindo um grupo racial quando agrupados coletivamente, mas que individualmente mantêm suas diferenças físicas e culturais por meio de mecanismos extremantes, tais como as barreiras geográficas ou sociais ${ }^{7,69}$.

\section{2- Considerações históricas etnológicas no Brasil}

Existe muita dificuldade em conhecer, perfeitamente, as diversas etnias provindas da África para o Brasil ${ }^{6,7,10,69}$. Um decreto de Rui Barbosa, ministro da Fazenda, determinava o recolhimento de todos os documentos relacionados com a escravidão, queimando os respectivos arquivos. Além disso, na época da migração dos escravos para o Brasil não existia um controle dos grupos étnicos provindos da África ${ }^{6,7,69}$. Desta maneira, não se sabe a quantidade de negros que chegaram ao país. Sabe-se que os negros sudaneses e bantos habitavam em terras brasileiras nesse período. Os primeiros originaram-se da região norte do golfo da Guiné. Já os bantos tiveram origem na região do grande cinturão que unia as regiões de Angola e do Congo à Moçambique $6,7,10,69,94$. Os sudaneses teriam composto, em alta escala, a população da Bahia, enquanto os bantos ocupariam uma área maior, que abrange a região central e sul do território brasileiro ${ }^{10,94}$. Com o crescimento desta população no território brasileiro tornou-se evidente o início da miscigenação pela união dos negros com os brancos, determinando-se o 
surgimento dos subgrupos como os mulatos ou pardos. Entretanto, a classificação da cor da pele para os indivíduos mulatos foi designada como feoderma, devido à miscigenação entre os leucodermas e o melanodermas.

A origem do termo mulato, na língua portuguesa e espanhola, deriva da palavra "MULE”, caracterizada por uma genérica designação a algo híbrido. Entretanto, na língua inglesa o termo biracial define a denominação para os mesmos $^{6,7,69}$.

Atualmente, o Brasil com 76 milhões de afrodescendentes é a segunda maior nação negra do mundo, atrás da Nigéria. É importante ressaltar que a classificação dos indivíduos afrodescendentes abrange homens e mulheres cuja pele é identificada como melanodermas (negros) e feodermas (mulatos ou pardos). Desta maneira, no ano de 1999 o IBGE divulgou dados relacionados à população brasileira negra, demonstrando apenas um valor de 5,4\%. Entretanto, com o acréscimo de 39,9\% do contingente de mulatos, o Brasil passou a ser definido como um país majoritariamente negro, como é, atualmente, considerado por muitos americanos e europeus.

Tendo em vista essas ponderações, é de extrema importância diferenciar as variações das estruturas esqueléticas craniofaciais que estão diretamente relacionadas ao posicionamento dos dentes superiores e inferiores com a caracterização do perfil facial nos indivíduos feodermas, uma vez que a relação de normalidade entre o posicionamento esquelético e dentário apresenta grande diversidade em função das variações étnicas. Nesse sentido, estudos devem ser estabelecidos para suportar o diagnóstico, principalmente 
em indivíduos feodermas (pardos ou mulatos), pois constituem uma grande comunidade dentro da população brasileira.

\section{3- Cefalometria: sua importância e aplicabilidade na atualidade}

Com o advento do cefalostato na cefalometria, em $1931^{16}$, os pesquisadores começaram a utilizar esse valioso instrumento para medir as várias partes do crânio e da face, possibilitando a obtenção de dados precisos e dinâmicos, contribuindo inegavelmente para o estudo do crescimento e desenvolvimento craniofacial. Além disso, foi possível estabelecer um diagnóstico e plano de tratamento ortodôntico mais acurado.

MARGOLIS ${ }^{59}$, em 1940 apresentou técnica para tomada de telerradiografia. O raio-X central, a posição da cabeça, a película radiográfica, bem como os detalhes de exposição, tempo, corrente, voltagem e processamento da película radiográfica eram utilizados como componentes que possibilitavam a execução de estudos comparativos.

Um ano depois, em 1941, MARGOLIS ${ }^{60}$ apresentou novos estudos que viabilizavam a observação dos contornos faciais, os dentes, mandíbula e os ossos da face, antes e após o tratamento ortodôntico, utilizando-se da telerradiografia em norma lateral e fotografia de perfil. Desta forma, observavase, ao mesmo tempo, o perfil facial da fotografia e os detalhes referentes à radiografia do mesmo paciente, facilitando a verificação das mudanças dentoesqueléticas e tegumentares no inicio e final do tratamento.

As análises cefalométricas foram estabelecidas a partir de uma população norte-americana, essencialmente, de origem anglo-saxônica. A 
avaliação da inclinação dos incisivos inferiores, além das inúmeras observações clínicas quanto à estética facial, TWEED ${ }^{90}$ e MARGOLIS ${ }^{61}$ advogaram que nos casos de padrão esquelético adequado, os incisivos deveriam estar posicionados verticalmente sobre o processo alveolar e osso basal.

SPEIDEL e STONER ${ }^{84}$, em 1944, pesquisaram em 42 telerradiografias, em norma lateral, de adultos jovens do gênero masculino e portadores de oclusão normal, a relação do longo eixo do incisivo inferior com o plano mandibular. Verificou-se uma inclinação do incisivo inferior ao plano mandibular de $92,64^{\circ}$, com desvio padrão de $6,15^{\circ}$, denotando um comportamento vertical dos incisivos inferiores.

Em 1945 TWEED ${ }^{91}$ desenvolveu o conceito de normalidade e relatou sua importância ao mencionar que os clínicos poderiam ter correta convicção ao iniciar e finalizar os casos. Descreveu a filosofia do tratamento ortodôntico para a correção da Classe I, II e da protrusão dos maxilares, baseado no posicionamento ideal dos incisivos inferiores. Enfatizou que o correto posicionamento dos incisivos inferiores deveria ser usado como referência para a posição dos superiores.

Considerando que as anomalias dentárias e esqueléticas, na sua grande maioria, podem apresentar uma combinação desfavorável, WYLIE98, em 1947, apresentou uma análise antero-posterior da face. Este cefalograma promovia uma correção dos elementos dentários, cranianos e faciais, verificando a harmonia entre as estruturas avaliadas.

Um método de análise cefalométrica, largamente difundido até hoje foi introduzido por DOWNS ${ }^{31}$, em 1948. Para tanto utilizou 20 telerradiografias 
de jovens leucodermas, dos 12 aos 17 anos, igualmente divididos quanto ao gênero, com oclusão ideal, tendo como objetivo determinar a média das variações estruturais esqueléticas e dentárias, com objetivo de estabelecer um padrão de normalidade, além de permitir uma expressiva definição nas mudanças horizontais e verticais induzidas pelo tratamento ortodôntico. Nesse sentido, destacou que os valores resultantes da sua análise não deveriam ser aplicados em pacientes com características raciais diferentes.

Já em 1952, DOWNS ${ }^{32}$ mencionou que o perfil facial refletia as características individuais e deveria ser considerado ao se realizar uma terapia ortodôntica. Descreveu três tipos faciais denominados: retrognático, mesognático, prognático. Realizou um estudo que correlacionava o padrão cefalométrico normal e os diferentes tipos faciais, relatando que existiam variações entre os portadores de oclusão normal perante aqueles que apresentavam má oclusão.

RIEDEL $^{79}$, em 1952, preocupou-se em estudar a posição ânteroposterior da maxila em relação ao complexo craniofacial em portadores de oclusão excelente, Classe II, divisão 1, 2 e Classe III.

STEINER ${ }^{85}$, em 1953, desenvolveu uma análise de utilização eminentemente prática. Para isso, selecionou linhas e planos de fácil localização, desenvolvendo uma técnica simples para o clínico.

Em 1956 DOWNS $^{33}$ sintetizou os seus dois trabalhos prévios e descreveu interpretações adicionais para auxiliar a utilização de sua análise na clínica ortodôntica. Mencionou que as estruturas dentofaciais sofriam variações quanto aos diferentes padrões raciais, gênero e idade. Relatou que os indivíduos possuíam padrões faciais particulares, afirmando, também, que os 
problemas ortodônticos eram complexos devido à grande variação no padrão dentoesquelético, durante o crescimento e desenvolvimento craniofacial.

Em face do exposto, pesquisas foram realizadas com o propósito fundamental de verificar, dentre as referidas análises, quais poderiam ser aplicadas em amostras de distintos grupos étnicos ${ }^{26,33,62}$. A primeira pesquisa foi publicada em 1951 por COTTON, TAKANO, WONG ${ }^{26}$, aplicando-se a análise de DOWNS ${ }^{33}$ em afro-americanos, nipo-americanos e sino-americanos. De forma seqüencial vários pesquisadores analisaram afro-americanos, africanos, chineses, índios e outros grupos étnicos $2,5,10,24,25,34,37,49,66$.

Atualmente a cefalometria continua exercendo uma importante função como diagnóstico complementar para o tratamento ortodôntico, avaliação do crescimento e desenvolvimento craniofacial e na elaboração de trabalhos científicos. Entretanto, mudanças ocorreram quanto aos objetivos do diagnóstico, principalmente quando se compara os planejamentos e análises cefalométricas realizadas nas décadas passadas ${ }^{19}$. Além disso, CAPELOZZA ${ }^{19}$ destacou que qualquer método de análise cefalométrica e facial numérica, utilizados para o exame de um indivíduo em particular, pode induzir equívocos no planejamento ortodôntico. Assim, ao usar valores médios no diagnóstico clínico, negligencia-se a possibilidade de grande variação em relação ao que se considera normal.

As análises cefalométricas sofreram mudanças significativas tendo em vista a realização de trabalhos críticos que mostraram falhas das grandezas inerentes, propondo sua substituição ou uso seletivo. Avaliações proporcionais foram desenvolvidas, no sentido de flexibilizar o posicionamento ideal dos incisivos e das características do perfil tegumentar, inferindo em maior valor Eduardo Jacomino Franco 
para o diagnóstico ortodôntico ${ }^{19,44}$. Essas alterações estenderam o uso da cefalometria como instrumento de diagnóstico auxiliar e secundário ${ }^{19}$.

Segundo CAPELOZZA ${ }^{19}$ a cefalometria atual, com utilização da telerradiografia em norma lateral, tem o objetivo de realizar uma avaliação morfológica das estruturas esqueléticas, dentárias e tegumentar. O exame visual da posição do incisivo inferior pode ser muito mais informativo do que o próprio ângulo formado com o plano mandibular. Em função desses aspectos, estudos não numéricos, devem definir as características de normalidade em diferentes grupos étnicos. ${ }^{19}$.

PINZAN ${ }^{76}$, em 2006, observou a influência dos pontos cefalométricos, das diferenças entre os gêneros, idades, grupos raciais e más oclusões, na interpretação da telerradiografia, destacando a importância da associação entre cefalometria e fotografias extrabucais no diagnóstico e plano de tratamento ortodôntico.

Sendo assim, é justificável estabelecer os valores normativos para a população brasileira mulata (feoderma), fruto da miscigenação entre o branco e o negro brasileiro.

Para permitir a comparação dos diferentes aspectos relacionados ao diagnóstico, envolvendo diversos grupos étnicos, serão apresentados tópicos disponíveis pela literatura científica. 


\section{4- Fatores relacionados ao crescimento e desenvolvimento craniofacial}

A difusão das análises buscam definir a orientação do crescimento facial, assim como a relação entre a maxila e mandíbula com a base do crânio e as posições dentárias ${ }^{33,46,63,78,85,91}$.

A variabilidade diferencial no crescimento facial condiciona um posicionamento dentário equilibrado ou em desarmonia com o sistema esquelético e muscular ${ }^{44,95}$.

Portanto, o conhecimento do crescimento craniofacial assume importância incomensurável no diagnóstico ortodôntico ${ }^{1,58,95}$. Este complexo processo recebe a influência de diversos fatores, como os genéticos e os ambientais $^{19}$. Alguns mecanismos serão brevemente abordados, principalmente no tópico que relaciona os dentes com as bases ósseas e suas implicações no tecido mole, tendo em vista a determinação do perfil facial $^{13,18,35,95}$.

Nesse sentido, o profissional deve identificar o relacionamento equilibrado e as variações esqueléticas do complexo craniofacial para determinar um prognóstico ortopédico ou cirúrgico futuro.

Quando o padrão de crescimento facial apresenta-se desfavorável, o tratamento pode ser prolongado e conduzido em uma ou duas fases, como também ser inviabilizado. O tratamento em uma única fase reduz o tempo de tratamento, pois é realizado com mecânica fixa compensatória e o paciente apresenta os dentes permanentes em oclusão. A terapêutica ortodôntica em duas fases é iniciada de maneira precoce para prevenir ou amenizar a má oclusão, durante a fase de crescimento, com posterior correção com mecânica 
fixa ou cirurgia ortognática. Desta forma, um diagnóstico auxiliar pode ser proporcionado pela observação das características faciais dos familiares, avaliando-se os aspectos hereditários e raciais ${ }^{19}$.

É importante conhecer as características normais das diversas etapas do desenvolvimento facial nos diferentes grupos étnicos que apresentam diversificações individuais quanto à morfologia craniofacial ${ }^{35}$. Deste modo, um plano de tratamento específico e individualizado pode garantir a estabilidade pós-tratamento, eficiência e harmonia facial.

\section{5- Mecanismo de compensação dentária}

O desenvolvimento dentário desempenha, igualmente, um importante papel no crescimento facial. Dentro do enfoque das variações dos padrões faciais, BJÖRK; SKIELLER ${ }^{14}$ descreveram um mecanismo dentoalveolar de compensação entre as bases apicais, incluindo-se as direções de rotação da mandíbula. Estas compensações foram definidas como um conjunto de alterações dentoalveolares para manter as relações interarcos normais ou na presença de discrepâncias entre as bases apicais. Este mecanismo depende do irrompimento dentário no sentido vertical e horizontal, determinando a relação dos dentes e bases apicais no sentido antero-posterior. Nesse sentido, diante de uma maxila retroposta, os incisivos superiores sofrem vestibularização, diminuindo o ângulo interincisivos. ${ }^{11,14,35}$.

A compensação dentoalveolar, também, manifesta-se sob a forma de migração dentária no arco inferior, como resposta a uma rotação mandibular que pode se manifestar pela abertura do ângulo goníaco, 
durante o crescimento mandibular ou sofrer influência da base do crânio ${ }^{12,35,48,66}$. Este mecanismo é fisiologicamente determinado para manter um equilíbrio entre as relações faciais, esqueléticas e dentárias. O desequilíbrio, acentuado, entre essas estruturas pode causar uma má oclusão severa ${ }^{83}$.

TWEED $^{93}$, ao selecionar quatro casos em que os pacientes apresentavam perfis faciais agradáveis, verificou a existência de semelhança com os valores de FMIA. Sequencialmente, propôs analisar uma amostra de 100 indivíduos portadores de faces equilibradas no intuito de correlacionar os valores da variável FMIA. Os resultados demonstraram a presença de compensação natural na inclinação dos incisivos inferiores em relação ao plano mandibular (IMPA $87^{\circ}$ ) e o FMIA $65^{\circ}$ nos casos em que a variável FMA fosse maior que $30^{\circ}$. Já nos portadores de FMA agudo, abaixo de $20^{\circ}$, a variável IMPA demonstrava um valor maior que $94^{\circ}$, com variação de $68^{\circ}$ a $85^{\circ}$ para a medida FMIA. Ao aplicar esta filosofia nos tratamentos ortodônticos limitou-se ultrapassar a inclinação de $94^{\circ}$ para os incisivos inferiores em relação ao plano mandibular.

Entretanto, as características faciais, esqueléticas e dentárias encontradas nos diferentes grupos étnicos não podem ser padronizadas em um único modelo cefalométrico. Alguns estudos evidenciam que em indivíduos brasileiros melanodermas ocorre maior inclinação dos incisivos inferiores devido, principalmente, a morfologia esquelética craniofacial e mandibular ${ }^{10,66,87,94}$. Assim, a compensação dentária ocorre para manter o 
equilíbrio entre essas estruturas, evitando o estabelecimento da má oclusão. ${ }^{12,34,35,46-48,94}$.

Segundo KEENE, ${ }^{55}$ a protrusão e inclinação vestibular dos incisivos em indivíduos melanodermas podem ser atribuídas ao tamanho das coroas dentárias. Em seu trabalho de investigação concluiu que os dentes permanentes dos indivíduos negros apresentavam-se significantemente maiores que as coroas dentárias encontradas nos leucodermas. Este resultado pode indicar um fator que infere maior protrusão dentária nos indivíduos melanodermas, haja vista que dentes maiores necessitam de um espaço favorável para acomodação intra-arco, ocorrendo um aumento no perímetro do arco por meio da protrusão dentária. Esta hipótese já havia sido salientada por GRESHAN, BROWN e BARRETT ${ }^{39}$, que atribuíram à protrusão dentária dos aborígines australianos em função da maior dimensão dos dentes, corroborando com o estudo de CRAVEN ${ }^{27}$, que observou nos arcos dentários dos aborígines uma relação tão grande que não permitiam uma acomodação adequada, frente a existência de faces proporcionalmente menores.

Outra causa da protrusão dentária pode ser atribuída ao desequilíbrio entre as matrizes funcionais que exercem influências sobre o posicionamento dos incisivos superiores e inferiores. DRUMMOND ${ }^{34}$, JACOBSON e OOSTHUIZEN ${ }^{52}$ evidenciaram que os negros apresentam o componente muscular interno (língua) mais forte que o componente muscular externo (lábios), estabelecendo uma acentuada inclinação para vestibular nos incisivos inferiores. Este processo de acomodação das 
estruturas do complexo craniofacial induz, também, uma compensação dos incisivos superiores por meio da relação com o arco inferior.

Conhecer as variações normais presentes nos diferentes grupos étnicos, com o intuito de padronizar individualmente as características específicas, entre as estruturas que abrangem o complexo craniofacial, apresenta importância incomensurável dentro do contexto da ortodontia $2,3,8,10,19,25,26,34,35,38,42,49,56,68,70,73,74,77,87,88$.

\section{6- Avaliação das variáveis cefalométricas nos diferentes grupos étnicos}

$\mathrm{Na}$ década de 50 , os ortodontistas começaram a observar que tanto o diagnóstico, como o resultado terapêutico e a estabilidade final da correção ortodôntica, dependiam das limitações impostas pelo tipo facial do paciente, que variava consideravelmente de acordo com o padrão morfogenético do grupo racial $\left.\right|^{4,26,33,34,56}$.

ALTEMUS $^{4}$, ao relacionar os dados cefalométricos de melanodermas americanos com oclusão normal, aos da análise de DOWNS ${ }^{31}$, verificou que existem diferenças mensuráveis e definidas na configuração dos padrões da cabeça e da face nos melanodermas e leucodermas, além disso, o grau e a natureza do prognatismo atribuídos aos melanodermas foram eminentemente dentários, pois os padrões esqueléticos do perfil facial apresentaram-se similares em ambos os grupos ${ }^{4,31}$. Assim, as diferenças no complexo craniofacial entre melanodermas e leucodermas indicaram que as normas e 
padrões de um grupo racial não podiam ser utilizados sem modificação, em outros grupos raciais $31,33,85,92$.

Entretanto, em 1968, ALTEMUS ${ }^{5}$ ao estudar 6 grupos étnicos diferentes (caucasianos, negros, chineses, japoneses, indianos e australianos) observou que os grupos avaliados apresentaram um FMA semelhante com exceção aos chineses e australianos (aborígines). Entretanto, ao comparar os valores das bases ósseas apicais superiores e inferiores concluiu que os negros demonstraram maior protrusão em relação aos aborígines e chineses. O componente esquelético vertical, nos negros, indianos e japoneses foi semelhante ao padrão facial dos caucasianos. Já nos chineses ocorreu maior retrusão do mento devido à influência acentuada do componente vertical. Por outro lado, os australianos apresentaram menor desenvolvimento vertical da face com maior protrusão do mento. Os negros e australianos demonstraram maior protrusão dos incisivos superiores e inferiores em relação aos demais grupos estudados.

A influência das variações da base do crânio pode induzir uma interpretação de protrusão das estruturas dentárias e esqueléticas, principalmente nos melanodermas ${ }^{5}$.

DRUMMOND, em $1968^{34}$, ao verificar que os ortodontistas americanos estavam recebendo uma porcentagem de pacientes melanodermas, considerou inadiável a determinação de um padrão cefalométrico para esse grupo étnico, não só para facilitar o diagnóstico e plano de tratamento, como para obter melhores resultados em relação à estética e a estabilidade final do tratamento ortodôntico. Para tanto determinou os valores cefalométricos de 40 
melanodermas americanos, com oclusão aceitável, e os comparou com os preconizados por TWEED ${ }^{92}$, TAYLOR e HITCHCOCK ${ }^{89}$, observando que as medidas cefalométricas padrões foram significativamente diferentes.

Baseado nos dados cefalométricos obtidos em adultos do gênero masculino, sendo 244 melanodermas e 381 leucodermas, KOWALSKI, NASJLETI e WALKER ${ }^{56}$ em 1974, evidenciaram que existia uma diferença substancial na morfologia dentoesquelética entre os dois grupos, tendo por base as medidas preconizadas por STEINER ${ }^{85}$. Observaram, ainda, que a inclinação do incisivo inferior com a linha NB apresentava-se muito alta nos indivíduos melanodermas, determinando um ângulo interincisivos consideravelmente maior nos leucodermas e menor nos melanodermas.

Já o estudo de GORMELEY ${ }^{38}$, que também avaliou a morfologia esquelética da base do crânio em melanodermas americanos, concluiu que as bases apicais apresentaram-se protruídas, determinando um posicionamento normal dos incisivos superiores.

Para comparar as medidas cefalométricas de indivíduos brasileiros com as da amostra de Bolton e do Centro de Crescimento de Burlington, JANSON $^{53}$, em 1992, realizou um estudo longitudinal em indivíduos leucodermas, com oclusão normal, não tratada ortodonticamente, na faixa etária dos 13 aos 18 anos. Observou que o padrão esquelético dos brasileiros não apresentou diferença significante em relação ao norte-americano. Entretanto, o padrão dentário mostrou-se ligeiramente mais protruído para os brasileiros. Infere-se, assim, que as medidas usadas em indivíduos norteamericanos podem ser usadas em jovens brasileiros leucodermas, não 
obstante deva ser considerado um grau de tolerância para as medidas dentárias.

DIAS; PINZAN; HENRIQUES ${ }^{30}$, em 1993, verificaram se os valores das medidas Co-A, Co-Gn, AFAI e Dif. Mand./Max. propostos pela análise de MCNAMARA JR. ${ }^{65}$ poderiam ser utilizados em crianças leucodermas brasileiras durante a fase da dentadura mista, assim como observaram as características do crescimento facial em ambos os gêneros. Os resultados obtidos apontaram que entre o grupo amostral brasileiro e o de Bolton não ocorreu diferença estatisticamente significante. Quando a amostragem de Burlington e a brasileira foram comparadas, algumas distinções foram encontradas. Destacaram, ainda, a possibilidade de aplicação da análise de MCNAMARA JR. ${ }^{65}$ para as crianças brasileiras, mas algumas considerações devem ser estabelecidas para o gênero masculino, que apresentou valores maiores para as medidas de Co-A e Co-Gn. A variação que ocorreu nas medidas citadas evidencia uma particularidade do perfil encontrado nos jovens brasileiros leucodermas. A característica convexa, em decorrência da miscigenação dos diversos grupos étnicos justifica um padrão facial próprio.

Ao estabelecer a preferência estética entre ortodontistas, artistas plásticos e leigos quanto ao contorno do perfil facial mole, OKUYAMA ${ }^{74}$, em 1995, selecionou 180 fotografias pertencentes a 60 jovens de diferentes etnias. Avaliou o tecido mole dos 21 perfis classificados como agradáveis, para cada grupo étnico. Constatou que os perfis dos melanodermas selecionados como agradáveis ou harmônicos se assemelhavam com os perfis dos indivíduos leucodermas. Além disso, verificou que os perfis preferidos pelos 27 avaliadores apresentaram uma suave convexidade facial para todas as etnias e Eduardo Jacomino Franco 
maior convexidade e protrusão labial para os brasileiros melanodermas. Por outro lado, YEHEZKEL ${ }^{100}$ relatou uma preferência por um perfil mais retilíneo dos indivíduos do gênero feminino afro-americanos do século 20. Porém, o conceito de estética é extremamente subjetivo e está condicionado a influências socioculturais.

Com o intuito de estabelecer medidas padrões para os jovens brasileiros, com base em estudos longitudinais, MARTINS et al. ${ }^{63}$, em 1998 , apresentaram os resultados de uma pesquisa, culminando na composição do Atlas de crescimento e desenvolvimento craniofacial. Um grupo amostral composto por indivíduos brasileiros leucodermas, descendentes de mediterrâneos, não submetidos ao tratamento ortodôntico, foi acompanhado dos 6 aos 18 anos de idade. Dados relacionados às diversas medidas de diferentes análises cefalométricas foram obtidas, tanto no sentido vertical como ântero-posterior, representando um valioso trabalho para a execução do diagnóstico e plano de tratamento, em pacientes da mesma origem pesquisada $^{63}$. Portanto, o profissional pode determinar padrões para jovens leucodermas na predição do diagnóstico e tratamento ortopédico e ortodôntico $35,48,95$.

Não obstante a literatura específica apresentar, com maior freqüência, pesquisas envolvendo indivíduos brancos e negros, o resultado da pesquisa realizada por TAKAHASHI ${ }^{87}$, em 1998, determinou os valores médios de normalidade para as grandezas cefalométricas esqueléticas, dentárias e tegumentares utilizando um padrão cefalométrico específico para os brasileiros, descendentes de xantodermas. HWANG, KIM e MACNAMARA. ${ }^{42}$ utilizando as $^{2}$ variáveis semelhantes às de TAKAHASHI ${ }^{87}$, avaliaram indivíduos coreanos e 
europeu-americanos com oclusão normal e faces equilibradas. Uma menor inclinação do ângulo nasal inferior e maior protrusão dos lábios foram relatados na amostra de indivíduos coreanos. Entretanto, a protrusão do mento nos coreanos foi menos proeminente em relação aos indivíduos europeuamericanos.

Além da determinação da relação das estruturas esqueléticas que influenciam no desenvolvimento horizontal do complexo craniofacial é importante avaliar as possíveis variações em decorrência do crescimento vertical anterior e posterior.

Ao considerar que os jovens xantodermas apresentavam um desenvolvimento vertical relevante TAKAHASHI ${ }^{88}$, em 2002, sentiu a necessidade de se utilizar um padrão cefalométrico específico, no sentido vertical da face, para os brasileiros descendentes de xantodermas e leucodermas. Encontrou dimorfismo entre gêneros e diferenças estatísticas entre os diferentes grupos, utilizando as medidas: AFAT; AFAS; AFAI; AFASIAFAT; AFAI/AFAT; AFPT; AFPS; AFPI; AFPSIAFPT; AFPI/AFPT; AFA; AFP; IAF.

UCHIYAMA ${ }^{94}$, em 2005, também analisou cefalometricamente, as alturas faciais anterior e posterior, em jovens brasileiros melanodermas, com "oclusão normal", demonstrando o dimorfismo entre os gêneros. A amostra foi constituída de 56 telerradiografias, em norma lateral, sendo 28 do gênero masculino, com idade média de 13,93 anos e 28 do gênero feminino, com idade média de 13,79 anos. Observou a presença de dimorfismo, com os valores das grandezas AFAT, AFAS, AFPT, AFPS, além das proporções AFPSIAFPT e AFPI/AFPT significantemente alteradas. Destacou, ainda, que 
existem variações entre os diversos grupos de indivíduos melanodermas com origens variadas, pois os resultados denotaram alturas faciais posteriores reduzidas no grupo com origem étnica banto, diferindo dos melanodermas que apresentam um desenvolvimento vertical mais acentuado ${ }^{8}$.

Esses achados são corroborados com o estudo clássico de BJÖRK ${ }^{12}$, 1950, que realizou uma comparação entre indivíduos suecos e bantos. Para indivíduos melanodermas ressaltou como características principais: incisivos mais protruídos e o mento retroposicionado, revelando uma altura facial ânteroinferior maior que a altura facial ântero-superior.

BACON; GIRARDIN; TURLOT ${ }^{8}$, em 1983, compararam indivíduos melanodermas "Bantu-africanos" e indivíduos leucodermas. Observaram um aumento significante da altura facial ântero-inferior nos melanodermas, em contraste com um desenvolvimento menor no terço médio da face nestes indivíduos.

As variações verticais e horizontais das estruturas esqueléticas que compreendem o complexo craniofacial influenciam na determinação de normalidade ou anormalidade em relação ao posicionamento dentário dos diferentes grupos étnicos ${ }^{46,88,94}$. Em alguns casos, as características hereditárias durante o processo de crescimento e desenvolvimento facial podem se manifestar. Entretanto, é importante observar uma inclinação acentuada do plano mandibular como reflexo natural da deflexão e o respectivo avanço anterior da fossa média craniana ${ }^{35}$. Em alguns grupos negróides a altura facial anterior é nitidamente aumentada com a rotação da mandíbula no sentido horário, para compensar o avanço da fossa média do crânio e evitar as 
características faciais padrão III, que raramente são observados em indivíduos afrodescendentes ${ }^{19,35,94}$.

Variações fundamentais são identificadas nas estruturas craniofaciais em diferentes padrões raciais, indicando a necessidade de avaliação detalhada da morfologia facial individual ${ }^{19,70}$.

\section{7- Relação dentária $x$ bases ósseas: influências na harmonia facial dos diferentes grupos étnicos}

Com o intuito de avaliar diferenças entre as medidas cefalométricas dentárias e tegumentares entre jovens melanodermas e leucodermas americanos, DRUMMOND ${ }^{34}$, em 1968, pôde observar que a posição protruída dos dentes anteriores e a espessura dos lábios influenciavam na determinação volumosa do terço inferior da face, sendo que a inclinação vestibular ou lingual, com protrusão ou retrusão dos incisivos relaciona-se intimamente com o tecido mole na determinação de perfil facial convexo ou côncavo, respectivamente. Quando o plano mandibular demonstra uma inclinação excessiva no sentido horário, o pogônio aparece pouco no contexto facial, determinando a protrusão dos incisivos inferiores, principalmente nos melanodermas que apresentam uma característica de protrusão bimaxilar ${ }^{10,13,24,37}$.

Para determinar uma média padrão entre a relação dos incisivos inferiores com as bases ósseas, INTERLANDI ${ }^{44}$, em 1971, propôs uma análise, definida como morfodiferencial, para o diagnóstico e planificação do tratamento ortodôntico. Esse estudo estabeleceu uma norma cefalométrica lateral para os

\section{Eduardo Jacomino Franco}


incisivos centrais inferiores, onde as referências anatômicas empregadas não estivessem distanciadas dos ossos basais superior e inferior, uma vez que a variabilidade diferencial no crescimento facial condiciona um posicionamento dentário equilibrado ou em desarmonia com o sistema esquelético e muscular. A proposta de determinação da linha "I", pelo autor, é obtida a partir da união dos pontos de referência $\mathrm{P}^{`}$ e $E$, localizados respectivamente na maxila e na mandíbula. Com base na avaliação estabelecida, observou ausência de discrepância cefalométrica quando a borda incisal do incisivo inferior coincidia com a linha "I". Pelo grupo amostral envolvido na análise, em relação à linha "I", encontrou uma média de $-1,28 \mathrm{~mm}$, com variabilidade de valores entre + 0,05 e $-2,50 \mathrm{~mm}^{44}$.

Entretanto, após alguns anos, INTERLANDI ${ }^{45}$ fez modificações para determinação da linha "I", no que se refere aos pontos de referência para medição da distância do incisivo central inferior, redefinindo-a como a distância do limite lingual da borda incisal dos incisivos centrais inferiores à linha "I". Dentre as análises cefalométricas, há referência do autor com relação à de TWEED $^{93}$, que observou clinicamente um perfil facial achatado, em face da retrusão dentária, uma vez que os resultados pós-tratamento ortodôntico eram mais estáveis quando se estabelecia uma verticalização dos incisivos ${ }^{93}$. Desta forma, a concepção da análise de INTERLANDI ${ }^{45}$ é o estabelecimento de um padrão para o posicionamento dentário, implicando em um menor grau de retrusão na movimentação dos incisivos, para promoção de maior estabilidade pós-tratamento, associando-se à estética facial harmoniosa. Portanto, o 
estabelecimento dessa medida linear, concebida como linha"l", foi para determinar o posicionamento dos incisivos em indivíduos leucodermas.

RICKETTS ${ }^{78}$ designou o ponto "A", localizado na região subespinhal da maxila e o ponto "Pog" situado na porção mais anterior do pogônio, na mandíbula, como referencial para determinação do limite anterior das bases ósseas. Esses pontos são conectados por uma linha AP com o intuito de localizar e quantificar a posição dos incisivos. Desta forma, a protrusão ou retrusão dos incisivos inferiores e superiores são mensurados pela distância linear até a linha AP. Em um grupo amostral, envolvendo 1.000 casos ortodônticos, determinou a média para as inclinações dos incisivos inferiores em aproximadamente $0,5 \mathrm{~mm}$ anterior à linha APog, com desvio padrão de 2,7mm e variação dos valores máximos e mínimos entre $6 \mathrm{~mm}$ a $-5 \mathrm{~mm}$. Concluiu que a mensuração do posicionamento dos incisivos pode ser efetuada de maneira confiável, devido a proximidade com as bases ósseas e a não utilização da base do crânio como referencial.

OLIVEIRA $^{75,}$ em 1977, determinou as medidas cefalométricas lineares 1-NB e P-NB em indivíduos brasileiros, leucodermas, dentro da faixa etária dos 12 aos 18 anos, no sentido de observar a variação dos incisivos, quanto à relação ântero-posterior. Não encontrou diferença estatisticamente significante nas medidas analisadas, mas, por outro lado, os valores de P-NB indicaram um aumento significativo, denotando crescimento do mento, com predominância, no gênero masculino. Do ponto de vista prático, considerou que a relação de 1-NB com P-NB diminui com a idade, a partir do crescimento do mento. A quantificação dessa redução foi de $0,5 \mathrm{~mm}$ no gênero feminino e 1 mm no gênero masculino dos 12 aos 18 anos. Ressaltou, entretanto, que a Eduardo Jacomino Franco 
medida de P-NB pode sofrer influência das estruturas relacionadas com a base do crânio, determinando uma variabilidade direta nos resultados da referida medida.

JACOBSON $^{51}$, em 1978, apresentou a possibilidade de visualização da inclinação dos incisivos e a correspondência com a quantidade de espaço ocupado, por meio de diagramas traçados sobre telerradiografias laterais. Observou que os incisivos superiores dos indivíduos melanodermas apresentaram-se ligeiramente mais inclinados para vestibular, em comparação aos caucasianos e, de forma correspondente, os incisivos inferiores situaramse, acentuadamente, vestibularizados.

FONSECA; KLEIN ${ }^{37}$, em 1978, estudaram comparativamente um grupo de 40 mulheres melanodermas, na faixa etária de 20 a 30 anos, com Classe I de Angle, tendo como grupo controle 20 mulheres leucodermas. Encontraram que nas mulheres negras tanto a maxila como a mandíbula apresentavam-se significantemente protruídas, devido ao avanço anterior da fossa média craniana, com a determinação de uma protrusão do complexo nasomaxilar. A rotação da mandíbula no sentido horário foi avaliada pela inclinação do plano palatino, corroborando com trabalhos que relatam uma inclinação acentuada dos incisivos inferiores para vestibular nos indivíduos melanodermas ${ }^{10,13,34,44,66}$. Com relação à espessura dos lábios, não foi observada diferença estatisticamente significante entre os grupos.

Para estabelecer um padrão de normalidade no grau de inclinação dos incisivos inferiores em jovens melanodermas, do gênero masculino, com “oclusão normal”, BERTOZ ${ }^{10}$, em 1981, realizou uma pesquisa para avaliar a 
linha "I", em adolescentes de 12 a 17 anos. Determinou que a linha "I", em melanodermas brasileiros deveria ser de $-7,35 \mathrm{~mm}$, caracterizando uma protrusão acentuada dos incisivos inferiores, comprovando que existe variação no posicionamento dentário para os grupos raciais.

Nessa mesma linha de pesquisa, MEDEIROS ${ }^{66}$, em 1988, avaliou o dimorfismo sexual em melanodermas brasileiros, a partir da análise de 30 telerradiografias de jovens melanodermas do gênero feminino, similarmente à amostra utilizada por BERTOZ ${ }^{10}$, comprovando que não ocorreu dimorfismo sexual entre os jovens para a variável Linha I.

A determinação do valor médio para a Linha "I", em indivíduos de origem nipônica, foi observada por RADDI ${ }^{77}$. Pôde observar que o valor médio encontrado para o incisivo inferior foi de $-4,40$ milímetros, com desvio padrão de 2,09 milímetros.

Evidencia-se, portanto, que com relação à linha "l" os valores padrões estimados para os jovens brasileiros leucodermas, melanodermas e xantodermas demonstraram diferenças estatisticamente significantes, indicando para os diferentes grupos étnicos, a existência de variações individuais das medidas cefalométricas ${ }^{10,44,66,77}$.

Ao relacionar os lábios e o posicionamento dentário, CONNOR; MOSHIRI ${ }^{24,}$, em 1985, descreveram um maior comprimento do lábio superior em indivíduos melanodermas, assim como uma inclinação vestibular acentuada dos incisivos centrais superiores, quando comparados aos indivíduos leucodermas, que apresentaram uma menor espessura do lábio superior, destacando, ainda, o fato dos incisivos estarem posicionados adequadamente na base óssea maxilar. 
Diante das variações no posicionamento dos incisivos inferiores entre os grupos étnicos, NOUER ${ }^{73}$, em 2005, comparou as análises de referência incisal em jovens brasileiros melanodermas de 10 a 14 anos com oclusão normal, avaliando também o comportamento do incisivo inferior, em relação às referências incisais preconizadas por ANDRADE (1-Jr), INTERLANDI $^{44}$ (1-linha I), VIGORITO ${ }^{97}$ (1-linha V) e RICKETTS ${ }^{78}$ (1-linha AP). Observou que a posição do incisivo inferior, em indivíduos melanodermas brasileiros, apresenta uma protrusão e inclinação vestibular acentuada, de acordo com as análises preconizada pelos autores consultados ${ }^{44,78,97}$ e que a análise de referência incisal de ANDRADE (1-Jr) se enquadrou de maneira adequada para este grupo étnico.

A análise de VIGORITO $^{97}$, por meio da cefalometria, também objetiva estabelecer um padrão de normalidade para as medidas esqueléticas, dentárias e tegumentares. Nesse sentido, determinou o padrão médio da posição dos incisivos inferiores em relação ao eixo médio da sínfise, utilizando como grupo amostral jovens portadores de oclusões excelentes e com perfis faciais harmoniosos. Para tanto, trinta telerradiografias foram tomadas de adolescentes brasileiros leucodermas, na faixa etária de 12 a 14 anos de idade. Encontrou que a distância entre a borda incisal do incisivo inferior e a linha VT (1-VT), através do plano oclusal, apresentou um valor médio de -6,28 mm e desvio padrão de 2,09.

Entretanto, ao avaliar comparativamente os resultados obtidos por NOUER ${ }^{73}$, com a utilização da análise de VIGORITO $^{97}$ em melanodermas, pode-se notar uma variabilidade nos valores que determinaram a protrusão dos Eduardo Jacomino Franco 
incisivos inferiores, ou seja, -5,45 mm, enquanto na amostra de VIGORITO ${ }^{97}$, estabelecida em leucodermas, os incisivos inferiores apresentaram um valor médio de $-6,28 \mathrm{~mm}$.

A dificuldade para estabelecer procedimentos metodológicos que permitam a avaliação individual dos dentes constitui, provavelmente, um dos motivos da escassez de trabalhos voltados para consignar o posicionamento dentário no sentido vestíbulo-lingual e mesio-distal ${ }^{21}$. Dentre os procedimentos, a tomografia computadorizada vem sendo amplamente utilizada na odontologia com o objetivo de facilitar o diagnóstico e proporcionar mensurações de áreas restritas ao sistema estomatognático. Assim, com a possibilidade desse recurso, CAPELOZZA ${ }^{21}$ utilizou essa técnica para medir as inclinações e angulações dentárias. Foram realizados cortes tomográficos dos dentes anteriores, a partir da documentação de dois indivíduos com padrões faciais II e III. Após análise, concluiu que a tomografia computadorizada pode ser usada para mensurar as inclinações e angulações dentárias, contribuindo com as pesquisais que objetivam individualizar o tratamento ortodôntico.

BROCK $^{17}$, em 2005, avaliou se existia diferença na posição do lábio superior dos indivíduos leucodermas e melanodermas submetidos à retração dos incisivos superiores. Concluiu que existem diferenças entre os grupos étnicos avaliados. A resposta dos lábios nos melanodermas apresentou uma modificação para baixo, enquanto nos leucodermas ocorreu alteração para posterior. Essa diferença entre ambos os grupos pode ser justificada pelas características iniciais em relação à espessura do lábio e inclinação dos incisivos. Os negros apresentaram maior espessura labial e maior inclinação e protrusão dos incisivos superiores quando comparados aos brancos. Desta Eduardo Jacomino Franco 
forma, CARTER ${ }^{22}, 1988$, indicou as extrações dentárias apenas para a dissolução de apinhamento, pois considera o prognóstico duvidoso para os protocolos de extrações que objetivam a exclusiva retroposição dos lábios. Evidenciou uma redução da estabilidade pós-tratamento com a abertura dos espaços na região das extrações.

Diante dos resultados apresentados pela literatura ${ }^{10,44,45,66,73,77}$, torna-se importante o conhecimento das variações relacionadas aos posicionamentos dentários, nos diferentes grupos étnicos citados.

Cabe ao profissional vinculado à área específica avaliar a inclinação dos incisivos, quantidade de apinhamento, relação ântero-posterior dos molares e caninos, tendo em vista a indicação do tratamento ortodôntico compensatório ou com extrações dentárias. Além disso, quando os incisivos superiores e inferiores apresentam-se bem posicionados após o tratamento pré-cirúrgico, melhor deverá ser o prognóstico no pós-cirúrgico, com estimativa de maior estabilidade em longo prazo. Neste caso, a individualização do diagnóstico clínico e radiográfico, tendo por base os diferentes trabalhos citados pode ser implementada, mas deverá prevalecer o bom senso profissional, no que diz respeito às características individuais de cada paciente. Assim, nenhuma variável numérica deve ser aplicada como regra única para o diagnóstico e plano de tratamento e, adicionalmente, os valores cefalométricos devem ter como objetivo a complementação para o diagnóstico clínico e facial individualizado e servir como parâmetro para os diferentes grupos étnicos ${ }^{10,12,19,21,66,74,77}$. 



$$
\text { 3. PROPOSIÇÃO }
$$





\section{PROPOSIÇÃO}

Com o propósito de apresentar um padrão cefalométrico específico do posicionamento dentário em jovens brasileiros feodermas na faixa etária de 12 a 14 anos de idade, este estudo teve como objetivo:

- obter os valores médios de normalidade para as grandezas cefalométricas dentárias;

- identificar a presença ou ausência de dimorfismo entre os gêneros. 



$$
\text { 4. MATERIAL E MÉTODOS }
$$





\section{MATERIAL E MÉTODOS}

Foram utilizadas quarenta telerradiografias, em norma lateral, referentes à uma amostra de brasileiros feodermas com oclusão normal de Angle, na faixa etária de 12 a 14 anos. Para a obtenção da amostra e elaboração da documentação ortodôntica, foi necessário examinar os jovens das escolas estaduais da cidade de Bauru.

As características étnicas e raciais foram precisamente avaliadas por meio de um questionário, que forneceu informações para classificar a cor da pele dos pais (Anexo 1). Desta forma, somente os jovens que apresentavam afro-descendência (união entre brancos com negros e entre pardos ou mulatos) foram incluídos na amostra. Uma sala contendo cadeiras comuns sob iluminação natural foi utilizada para promover o exame clínico dos adolescentes, sendo empregada uma espátula de madeira descartável como um instrumental efetivo para exploração intrabucal.

Os critérios adicionais para inclusão dos indivíduos na amostra foram: presença dos dentes permanentes em oclusão, exceto os terceiros molares; as relações normais de molares e pré-molares; pequeno ou nenhum grau de apinhamento; ausência de mordida cruzada posterior; trespasses vertical e horizontal normais; perfil tegumentar agradável com padrão facial equilibrado (Figura 1; 2, 3 e 4). Além disso, nenhum indivíduo da amostra poderia ter sido submetido a qualquer intervenção ortodôntica.

Para determinar o equilíbrio entre os terços faciais e ausência de assimetria foi realizada a análise facial subjetiva, no sentido de selecionar somente jovens com padrão facial equilibrado. 
A amostra de oclusão normal de brasileiros feodermas foi composta por 40 jovens, sendo 20 do gênero masculino e 20 do gênero feminino, com idade média de 13,15 anos (idade mínima de 12,0 anos e máxima de 14,30 anos) (Figura $1 ; 1.1 ; 1.2 ; 2 ; 3 ; 3.1 ; 3.2$ e 4 ). 

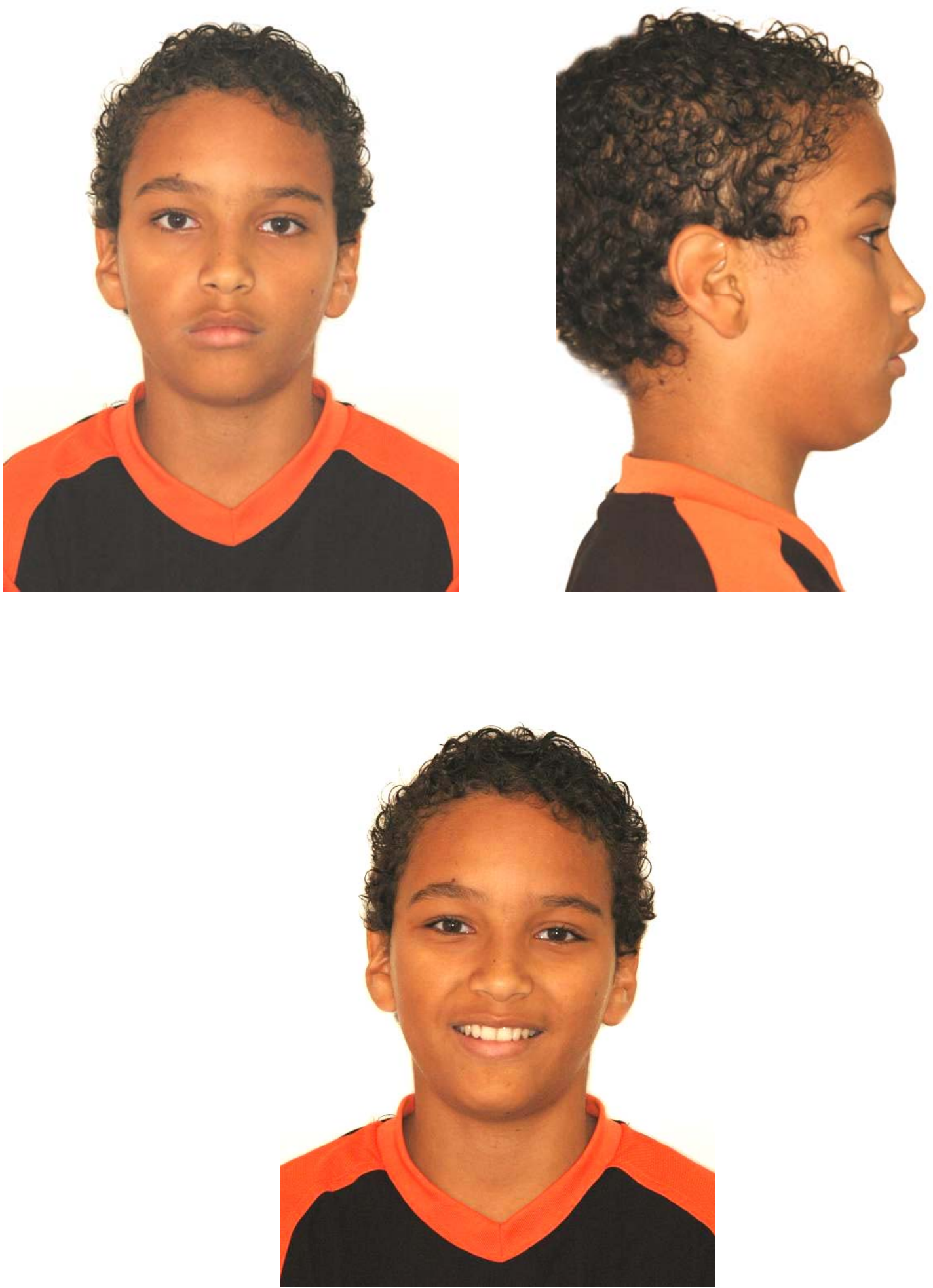

Figura 1- Fotos extrabucais. Jovem feoderma do gênero masculino. 


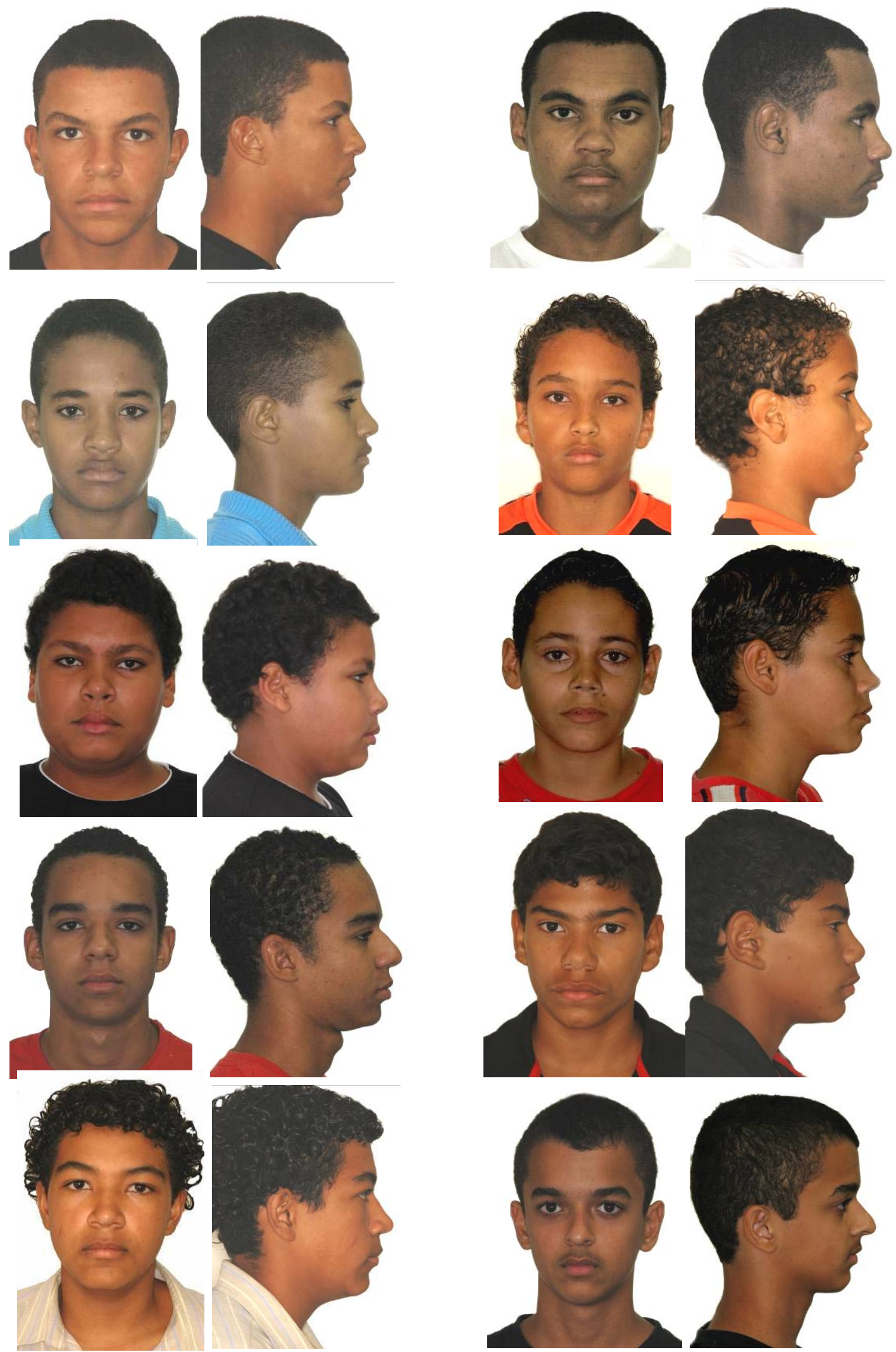

1.1- Fotos extrabucais frontal e lateral, representando a amostra de indivíduos feodermas, do gênero masculino. 


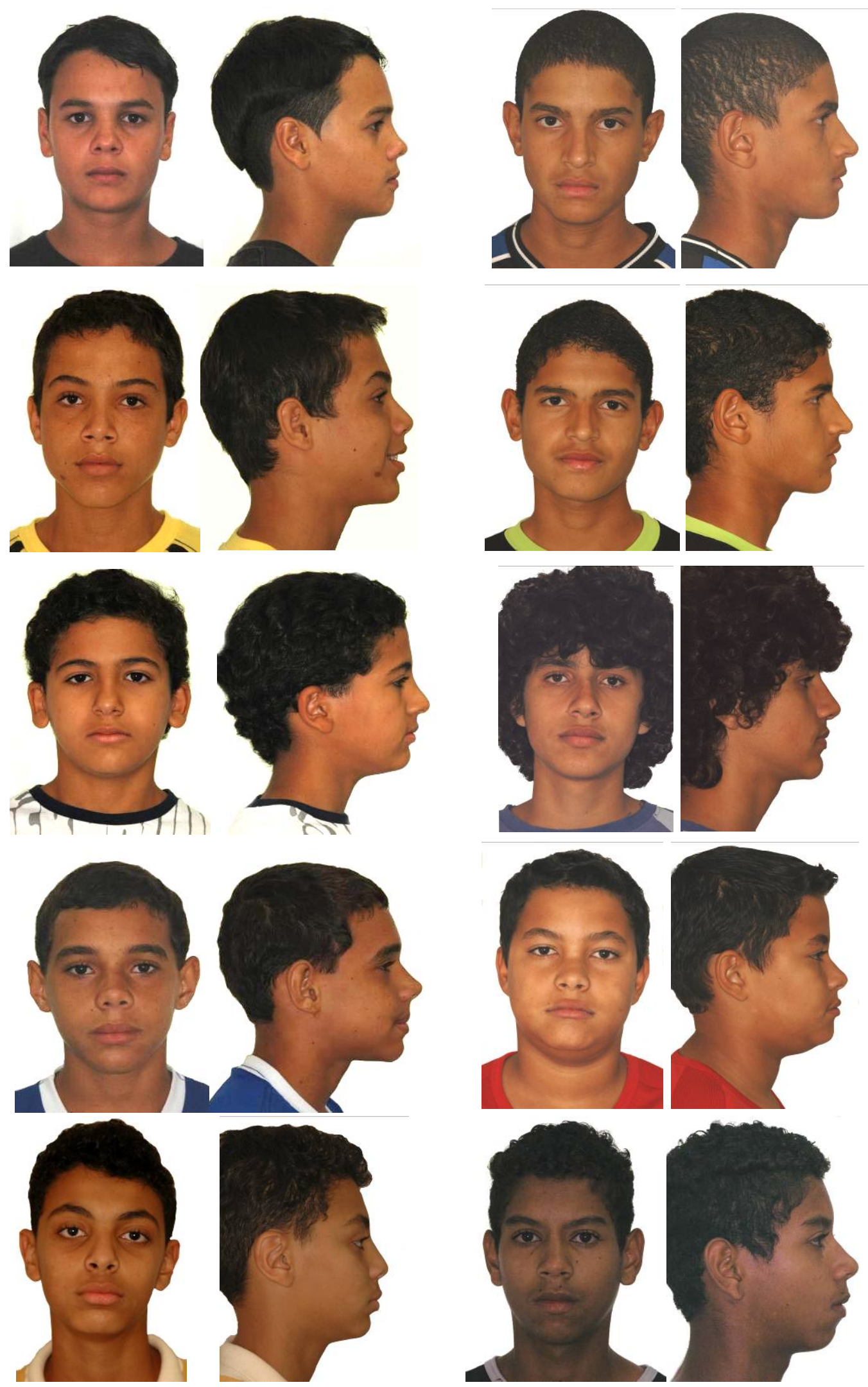

1.2- Fotos extrabucais frontal e lateral, representando a amostra de indivíduos feodermas, do gênero masculino. 


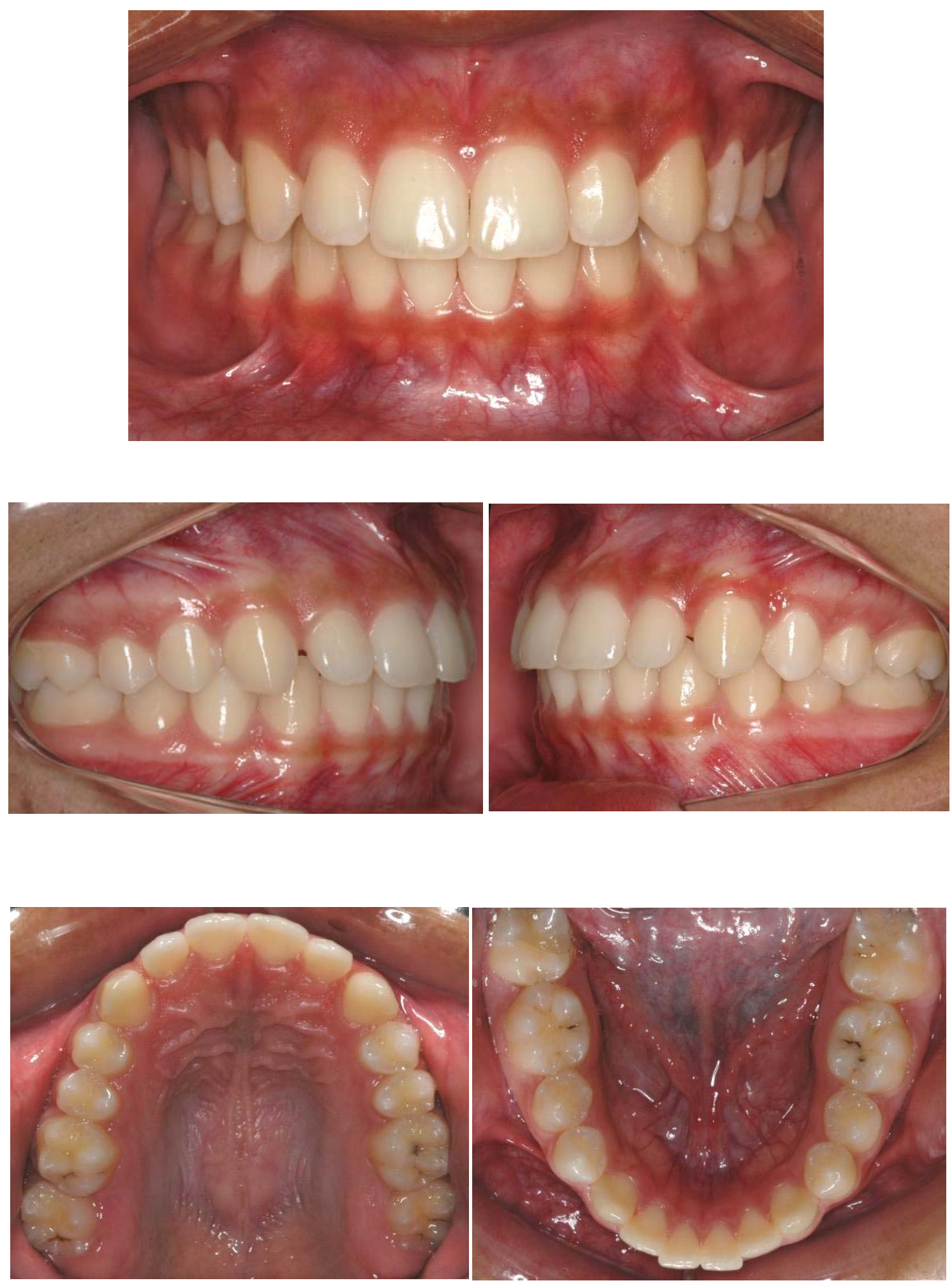

Figura 2- Fotos intrabucais. Determinação das características oclusais em um indivíduo jovem do gênero masculino, com "oclusão normal". 


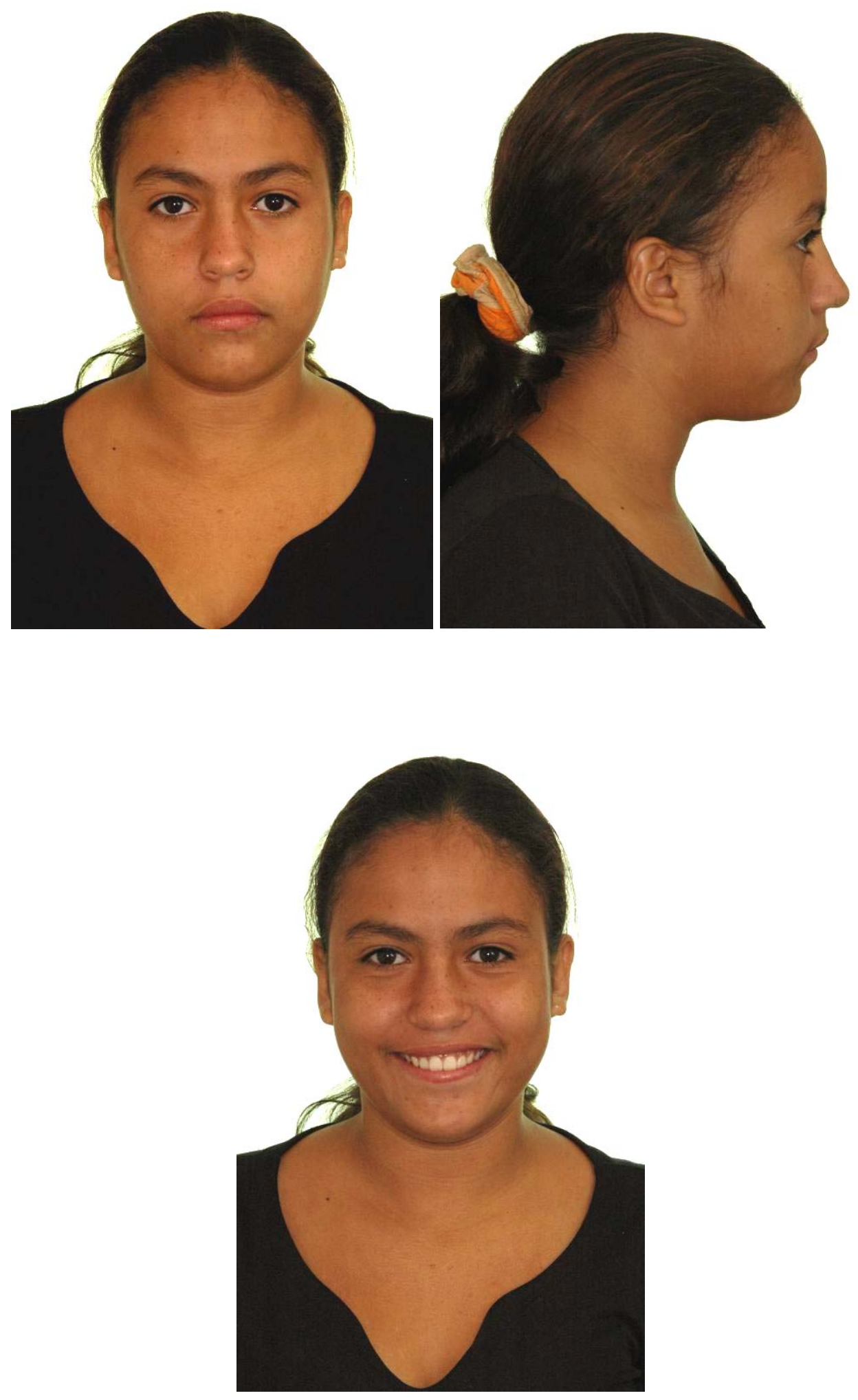

Figura 3- Fotos extrabucais. Jovem feoderma do gênero feminino. 


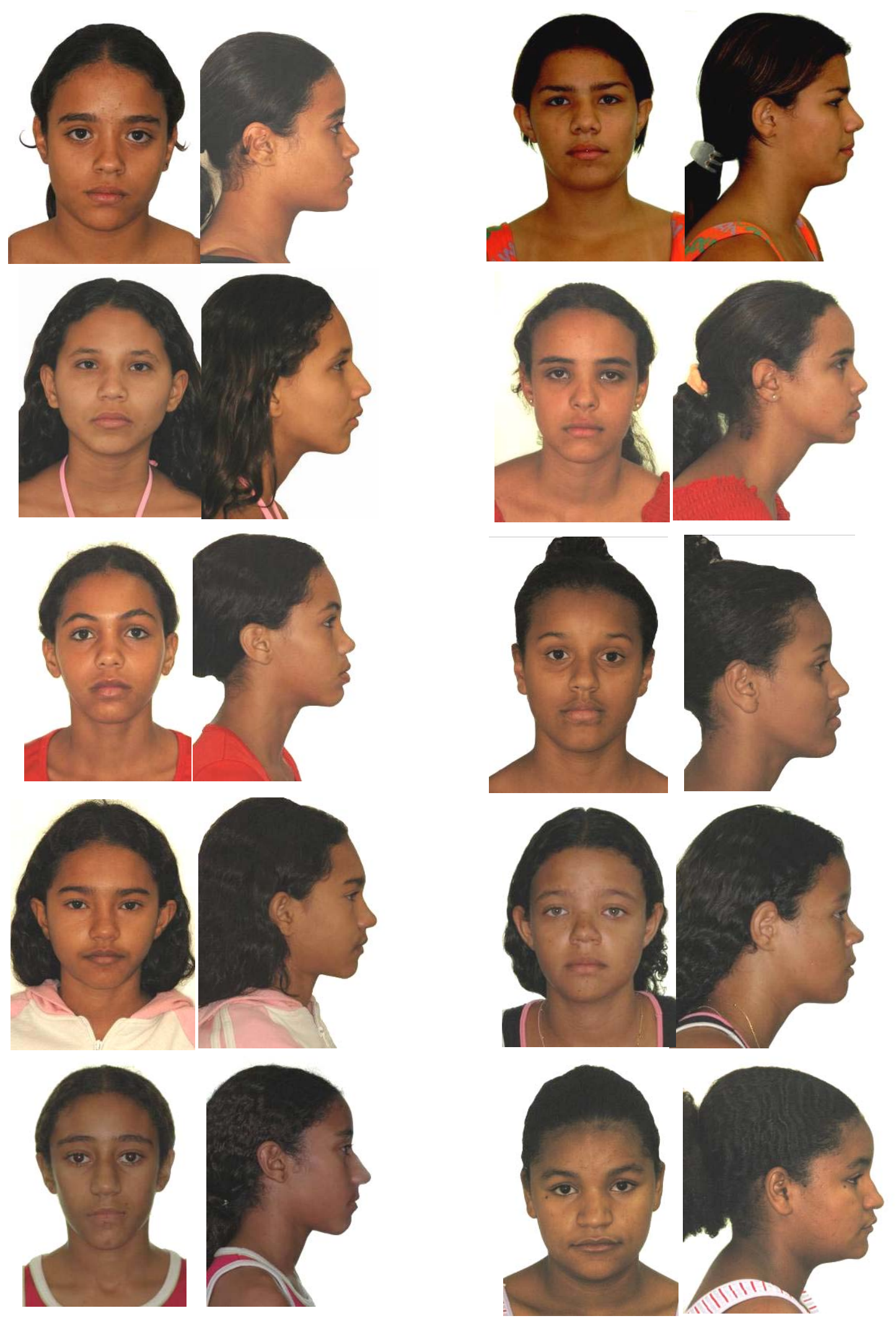

3.1- Fotos extrabucais frontal e lateral, representando a amostra de indivíduos feodermas, do gênero feminino 


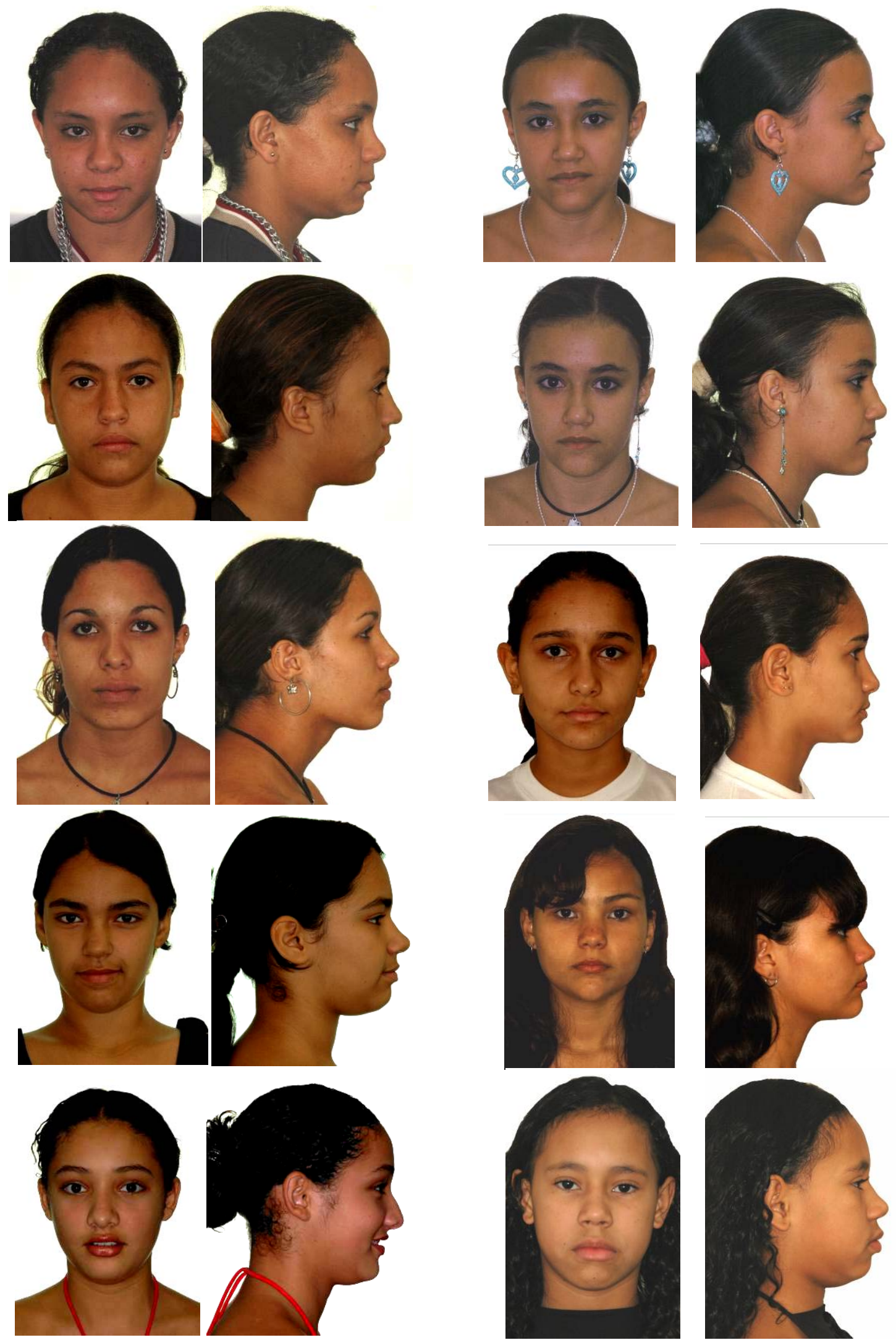

3.2- Fotos extrabucais frontal e lateral, representando a amostra de indivíduos feodermas, do gênero feminino. 


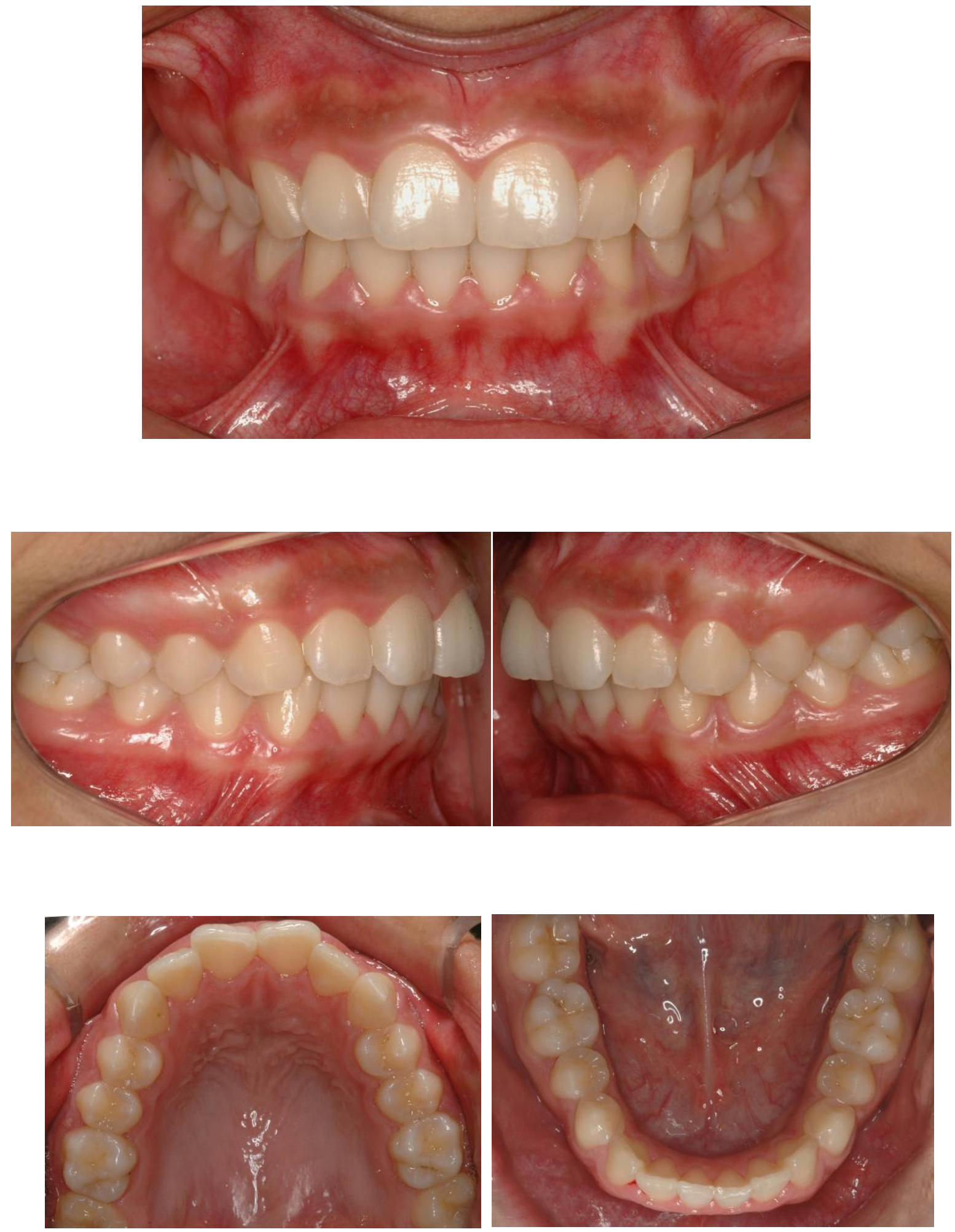

Figura 4- Fotos intrabucais. Determinação das características oclusais em um indivíduo jovem do gênero feminino, com "oclusão normal". 



\section{1- Radiografias}

Com a finalidade de avaliar as características cefalométricas do grupo estudado, telerradiografias em norma lateral foram precisamente tomadas e reveladas de acordo com as normas preconizadas pela Disciplina de Radiologia da Faculdade de Odontologia de Bauru da Universidade de São Paulo (FOB-USP). Todas as imagens radiográficas foram obtidas com os lábios em repouso e na posição de máxima intercuspidação habitual, com auxílio do cefalostato de Broadbent $^{16}$ para uma padronização do posicionamento da cabeça (Figura. 5).

O fator de magnificação da imagem radiográfica do aparelho utilizado foi calculado e posteriormente efetuou-se a correção deste fator para que se obtivesse maior precisão. O aparelho apresentou o fator de magnificação de $9,8 \%{ }^{88,94}$. 


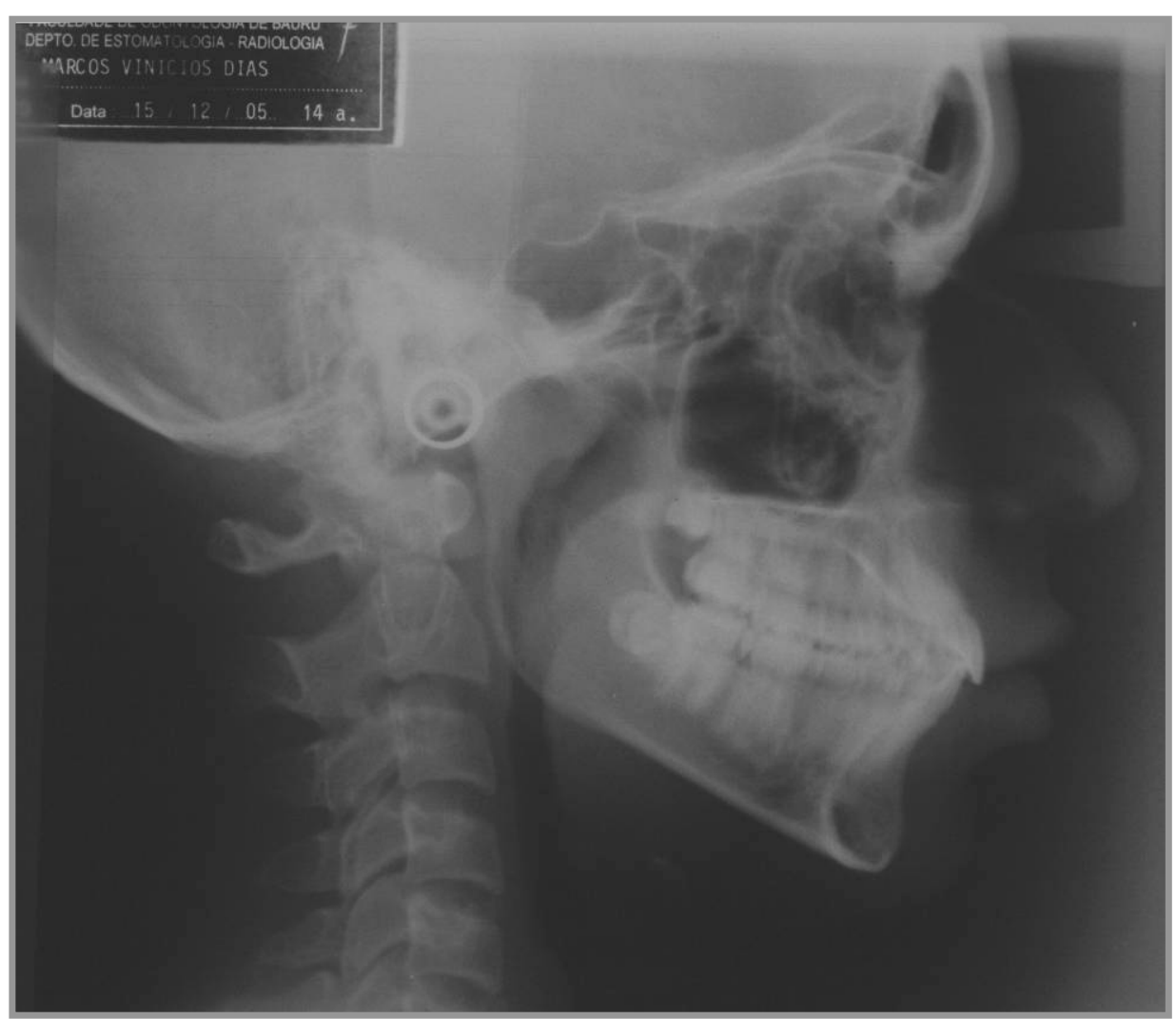

Figura 5- Telerradiografias em norma lateral.

\section{2- Elaboração do cefalograma}

Para a obtenção dos cefalogramas foi utilizado um negatoscópio, folhas de acetato transparente "ultraphan" para traçado cefalométrico, de $0,07 \mathrm{~mm}$ de espessura recortado em $17,5 \times 17,5 \mathrm{~cm}$; lapiseira 0,3 mm; fita adesiva (Scotch - 3M) e uma moldura preta de polipropileno, semi-rígida, com recorte central de $47 \times 19 \mathrm{~cm}$ e outra de $17,5 \times 18,5 \mathrm{~cm}$ adaptadas ao negatoscópio no intuito de concentrar a luz para promover melhor visualização das áreas anatômicas de interesse na telerradiografia.

O desenho do traçado anatômico, a localização e a demarcação dos pontos cefalométricos de todos os traçados foram realizados em uma sala escura, onde a luz do negatoscópio foi a única fonte de iluminação. 
Após a execução do desenho anatômico, os pontos foram identificados e, posteriormente, digitalizados por intermédio de uma mesa digitalizadora Numonics A-30TL. $F^{1}$, conectado a um microcomputador com processador AMD K-6 II 500MHz, para obtenção das grandezas cefalométricas. Os traçados e a digitalização dos pontos foram realizados pelo examinador, utilizando-se uma configuração personalizada "Eduardo Franco" do programa Dentofacial Planner $7.02^{2}$ para a realização das medições. Foi efetuada a correção do fator de magnificação $(9,8 \%)$, realizada pelo próprio programa.

\footnotetext{
${ }^{1}$ Numonics Corporation, Montgomeryville, PA, EUA.

${ }^{2}$ Dentofacial Planner Software Inc., Toronto, Ontário, Canadá. 


\section{3- Delimitação das estruturas anatômicas (Figura 5.1).}

Foram delimitadas as seguintes estruturas anatômicas:

- Sela Túrcica;

- Clívus do osso esfenóide;

- Cortical externa do osso frontal e ossos nasais;

- Fissura pterigomaxilar;

- Limite póstero-inferior da cavidade orbitária;

- Contorno do meato acústico externo;

- Maxila;

- Mandíbula;

- Incisivos centrais permanentes superior e inferior;

- Primeiros molares permanentes superior e inferior;

- Perfil tegumentar. 


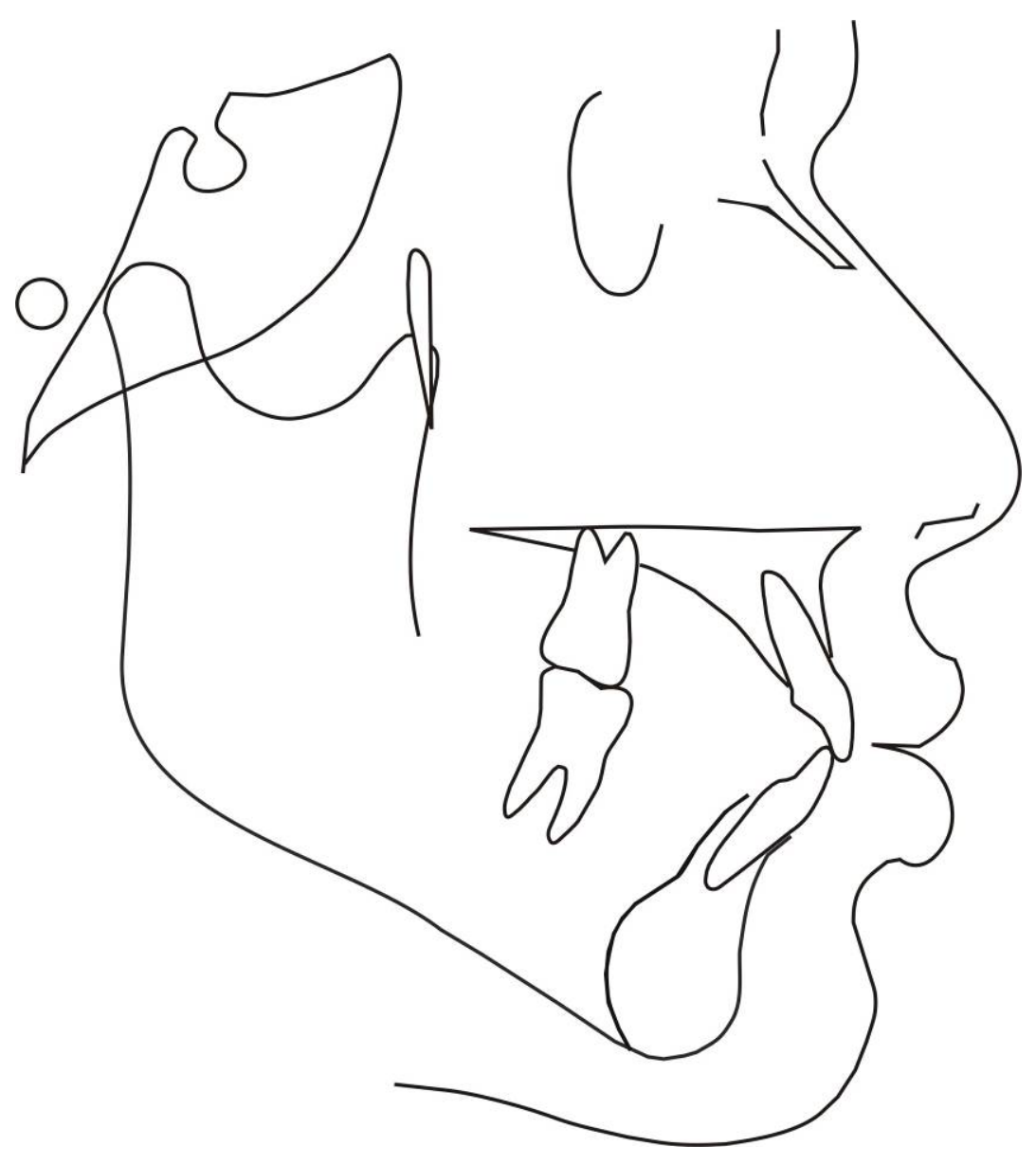

Figura 5.1- Desenho das estruturas anatômicas.

\section{4- Demarcação dos pontos cefalométricos (Figura 5.2).}

Após a confecção do desenho anatômico foram localizados os pontos cefalométricos, de acordo com KROGMAN; SASSOUNI ${ }^{57}$, MCNAMARA ${ }^{65}$, MARTINS et al. ${ }^{63}$ e INTERLANDI ${ }^{43}$.

1. S (sela túrcica): ponto central da sela túrcica;

2. $\mathbf{N}$ (násio): ponto anterior da sutura frontonasal; 
3. Or (orbitário): ponto médio inferior da margem infraorbitária;

4. Po (pório anatômico): ponto superior do meato acústico externo;

5. Ponto PTM: ponto póstero-superior da fissura pterigomaxilar;

6. ENA (espinha nasal anterior): ponto da espinha nasal anterior;

7. ENP (espinha nasal posterior): ponto posterior do assoalho da fossa nasal;

8. Ponto A (subespinhal): ponto profundo da concavidade anterior da maxila;

9. Ponto $P$ ': cruzamento da linha NA com a linha $p$;

10. Ponto B (supramentoniano): ponto profundo da concavidade da sínfise mentoniana;

11. Pog (pogônio): ponto anterior do contorno do mento ósseo;

12. Me (mentoniano): ponto inferior da sínfise mentoniana;

13. Go (gônio): ponto determinado pela intersecção da bissetriz do ângulo formado pelas tangentes às bordas posterior e inferior da mandíbula; 
14.Ponto E: resultante da bissetriz entre a perpendicular do plano mandibular (GoMe) com o ponto mais anterior da eminência mentoniana (Pog).

15. BIS (borda incisal superior): ponto inferior da borda incisal do incisivo central superior permanente;

16. AIS (ápice incisal superior): ponto superior do ápice radicular do incisivo central superior permanente;

17. BII (borda incisal inferior): ponto superior da borda incisal do incisivo central inferior;

18. All (ápice incisal inferior): ponto inferior do ápice radicular do incisivo central inferior. 


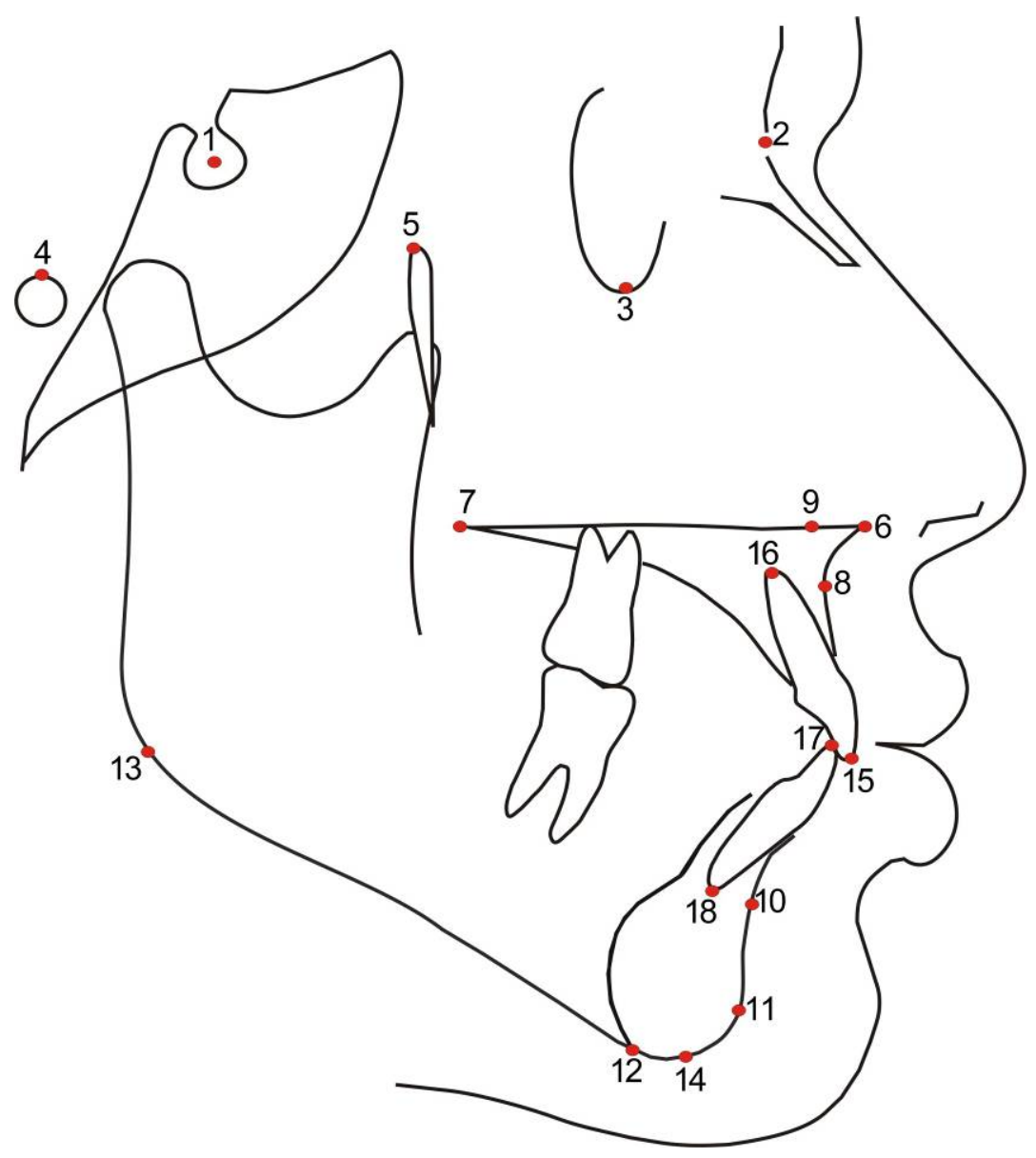

Figura 5.2- Pontos Cefalométricos

4.5- Demarcação das linhas e planos (Figura 5.3)

HORIZONTAIS:

A - Linha SN: do ponto sela ao násio;

B - Plano horizontal de Frankfurt (PoOr): do ponto pório ao orbitário; 
C - Plano palatino (ENA-ENP): do ponto espinha nasal anterior ao ponto espinha nasal posterior;

D - GoMe (plano mandibular); do ponto gônio ao mentoniano;

VERTICAIS:

E - Linha NA: une o ponto násio ao ponto A;

F - Linha NB: une o ponto násio ao ponto B;

G - Linha BIS-AIS (longo eixo do incisivo superior): une os pontos correspondentes da borda incisal ao ápice do incisivo central superior permanente;

H - Linha Bll-All (longo eixo do incisivo inferior): une os pontos correspondentes da borda incisal ao ápice do incisivo central inferior permanente;

I - Linha I: União dos pontos P' e "E", traçado numa extensão de apenas 1 cm, no cruzamento com o plano oclusal;

J - Plano Pterigomaxilar Vertical (PTV): União do ponto (PTM) da fissura pterigomaxilar perpendicular ao plano de Frankfurt (Po-Or);

K - Linha A-Pog: União entre o ponto A e o ponto Pog; 
L - Linha A-perp: Linha vertical perpendicular ao plano de Frankfurt (Po-Or) até o ponto $A$.

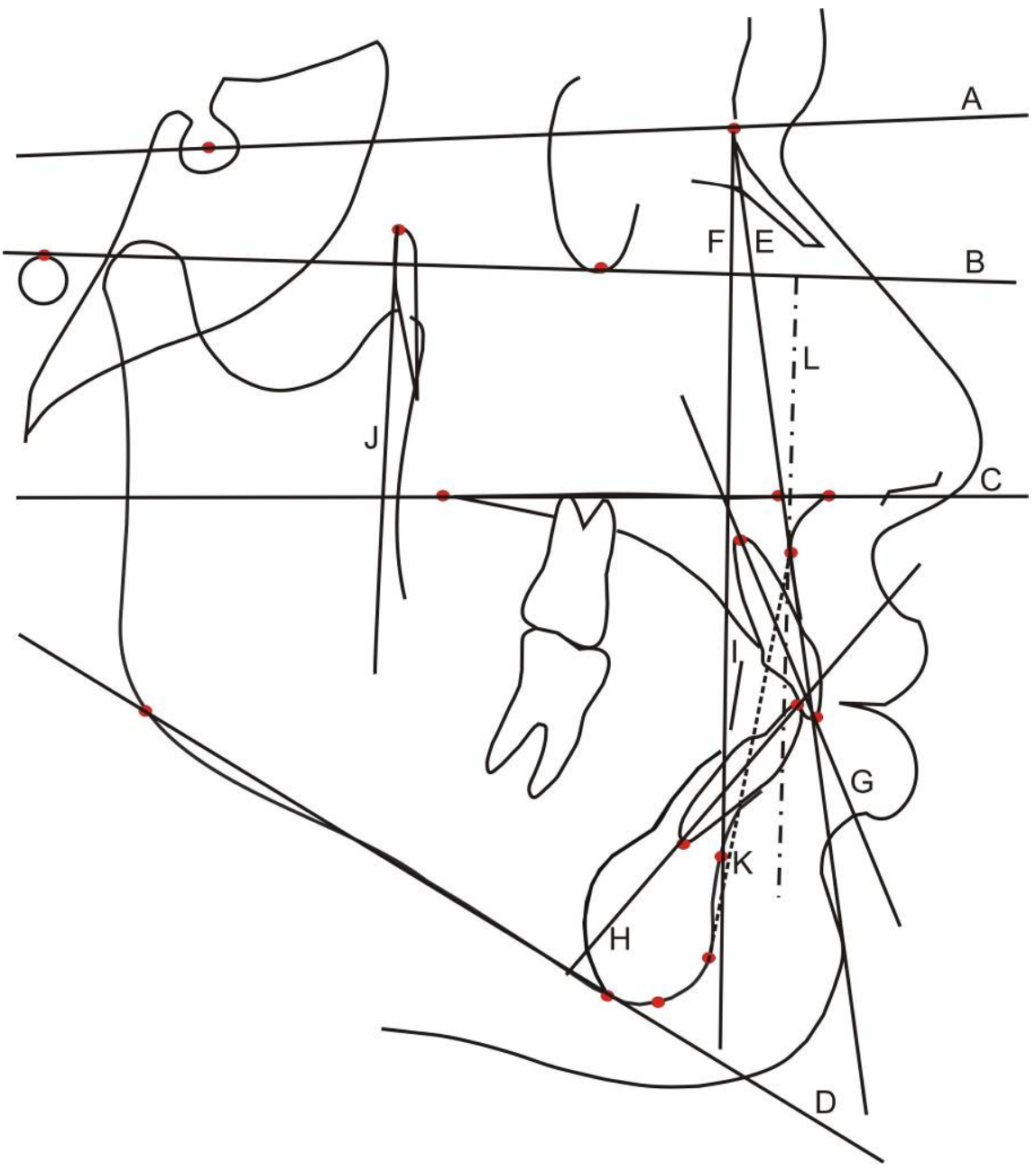

Figura 5.3 - Representação das linhas e planos. 


\section{6- Variáveis cefalométricas dentárias}

\section{- Componente dentoalveolar maxilar (Figura 5.4)}

1- Mx1.NA ( ${ }^{\circ}$ ): ângulo entre o longo eixo do incisivo central superior e a linha NA. Representa o grau de inclinação do incisivo central superior em relação à maxila e ao ponto násio.

2- Mx1.PP ( $\left.{ }^{\circ}\right)$ : ângulo entre o longo eixo do incisivo central superior e o plano palatino. Representa o grau de inclinação do incisivo central superior em relação à maxila.

3- Mx1-NA (mm): distância entre o ponto mais anterior da coroa do incisivo central superior e a linha NA. Representa a posição ântero-posterior do incisivo superior em relação à maxila e o násio.

4- Mx1-PP (mm): distância perpendicular entre a borda incisal do incisivo central superior e o plano palatino. Representa a posição vertical do incisivo central superior permanente na maxila.

5- Mx1-Aperp (mm): distância entre o ponto BIS (borda incisal do incisivo central superior) e a linha Aperp.

6- Mx1-PTV (mm): distância entre o ponto BIS até o Plano Pterigomaxilar Vertical (PTV). 


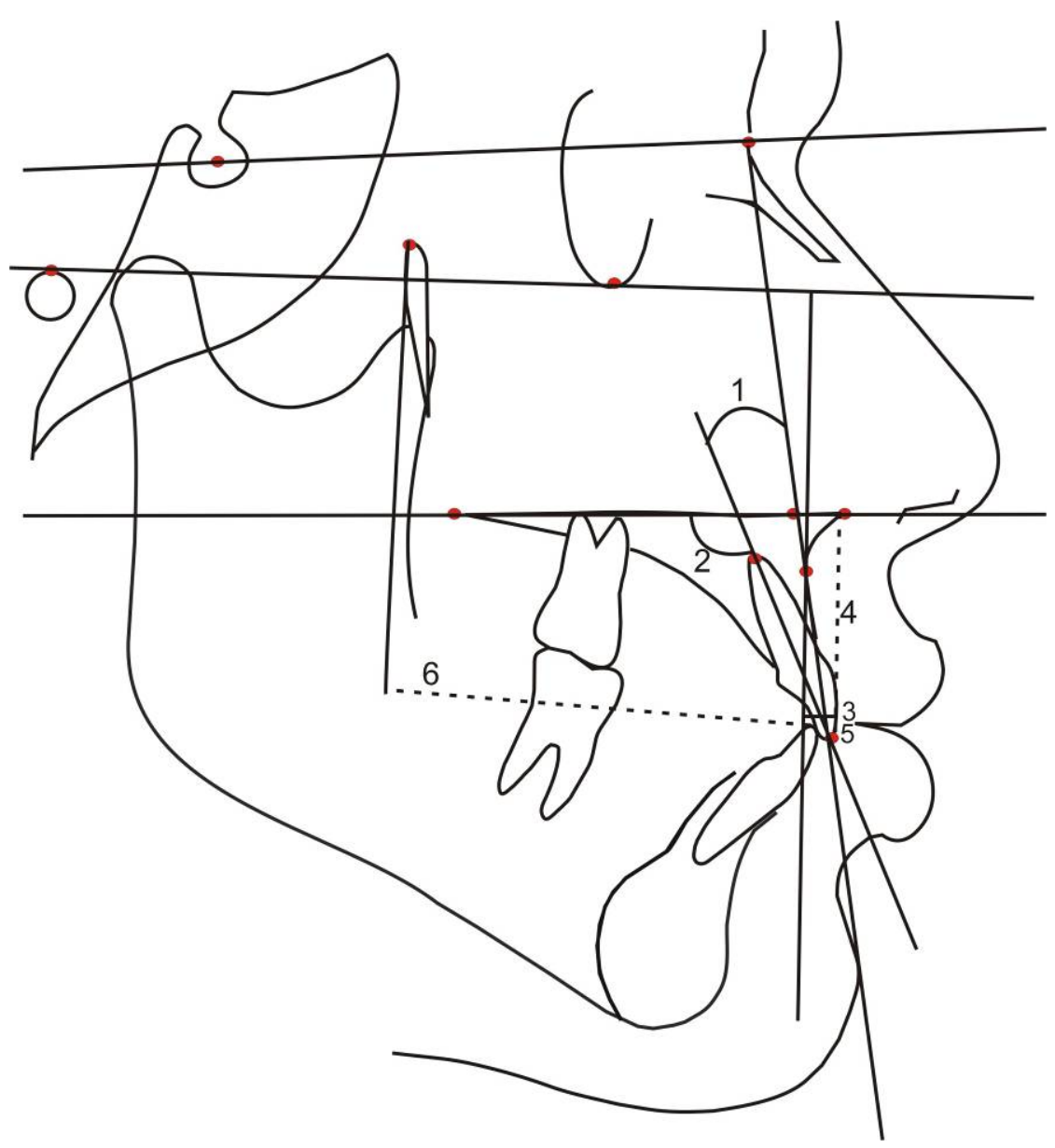

Figura 5.4 - Componente dentoalveolar anterior superior

\section{- Componente dentoalveolar mandibular (Figura 5.5)}

7- Md1.NB ( $\left.{ }^{\circ}\right)$ : ângulo entre o longo eixo do incisivo central inferior e a linha NB. Representa o grau de inclinação do incisivo central inferior em relação à mandíbula e o ponto násio.

8- Md1-NB (mm): distância perpendicular entre o ponto mais anterior da coroa do incisivo central inferior e a linha NB. Representa a posição ântero-posterior do incisivo inferior em relação à mandíbula e o násio. 
9- IMPA $\left({ }^{\circ}\right)$ : ângulo entre o longo eixo do incisivo central inferior e o plano mandibular GoMe. Representa a inclinação do dente em relação à mandíbula.

10-Linha I (mm): união dos pontos $P$ ' e "E", traçado numa extensão de apenas $1 \mathrm{~cm}$, no cruzamento com o plano oclusal. Determina o grau de retrusão ou protrusão do incisivo central inferior.

11-Md1-APog (mm): distância entre o ponto (BII) borda incisal do incisivo central inferior e a linha A-Pog.

12- Md1-PM (mm): distância perpendicular entre a borda incisal do incisivo central inferior e o plano mandibular. Representa a posição vertical do incisivo central inferior permanente na sínfise mandibular.

13- Md1-PTV (mm): distância entre o ponto Bll até o Plano Pterigomaxilar Vertical (PTV). 


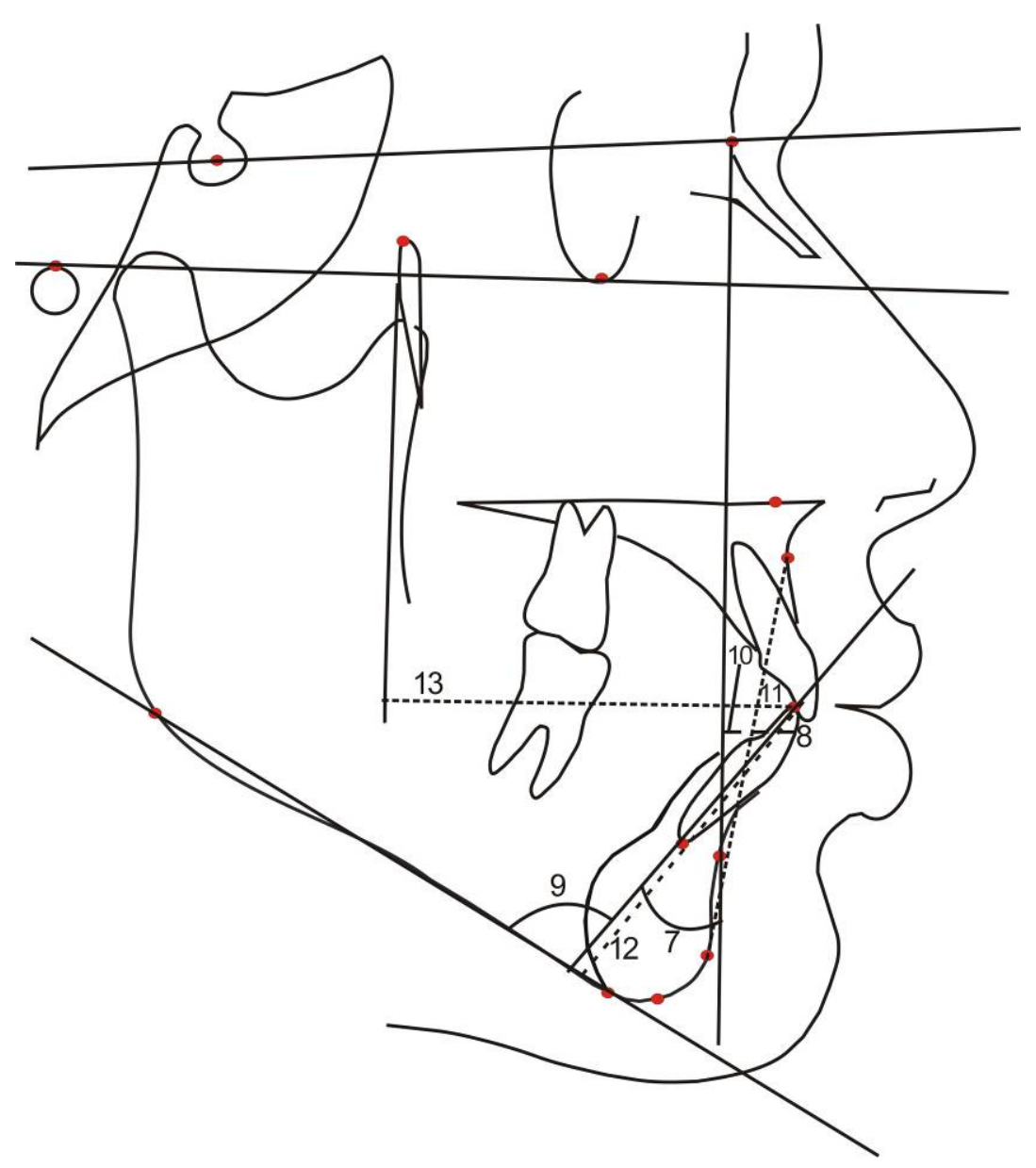

Figura 5.5 - Componente dentoalveolar anterior inferior

\section{7- Análise estatística}

\subsection{1- Erro do Método}

Os traçados e as mensurações das grandezas cefalométricas foram refeitos pelo mesmo examinador, após a obtenção dos cefalogramas iniciais. Para a determinação da confiabilidade dos resultados, quinze radiografias selecionadas ao acaso foram traçadas e digitalizadas, pelo mesmo pesquisador, com um intervalo de 20 dias. 
Para cada uma das grandezas cefalométricas estudadas, foram avaliados os erros sistemáticos e casuais, independentemente. O erro sistemático foi calculado pelo teste "t" pareado, conforme preconizado por HOUSTON $^{41}$. A aplicação da fórmula proposta por DAHLBERG ${ }^{28}\left(\mathrm{Se}^{2}=\right.$ somatória $\mathrm{d}^{2} / 2 \mathrm{n}$ ) possibilitou estimar a resultante dos erros casuais. Consideram-se significantes os erros acima de 1 milímetro para as medidas lineares e 1,5 grau para as angulares ${ }^{28}$ (Tabela 1$)$.

\subsection{2- Análise descritiva e comparativa}

Os valores em relação à idade cronológica dos integrantes foram compatibilizados e estão citados na tabela 2. Uma avaliação descritiva dos valores obtidos em relação as variáveis cefalométricas dentárias, nos adolescentes brasileiros feodermas, está ilustrada na tabela 3.

Para a análise estatística dos dados utilizou-se o teste "t" independente, com valor de $p<0,05$, para comparação dos valores das variáveis cefalométricas entre os gêneros. Estes testes foram realizados no programa de computador Statistica for Windows $5.0^{3}$.

\footnotetext{
${ }^{3}$ STATISTICA for Windows. StatSoft, Inc. (1995). Tulsa, OK, EUA.
} 

5. RESULTADOS 



\section{RESULTADOS}

Os resultados observados estão apresentados sob a forma de tabelas. A tabela 1 indica os resultados da avaliação do erro intra-examinador nas telerradiografias em norma lateral.

Os valores em relação à idade cronológica dos integrantes foram compatibilizados e estão citados na tabela 2. A média de idade entre os indivíduos da amostra ( $\mathrm{N}=40)$ foi de 13.15 anos, de acordo com o teste "t".

Uma avaliação descritiva dos valores obtidos em relação às variáveis cefalométricas dentárias nos adolescentes brasileiros feodermas está ilustrada na tabela 3.

$\mathrm{Na}$ tabela 4, podem ser avaliados os resultados obtidos pelo teste "t", independente da comparação das variáveis cefalométricas nos gêneros masculino e feminino, determinando a existência ou não de dimorfismo entre os gêneros. Em face dos resultados e da análise estatística aplicada, não foi observada diferença significante para todas as variáveis estudadas. 
Tabela 1- Avaliação do erro intra-examinador. Resultado do teste t dependente (erro sistemático) e do erro casual.

\begin{tabular}{l|c|c|c|c|c|c|c}
\hline Medidas & Média 1 & DP 1 & Média 2 & DP 2 & t & p & $\begin{array}{c}\text { Dahlberg } \\
\text { Erro casual }\end{array}$ \\
\hline
\end{tabular}

\section{Componente dentoalveolar anterior superior}

\begin{tabular}{c|c|c|c|c|c|c|c}
\hline Mx1.NA & 24,07 & 3,93 & 23,52 & 4,36 & 1,657 & 0,120 & 0,95 \\
\hline Mx1.PP & 113,81 & 4,70 & 113,28 & 4,77 & 1,562 & 0,141 & 0,97 \\
\hline Mx1-NA & 5,95 & 2,02 & 6,19 & 2,16 & 1,430 & 0,175 & 0,46 \\
\hline Mx1-PP & 26,33 & 2,42 & 26,63 & 2,42 & 1,482 & 0,160 & 0,58 \\
\hline Mx1-PTV & 53,08 & 4,59 & 52,95 & 4,44 & 0,619 & 0,546 & 0,58 \\
\hline Mx1-Aperp & 6,02 & 2,16 & 6,09 & 2,20 & 0,455 & 0,656 & 0,39 \\
\hline
\end{tabular}

Componente dentoalveolar anterior inferior

\begin{tabular}{|c|c|c|c|c|c|c|c|}
\hline Md1.NB & 28,00 & 5,87 & 27,73 & 5,14 & 0,726 & 0,480 & 1,01 \\
\hline IMPA & 93,53 & 5,30 & 93,49 & 5,15 & 0,149 & 0,883 & 0,83 \\
\hline Md1-NB & 5,45 & 2,07 & 5,31 & 1,87 & 0,841 & 0,414 & 0,43 \\
\hline Md1-GoMe & 38,75 & 2,30 & 38,73 & 2,21 & 0,066 & 0,948 & 0,53 \\
\hline Md1-PTV & 49,63 & 4,47 & 49,43 & 4,28 & 0,779 & 0,449 & 0,67 \\
\hline Md1-APog & 4,09 & 1,43 & 4,08 & 1,48 & 0,061 & 0,952 & 0,29 \\
\hline Linha I & $-4,92$ & 1,70 & $-4,83$ & 1,82 & 0,384 & 0,706 & 0,60 \\
\hline
\end{tabular}

Significante para $p<0,05$. 
Tabela 2- Análise estatística das médias das idades em ambos os gêneros.

\begin{tabular}{|c|c|c|c|c|c|c|c|c|}
\hline & \multicolumn{2}{|c|}{ Total $(\mathrm{N}=40)$} & \multicolumn{2}{|c|}{ Fem. $(\mathrm{N}=20)$} & \multicolumn{2}{|c|}{ Masc. $(\mathrm{N}=20)$} & & \\
\hline & $X$ & D.P & $x$ & D.P & $X$ & D.P & $\mathbf{t}$ & $\mathbf{p}$ \\
\hline Idade & 13,15 & 0,61 & 13,10 & 0,78 & 13,25 & 1,04 & $-0,585$ & 0,560 \\
\hline Idade mínima & 12,00 & & 12,00 & & 12,20 & & & \\
\hline Idade máxima & 14,30 & & 14,21 & & 14,30 & & & \\
\hline
\end{tabular}

Significante para $p<0,05$. 
Tabela 3- Análise descritiva da amostra, com os valores das médias e desviospadrão em jovens brasileiros feodermas.

\begin{tabular}{c|c|c|c|c|c}
\hline Variáveis & $\mathbf{N}$ & Média & Mínimo & Máximo & D.P \\
\hline \multicolumn{5}{c|}{ Componente dentoalveolar anterior superior } \\
\hline Mx1.NA & 40 & 24,23 & 14,8 & 33,4 & 4,40 \\
\hline Mx1.PP & 40 & 113,61 & 101,4 & 124,1 & 4,68 \\
\hline Mx1-NA & 40 & 6,40 & 3 & 12,6 & 2,16 \\
\hline Mx1-PP & 40 & 26,58 & 21,2 & 30,3 & 2,26 \\
\hline Mx1-PTV & 40 & 52,95 & 42,3 & 66,3 & 4,78 \\
\hline Mx1-Aperp & 40 & 5,95 & 2 & 11,5 & 2,18 \\
\hline \multicolumn{2}{|c|}{ Componente dentoalveolar anterior inferior } \\
\hline Md1.NB & 40 & 28,10 & 13,1 & 36,8 & 5,23 \\
\hline IMPA & 40 & 94,63 & 80,5 & 105,3 & 5,58 \\
\hline Md1-NB & 40 & 5,23 & 1,2 & 9,2 & 2,00 \\
\hline Md1-GoMe & 40 & 38,82 & 34,9 & 43,8 & 2,26 \\
\hline Md1-PTV & 40 & 49,37 & 38,9 & 61,5 & 4,46 \\
\hline Md1-APog & 40 & 4,10 & 0,4 & 7,9 & 1,56 \\
\hline Linha I & 40 & $-4,82$ & $-9,7$ & $-0,5$ & 1,91 \\
\hline & & & & & \\
\hline
\end{tabular}


Tabela 4- Análise estatística do teste "t" independente para o dimorfismo entre os gêneros, em jovens brasileiros feodermas.

\begin{tabular}{l|c|c|c|c|c}
\hline Variáveis & \multicolumn{2}{|c|}{ Masculino } & \multicolumn{2}{c|}{ Feminino } & P \\
\hline & Média & D.P & Média & D.P & \\
& & & & & \\
\hline
\end{tabular}

Componente dentoalveolar anterior superior

\begin{tabular}{c|c|c|c|c|c}
\hline Mx1.NA & 24,44 & 4,46 & 24,01 & 4,43 & 0,762 \\
\hline Mx1.PP & 113,81 & 5,09 & 113,42 & 4,37 & 0,796 \\
\hline Mx1-NA & 6,53 & 2,28 & 6,26 & 2,08 & 0,698 \\
\hline Mx1-PP & 26,70 & 2,51 & 26,46 & 2,04 & 0,743 \\
\hline Mx1-PTV & 53,44 & 4,95 & 52,47 & 4,69 & 0,529 \\
\hline Mx1-Aperp & 5,82 & 2,29 & 6,09 & 2,13 & 0,697 \\
\hline \multicolumn{7}{c}{ Componente dentoalveolar anterior inferior }
\end{tabular}

\begin{tabular}{c|c|c|c|c|c}
\hline Md1.NB & 27,65 & 5,70 & 28,55 & 4,81 & 0,591 \\
\hline IMPA & 94,63 & 5,30 & 94,64 & 5,98 & 0,993 \\
\hline Md1-PM & 39,51 & 2,29 & 38,14 & 2,07 & 0,056 \\
\hline Md1-PTV & 49,90 & 4,62 & 48,84 & 4,34 & 0,462 \\
\hline Md1-NB & 4,96 & 2,15 & 5,49 & 1,85 & 0,410 \\
\hline Md1-APog & 4,00 & 1,73 & 4,20 & 1,42 & 0,700 \\
\hline Linha I & $-4,69$ & 2,19 & $-4,95$ & 1,62 & 0,667 \\
\hline
\end{tabular}

Significante para $p<0,05$. 




\section{DISCUSSÃO}

\subsection{Características da amostra}

Para a obtenção da amostra foi selecionado um grupo de indivíduos feodermas, de ambos os gêneros, apresentando uma faixa etária entre 12 e 14 anos, com idade média de 13,15 anos. Devido aos processos de crescimento e desenvolvimento facial, pode-se esperar que as características cefalométricas avaliadas em crianças sejam diferentes daqueles avaliados em adultos. Desta forma, os estudos cefalométricos cujas amostras incluíram predominante ou exclusivamente crianças leucodermas, melanodermas, xantodermas $^{4,5}$ se diferenciam em seus valores daqueles realizados com amostra composta por adultos $^{2,8,24,56}$.

$\mathrm{Na}$ literatura consultada nenhum trabalho de investigação foi publicado para determinar as características de normalidades faciais, esqueléticas e dentárias, englobando especificamente jovens brasileiros pardos ou mulatos. Assim, alguns parâmetros cefalométricos estabelecidos em avaliações de indivíduos melanodermas foram utilizados para a consecução do presente estudo, mas incorporando jovens feodermas ${ }^{10,66,70,94}$. Do ponto de vista metodológico, observa-se grande variabilidade quanto ao número de indivíduos que compõem a amostragem. COTTON; TAKANO; WONG ${ }^{26}$ selecionaram apenas 20 indivíduos para um trabalho de investigação. BERTOZ $^{10}$ baseou-se em 30 indivíduos melanodermas que apresentavam Classe I de Angle. ALTEMUS ${ }^{4,5}$ selecionou 80 indivíduos, de um grupo de 
3289, com as melhores relações oclusais. Por outro lado, KOWALSKI et al. ${ }^{56}$ estudaram uma amostra considerável de 244 indivíduos.

O presente estudo utilizou uma amostra de 40 jovens brasileiros feodermas, 20 do gênero masculino, com idade média de 13,25 (mínima de 12,20 e máxima de 14,30) e 20 do gênero feminino, com idade média de 13,10 (mínima de 12,00 e máxima de 14,21). Para possibilitar a composição da referida amostra foram examinados 300 indivíduos.

O principal requisito para viabilização da pesquisa foi uma oclusão dentária com relações normais de molares, sem a presença de mordida profunda, mordida aberta, rotações ou apinhamentos dentários significativos.

A literatura apresenta uma grande diversidade nos critérios de inclusão, em relação às características oclusais adotadas. A maior parte dos estudos utiliza modelos para oclusão de Classe I de Angle $10,15,29,44,52,63,66,77,87,88,94$, enquanto outros não ${ }^{38,39,56}$. ALTEMUS ${ }^{4,5}$, DANDAGENA ${ }^{29}$, BACON$^{8}$ realizaram a seleção de acordo com o alinhamento ideal e presença de todos os dentes permanentes. Por outro lado FONSECA ${ }^{37}$ e CONNOR ${ }^{24}$ exigiram apenas a Classe I de Angle sem a especificação oclusal detalhada como mordida aberta, mordida profunda, ou outras condições anormais. Entretanto, a maior parte dos relatos excluiu indivíduos que sofreram trauma facial ou foram submetidos à cirurgia ortognática ou tratamento ortodôntico ${ }^{10,63,66,87}$.

Portanto, o grupo amostral, da presente pesquisa, tomando por base indivíduos feodermas apresentavam características faciais agradáveis, de acordo com as observações de CAPELOZZA ${ }^{19}$. As análises faciais, frontal e lateral foram utilizadas, respectivamente, como instrumento para avaliação do 
equilíbrio entre os terços, superior, médio e inferior da face, assim como para classificação do perfil facial em: reto, côncavo e convexo. Portanto, uma análise facial subjetiva, por meio das fotografias extra-bucais frontais e laterais, foi adotada para quantificar o padrão do crescimento facial e as características morfológicas faciais que poderiam influenciar nos resultados, em relação ao posicionamento dentário nos arcos superiores e inferiores, corroborando com o trabalho de CAPELOZZA ${ }^{19}$.

Ao considerar a face dos jovens brasileiros feodermas como equilibrada e agradável, foram encontrados na literatura diferentes classificações em relação aos tipos faciais ${ }^{19,35,72}$. Nesse sentido, a literatura evidencia que as características estruturais craniofaciais dos indivíduos avaliados podem sofrer alterações, durante a fase de crescimento, pois recebem influências genéticas dos pais e avós ${ }^{11,12,19,95}$.

Outro aspecto importante é a origem dos indivíduos feodermas brasileiros. A miscigenação entre o colonizador português, o indígena e o negro resultou na formação, desde os primórdios históricos, em uma população diversificada. Os negros e mulatos assumiram parcela ponderável da população brasileira ${ }^{10,66,94}$. Cada um dos três grupos básicos (índio, branco e negro) está longe de representar uma etnia pura. Em particular, o pardo ou mulato apresenta uma heterogeneidade das suas características morfológicas faciais, dentárias e esqueléticas. Sabe-se que a origem desse grupo étnico surgiu da miscigenação entre os diversos grupos negroides com leucodermas provenientes de diversas descendências geográficas. Este processo proporcionou uma diferenciação dos traços faciais marcantes do indivíduo melanoderma com a suavidade do aspecto facial encontrado nos leucodermas. 
Portanto, variações hereditárias individuais podem ser avaliadas, principalmente, nos indivíduos feodermas com relação aos aspectos facial e esquelético, encontrando-se indivíduos mulatos com características isoladas dos brancos ou somente dos negros (Fig. $1.1 ; 1.2 ; 3.1 ; 3.2$ ).

A padronização da respectiva amostra teve como objetivo selecionar jovens com aspecto facial agradável e com características intermediárias entre o padrão facial do negro com o branco. A classificação da cor da pele foi, também, de fundamental importância para validar a metodologia deste trabalho ${ }^{6}$, sendo que a adoção dos critérios de inclusão dos indivíduos e a abordagem metodológica estabelecida possibilitaram uma avaliação representativa, com a segurança de uma amostra homogênea e confiável.

\subsection{Considerações da metodologia}

Muitos estudos ${ }^{4,15,52,73}$ que compararam modelos estatísticos entre melanodermas e leucodermas utilizaram os valores médios para indivíduos leucodermas, a partir da análise desenvolvida por pesquisadores de diferentes origens, gerando variações na demarcação dos pontos de reparo e técnicas de medidas.

Outro aspecto importante é o fator de magnificação. Neste estudo, efetuou-se a correção do fator calculado no valor de 9.8\%. Entretanto, diversos trabalhos não especificam a realização da correção do fator de magnificação $8,15,36,71,80$. A omissão de alguns dados importantes como o fator de magnificação inviabiliza a compatibilização e comparação dos resultados 
entre as amostras dos trabalhos citados na literatura, pois existe diferença significativa entre os valores que não foram devidamente corrigidos.

Para melhor esclarecimento, o fator de magnificação corresponde à porcentagem de ampliação da imagem radiográfica em relação ao tamanho real das estruturas do complexo craniofacial, sendo que para seu cálculo é preciso primeiramente medir a distância de uma oliva metálica a outra (A). Em seguida, mantendo-se a mesma medida $A$ entre as olivas, obtém-se uma radiografia PA (póstero-anterior) na qual apareça a imagem radiográfica apenas das olivas metálicas (B). Assim, o fator de magnificação (X) é obtido por meio da seguinte fórmula matemática:

$X=B-A / A \times 100$

Em que:

X= Fator de magnificação

A= Distância de uma oliva metálica a outra

B= Distância de uma oliva metálica a outra na imagem radiográfica

Na presente pesquisa, a implementação das 13 variáveis dentárias foi em função da diversidade das estruturas que compreendem o complexo craniofacial. Muitas medidas cefalométricas são obtidas por meio da estrutura basal craniana ou nas bases apicais, maxilar e mandibular. Entretanto, existe grande variação da morfologia estrutural que abrange a base do crânio ${ }^{8,35}$. O encurtamento da linha SN pode induzir o ortodontista para um diagnóstico com menor precisão, podendo evidenciar, equivocadamente, a protrusão ou retrusão das bases ósseas e dentárias ${ }^{76,96}$. 
A deflexão da base do crânio pode, também, inferir em interpretações equivocadas durante o diagnóstico complementar. Entretanto, muitas destas variações podem ser analisadas como características típicas de um determinado grupo étnico ${ }^{35,76}$.

Algumas das variáveis difundidas por DOWNS ${ }^{33}$, STEINER $^{85}$ são obtidas a partir da base do crânio. Por outro lado, RICKETTS ${ }^{78}$, McNAMARA $^{65}$ e TWEED $^{92,93}$ avaliaram as variáveis dentárias sem a utilização da base craniana como referência.

Assim, as variáveis dentárias eleitas para consecução do presente trabalho visaram estabelecer as características do posicionamento dentário em relação aos pontos de referência craniana e com as bases ósseas apicais, tendo em vista que as grandezas cefalométricas devem ser discutidas com pesquisas que especifiquem as características do posicionamento dentário em indivíduos leucodermas, melanodermas e xantodermas. Deve ser destacado que, de acordo com a literatura consultada, nenhum outro trabalho descreveu as características morfológicas esqueléticas e o posicionamento dentário em jovens brasileiros mulatos ou pardos.

\subsection{Discussão dos resultados}

As variáveis cefalométricas americanas eram rigidamente usadas pelos ortodontistas no diagnóstico e plano de tratamento das diversas más oclusões sem, entretanto, individualizar adequadamente a morfologia facial, variáveis esqueléticas e dentárias dos diferentes grupos étnicos ${ }^{33,78,85,92}$. Desta forma, muitos resultados insatisfatórios, principalmente nos casos tratados com 
extrações dentárias refletiam, diretamente, em uma alteração negativa do perfil facial. Além disso, deslumbrava-se um único padrão de beleza facial ditado por um perfil reto, caracterizando tipicamente os povos anglo-saxônicos ${ }^{92}$.

No Brasil, entretanto, existe uma miscigenação exacerbada entre os grupos étnicos que migraram das diversas regiões do mundo. O padrão de beleza e harmonia facial podem ser determinados de acordo com a cultura e localidade regional $^{74}$. Portanto, poucos estudos são referenciados na literatura específica e que tragam contribuição na definição do padrão da maioria da população brasileira que é composta por indivíduos afrodescendentes $^{10,66,70,73,74,94}$.

De acordo com as classificações e análises faciais observadas na literatura consultada, pode-se concluir, subjetivamente, que os jovens brasileiros feodermas apresentam peculiaridades individuais quanto ao aspecto facial, diferindo das características padrões observadas em indivíduos leucodermas, melanodermas e xantodermas $2,3,13,19,34,35,51,63,74,100$. Essa individualidade das características faciais, dentárias e esqueléticas pode ser explicada pela miscigenação entre os indivíduos leucodermas e melanodermas.

Não obstante, a avaliação facial ser um importante elemento para definir o equilíbrio entre os componentes esquelético, dentário e tegumentar, somente as variáveis dentárias serão quantificadas e discutidas, tendo por base estudos com diferentes grupos étnicos, conforme publicações específicas divulgadas por diferentes autores.

Observa-se, assim, que muitas das análises cefalométricas relacionam os dentes com as demais estruturas do complexo Eduardo Jacomino Franco 
craniofacial $^{33,65,78,85,92,93}$. O posicionamento do incisivo central inferior é utilizado como um parâmetro para o diagnóstico e planejamento cefalométrico. ${ }^{44,61,92,93}$. Dentre os principais pontos de referência para o tratamento ortodôntico destacam-se: a curva de Spee, apinhamento dentário anterior e posterior, inclinação dos incisivos superiores e, principalmente, os inferiores ${ }^{33,44,61,85,92,93}$. Portanto, ao estabelecerem estas análises, os diferentes autores sinalizaram quanto à especificidade e aplicabilidade em grupos raciais distintos que demonstram diferenças craniofaciais e dentárias evidentes. Não obstante essa observação, estudos foram implementados para elaboração de padrões cefalométricos específicos para os diferentes grupos étnicos ${ }^{3-}$ $5,10,12,24,26,34,37,51,56$

Portanto, satisfazendo os critérios citados, convêm mencionar a necessidade de discutir, minuciosamente, os resultados quanto ao aspecto do posicionamento dentário em jovens brasileiros feodermas por meio das variáveis lineares e angulares em relação ao posicionamento dos incisivos superiores e inferiores. Assim, os valores obtidos serão comparados aos diferentes grupos étnicos, com finalidade de referendar o clínico no diagnóstico e plano de tratamento ortodôntico individualizado.

As variáveis lineares $(\mathrm{mm})$ representam o posicionamento dentário "de corpo". A protrusão é determinada por um valor negativo e os incisivos assumem uma posição anterior. Por outro lado, a retrusão é classificada por uma variável positiva, pois os incisivos estão situados posteriormente. Já as variáveis angulares ${ }^{(0)}$ representam as inclinações dentárias e podem ser classificadas como inclinação da coroa dentária para vestibular ou lingual. 
6.3.1 Posicionamento dos incisivos superiores e inferiores para os diferentes grupos étnicos

Ao se comparar algumas das variáveis lineares e angulares, do presente trabalho com o estudo de MEDEIROS ${ }^{66}$, pode-se inferir que as variáveis 1.NB, 1-NB e a LINHA "I" apresentaram diferenças significantes. De acordo com a tabela 6.1 verifica-se uma protrusão e inclinação mais acentuada, principalmente nos incisivos inferiores dos jovens brasileiros melanodermas, corroborando com os estudos de ALEXANDER ${ }^{3}$, ALTEMUS $^{4}$, BJORK $^{12}$, CONNOR $^{24}$, COTTON $^{26}$, DRUMMOND $^{34}$, FONSECA $^{37}$, JACOBSON $^{2}$

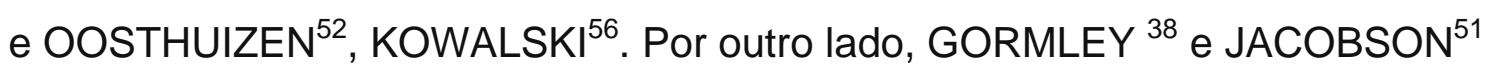
encontraram um posicionamento semelhante para os incisivos superiores dos melanodermas e leucodermas. Entretanto, ao analisar o trabalho realizado por GORMELEY ${ }^{38}$ pode-se admitir que os valores obtidos podem estar relacionados às características do grupo amostral utilizado, uma vez que os critérios de inclusão, em relação à oclusão dentária e às características raciais, não foram precisamente descritas. As diferenças relacionadas às observações estabelecidas por JACOBSON e OOSTHUIZEN ${ }^{52}$ devem estar associadas à especificidade de sua amostra, uma vez que embora haja detalhamento quanto à inclusão de melanodermas africanos, estes apresentam miscigenação insignificante, quando comparados aos melanodermas brasileiros ${ }^{66,74,94}$. Nesse aspecto, pode-se destacar que a principal diferença entre os negros da África e os da América é a protrusão dos incisivos superiores, atribuindo-se maior protrusão nos negros americanos devido ao processo de miscigenação do melanoderma americano com leucodermas do oeste europeu e o índio americano. 
Tabela 6.1- Médias observadas em jovens brasileiros feodermas, comparativamente às obtidas em melanodermas por MEDEIROS ${ }^{66}$, com relação ao posicionamento dentário, na faixa etária de 12 a 14 anos de idade.

\begin{tabular}{|c|c|c|}
\hline VARIÁVEIS & $\begin{array}{c}\text { Médias melanodermas } \\
\text { (MEDEIROS, MA) }\end{array}$ & $\begin{array}{c}\text { Médias feodermas } \\
\text { (FRANCO, EJ) }\end{array}$ \\
\hline $1 . N A^{(0)}$ & 25,35 & 24,23 \\
\hline 1-NA (mm) & 7,12 & 6,40 \\
\hline $1 . \mathrm{NB}^{(0)}$ & 35,18 & 28,10 \\
\hline 1-NB (mm) & 8,75 & 5,23 \\
\hline LINHA“I” (mm) & $-6,48$ & $-4,82$ \\
\hline
\end{tabular}

Ao analisar os trabalhos que determinam a protrusão dos incisivos inferiores, por meio da análise morfodiferencial estabelecida por INTERLANDI ${ }^{44,45}$, BERTOZ ${ }^{10}$, MEDEIROS $^{66}$, RADI $^{77}$, pode-se concluir que existe, igualmente, variação dos valores médios, quando se analisa a variável referente à LINHA “I”, de acordo com os grupos étnicos estudados (Tabela 6.2).

Tabela 6.2 - Valores médios entre o posicionamento do incisivo inferior nos diferentes grupos étnicos para a variável Linha I, de acordo com diferentes autores.

\begin{tabular}{l|c}
\hline TRABALHOS & $\begin{array}{c}\text { VALORES MÉDIOS } \\
\text { LINHA “I” }\end{array}$ \\
\hline INTERLANDI (leucodermas) & $-1,28 \mathrm{~mm}$ \\
\hline BERTOZ (melanodermas/Masculino) & $-7,35 \mathrm{~mm}$ \\
\hline MEDEIROS (melanodermas/Feminino) & $-6,48 \mathrm{~mm}$ \\
\hline RADI (xantodermas) & $-4,40 \mathrm{~mm}$ \\
\hline FRANCO (feodermas) & $-4,82 \mathrm{~mm}$ \\
\hline
\end{tabular}


NOUER ${ }^{73}$ considerou que somente a análise de referência incisal de ANDRADE (1-Jr) deveria ser utilizada como parâmetro em indivíduos melanodermas de 10 a 14 anos, uma vez que as demais variáveis estudadas apresentaram valores que indicavam protrusão e inclinação acentuada dos incisivos inferiores. Entretanto, em indivíduos leucodermas os valores médios estipulados por RICKETTS ${ }^{78}(0,5 \mathrm{~mm})$, INTERLANDI ${ }^{44}(-1,28 \mathrm{~mm})$, VIGORITO $^{97}$ $(6 \mathrm{~mm})$, diferiram, também, dos resultados obtidos por NOUER ${ }^{73}$ em indivíduos melanodermas.

DANDAJENA E NANDA ${ }^{29}$, também avaliaram as múltiplas referências incisais. Relataram que os melanodermas demonstraram maior protrusão dentária, pois os valores apresentados foram superiores aos resultados encontrados na literatura com IMPA de 105,8 ${ }^{\circ}$, Md1-APog de 6,9mm e Md1.NB de $37,6^{\circ}$.

Outro trabalho realizado, em jovens leucodermas, por MARTINS et al. ${ }^{63}$ elucidou o crescimento e desenvolvimento craniofacial das várias medidas do complexo craniofacial, em jovens de 6 a 18 anos de idade. Com o intuito de permitir uma análise comparativa com esses indivíduos leucodermas, foram selecionadas algumas variáveis pertinentes relacionadas aos jovens feodermas, com idades entre 12 e 14 anos de idade, envolvidos no presente estudo (Tabela 6.3). 
Tabela 6.3- Médias das variáveis dentárias em jovens brasileiros leucodermas e feodermas na faixa etária de 12 a 14 anos de idade.

\begin{tabular}{c|c|c}
\hline VARIÁVEIS & $\begin{array}{c}\text { Médias leucodermas } \\
\text { Atlas de crescimento } \\
\text { (MARTINS, et al) }\end{array}$ & $\begin{array}{c}\text { Médias feodermas } \\
\text { (FRANCO, EJ) }\end{array}$ \\
\hline \multicolumn{2}{c}{ COMPONENTE DENTÁRIO SUPERIOR } \\
\hline Mx1.NA (0) & 23,3 & 24,2 \\
\hline Mx1.PP (0) & 113,4 & 113,8 \\
\hline Mx1-PP (mm) & 28,4 & 26,5 \\
\hline Mx1-Aperp (mm) & 3,6 & 5,9 \\
\hline Mx1-PTV (mm) & 57,8 & 53,4 \\
\hline \multicolumn{2}{c}{ COMPONENTE DENTÁRIO INFERIOR } \\
\hline Md1.NB ${ }^{(0)}$ & 25,6 & 28,1 \\
\hline IMPA ${ }^{(0)}$ & 91,0 & 94,6 \\
\hline Md1-APog (mm) & 2,2 & 4,1 \\
\hline Md1- GoMe (mm) & 41,2 & 38,8 \\
\hline
\end{tabular}

A análise comparativa dos valores permite observar que na maioria das variáveis dentárias avaliadas por MARTINS et al. ${ }^{63}$ houve grande proximidade ou similaridade com os resultados do presente estudo. Entretanto, pode-se evidenciar que as variáveis dentárias, nos jovens brasileiros feodermas e objeto deste estudo, demonstram ligeira protrusão e inclinação dos incisivos em relação aos leucodermas, com exceção da variável Mx-PTV. Para as medidas Md1-GoMe e Mx1-PP, que quantificam a extrusão dentária e as fases do processo de irrompimento dos incisivos inferiores e superiores, nota-se um valor ligeiramente maior para os jovens leucodermas. 
BEHRENTS ${ }^{9}$ avaliou algumas medidas dentárias, em americanos, com a intenção de investigar o crescimento em adultos. Para a variável Md1-GoMe, em indivíduos de 17 anos obteve uma média de 42,7 milímetros. Dentro desta mesma linha de pesquisa, MARTINS et al. ${ }^{63}$ obtiveram um valor de 43,9 mm para os jovens brasileiros leucodermas, na mesma faixa etária. A justificativa para os 38,8 milímetros encontrados na variável Md1-GoMe pode estar fundamentada no processo de desenvolvimento dentoalveolar e esquelético vertical aos 12 anos de idade. Essa argumentação também se aplica para a variável Mx1-PP, pois ao avaliar os resultados obtidos por BEHRENTS ${ }^{9}$ e MARTINS et al. ${ }^{63}$, em pacientes com 17 anos, notou-se ligeira extrusão dos incisivos superiores em relação aos jovens feodermas com 12 anos de idade.

Embora as variáveis dentárias estudadas, Mx1-PTV, Md1-PTV, não utilizem a base do crânio como referência ${ }^{78}$, as mesmas foram estabelecidas, no presente estudo, principalmente para possibilitarem referências para futuras pesquisas, envolvendo estudos de crescimento longitudinal.

6.3.2. Avaliação, quantitativa, em relação ao posicionamento dos incisivos, de acordo com as variáveis de Steiner (1.NA, 1-NA, 1.NB, 1-NB) em leucodermas, melanodermas, xantodermas e feodermas.

\subsubsection{Mx1.NA}

A diferença entre o posicionamento dos incisivos nos diferentes grupos étnicos, foi enfatizada pelo trabalho de TAKAHASHI ${ }^{88}$, destacando que a média da variável dentária $1 . \mathrm{NA}$ foi de $22,56^{\circ}$, em jovens japoneses brasileiros, semelhante à obtida por SHISHIKURA ${ }^{82}$, também em xantodermas. Entretanto, as mesmas foram ligeiramente inferiores aos $24,1^{\circ}$ obtidos por MIURA; INOUE; 
SUZUKI ${ }^{67}$ em japoneses adultos. Portanto, a inclinação do incisivo superior de $22^{\circ}$, proposta por STEINER ${ }^{85}$, em indivíduos norte americanos é menor que os valores médios $23,3^{\circ}$ encontrados por MARTINS et al. ${ }^{63}$, indicando que os leucodermas brasileiros apresentam os incisivos superiores inclinados para vestibular. Segundo MEDEIROS ${ }^{66}$, os melanodermas apresentaram uma média de $25,35^{\circ}$ superior aos valores encontrados nos jovens feodermas $24,2^{\circ}$, leucodermas $23,3^{\circ}$ e xantodermas 22,56 .

\subsubsection{Mx1-NA}

Na determinação do valor médio de 6,40 (mm) para a variável linear 1NA, em jovens feodermas, pode-se correlacionar com o resultado provindo do trabalho de TAKAHASHI ${ }^{88}$, mostrando diferença insignificante, uma vez que o valor foi muito próximo, ou seja, de 6,07 ( $\mathrm{mm})$. De certa forma, mostra há configuração de proximidade aos resultados obtidos por de MIURA; INOUE; SUZUKI $^{67}$ 5,9 (mm) e SHISHIKURA ${ }^{82}$ 5,4 (mm), assim como quando se compara aos dados obtidos por MARTINS ${ }^{62}$, que obteve o valor de 5,64 (mm) para a referida variável em indivíduos leucodermas. Por outro lado, MEDEIROS ${ }^{66}$ observou em indivíduos melanodermas, valor superior da ordem de 7,12 (mm), indicando maior protrusão em comparação aos indivíduos feodermas, leucodermas e xantodermas.

\subsubsection{Md1.NB}

Na avaliação da inclinação dos incisivos inferiores pôde-se determinar os valores médios padrões para os jovens brasileiros feodermas, situando-os 
dentro da faixa de $28,10^{\circ}$. Nesse sentido, TAKAHASHI ${ }^{88}$ obteve uma média de $26,77^{\circ}$ para os jovens japoneses do gênero masculino e feminino, mas que difere dos valores de $31,2^{\circ}$ encontrados por MIURA; INOUE; SUZUKI ${ }^{67}$. Por outro lado, em indivíduos melenodermas, MEDEIROS ${ }^{66}$ observou uma inclinação acentuada para vestibular nos incisivos inferiores, com valor médio de $35,18^{\circ}$. Essa inclinação acentuada dos incisivos inferiores, do referido grupo étnico, pode ser explicada pela variação esquelética, principalmente, na base do crânio. Entretanto, ao se avaliar as variáveis cefalométricas que não utilizam a base do crânio como referência, pode-se observar um valor inferior de protrusão e inclinação vestibular dos incisivos, para esse mesmo grupo. ${ }^{34,51,52}$. Dentro da análise estabelecida por STEINER ${ }^{85}$, em indivíduos leucodermas, foi observado um valor médio de $25^{\circ}$, que é muito semelhante ao relatado por MARTINS et al. ${ }^{63}$, ou seja, valor médio de $25,6^{\circ}$. Desta forma, pode-se inferir que a miscigenação, entre indivíduos leucodermas e melanodermas, implica em alterações esqueléticas que associam ou mesclam seus efeitos em indivíduos feodermas, uma vez que a literatura ressalta a existência de grande variação em relação ao posicionamento do incisivo inferior para os diferentes grupos étnicos.

\subsubsection{Md1-NB}

O valor médio de 5,23mm, obtido a partir da análise dos jovens feodermas, demonstra ligeira diferença, quando se compara com o resultado de 6,5mm obtido por TAKAHASHI ${ }^{88}$ e 7,8mm encontrado por MIURA; INOUE; SUZUKI ${ }^{67}$. 
Em indivíduos melanodermas, MEDEIROS ${ }^{66}$ observou acentuada protrusão nos incisivos inferiores ao encontrar a média de 8,75mm, corroborando com as observações decorrentes dos estudos de $\operatorname{ALTEMUS}^{4,5}$ e DRUMMOND ${ }^{34}$.

O estudo de STEINER ${ }^{85}$ indicou uma média de $4 \mathrm{~mm}$ em indivíduos brasileiros leucodermas, enquanto MARTINS et al. ${ }^{62}$ obteve valores superiores que atingiram uma média de 5,23mm. Portanto, esses dados indicam que os brasileiros possuem maior tendência à protrusão dentária, em relação aos indivíduos norte-americanos, provavelmente à maior miscigenação no Brasil.

6.3.3- Avaliação quantitativa, em relação ao posicionamento do incisivo inferior, de acordo com a variável de Tweed (IMPA).

Para os indivíduos feodermas analisados por este estudo foi observado um valor médio de $94,6^{\circ}$ para a variável IMPA. Em sentido comparativo, TAKAHASHI $^{88}$ encontrou uma média de $92,3^{\circ}$ para a inclinação do incisivo inferior com o plano mandibular em brasileiros descendentes de japoneses, superando o valor de $90^{\circ}$ verificado por MARGOLIS ${ }^{61}$ e TWEED $^{93}$ em indivíduos norte-americanos, assim como do observado por MARTINS et al. ${ }^{63}$, que encontraram o valor de $91^{\circ}$, em indivíduos leucodermas de 12 a 14 anos de idade. Por outro lado, HARRIS; KOWALSKI; WALKER ${ }^{40}$ observaram um valor de $95,6^{\circ}$ para indivíduos melanodermas, superando os resultados encontrados por IWASAWA; MORO; NAKAMURA ${ }^{50}$ que também encontraram, em indivíduos japoneses adultos, grande vestibuloversão dos incisivos inferiores com $95,5^{\circ}$. 
6.3.4- Comparação entre os gêneros masculino e feminino

Diversos trabalhos $24,29,38,39,52,75,77,87,94$ estabeleceram padrões para os diferentes grupos étnicos com amostras padronizadas, correlacionando a presença ou ausência de dimorfismo entre os gêneros. Entretanto, outros estudos $^{10,15,37,56,66}$ avaliaram, isoladamente, os valores ideais para os jovens e adultos melanodermas.

A avaliação comparativa entre os gêneros é importante para identificar diferenças no processo de crescimento e desenvolvimento entre os jovens do gênero masculino e feminino ${ }^{76}$. MARTINS et al. ${ }^{63}$ verificaram tendências de maior precocidade no desenvolvimento craniofacial para os jovens do gênero feminino, quando comparados aos do masculino, em diferentes idades.

A observação de similaridade numérica e estatística, quando da análise entre os gêneros masculino e feminino, indicam a ausência de dimorfismo sexual entre os jovens brasileiros feodermas (tabela 4), admitindo-se que as variáveis dentoalveolares podem ser aplicadas para ambos os gêneros.

\subsection{Considerações finais}

O conhecimento das diferenças cefalométricas entre os diferentes grupos étnicos, admitindo-se a miscigenação entre os mesmos, tem como finalidade o melhor entendimento das alterações inerentes aos aspectos genéticos, assim como para contribuir no diagnóstico e tratamento das 
discrepâncias faciais, dentárias, esqueléticas ântero-posteriores e verticais $^{19,47,56,72,81}$.

A importância do controle da mecânica estabelecida no tratamento ortodôntico, nos sentidos ântero-posterior e vertical, influi diretamente no sucesso do tratamento ${ }^{64}$. O desenvolvimento e o crescimento facial devem ser perfeitamente entendidos pelo clínico, visto que a quantidade e direção do crescimento proporcionam uma alteração significativa na aplicação de uma terapia ortodôntica ${ }^{76,83}$. Os efeitos da ação terapêutica ortodôntica atuam principalmente nos componentes dentoalveolares. Entretanto, as estruturas do complexo facial podem ser ligeiramente alteradas pela influência da mecânica compensatória ou extracionista ${ }^{17,20,99}$.

O crescimento craniofacial e a influência no desenvolvimento dentoalveolar participam diretamente na determinação do perfil e estética facial devido ao potencial morfogenético individual ${ }^{1,11,12,19,23,47,48,56,72,74,100}$.

A relação entre a rotação dos maxilares e as alterações nas proporções faciais devem continuar sendo investigadas. Assim, a harmonia na quantidade, direção de crescimento e grau de rotação entre a maxila e a mandíbula, necessitam ser devidamente avaliados pelo profissional| ${ }^{11,13,14,47,48,72,75,86,94}$. A correlação entre as alturas faciais ântero-inferior e a posição vertical dentoalveolar, constitui fator de grande relevância no planejamento ortodôntico $^{54}$. Um exemplo seria a aplicação de mecânica com forças extrusivas dentoalveolares para melhorar e interferir no componente vertical, em indivíduos com altura facial ântero-inferior diminuída ${ }^{54}$.

A modificação do posicionamento dentário ântero-posterior, em casos de tratamento ortodôntico com extrações pode afetar a postura labial devido à Eduardo Jacomino Franco 
íntima relação que os lábios mantêm com a posição dos dentes e osso alveolar $^{17}$. Nestes casos, a alteração do perfil facial convexo pode ser aplicada, principalmente nos indivíduos melanodermas com aspecto facial excessivamente protruído ${ }^{17}$.

Considerando que o tratamento ortodôntico pode influenciar nas características faciais, é importante que se discuta e sejam levados em consideração os interesses do paciente quanto ao resultado estético final $^{19,74,100}$.

Ao se avaliar as principais diferenças entre os grupos étnicos, notou-se a existência de variações quanto aos padrões cefalométricos dentários, esqueléticos e tegumentares para os leucodermas, melanodermas e xantodermas.

A análise específica do posicionamento dentário nos jovens feodermas apresentou valores intermediários aos encontrados nos leucodermas e melanodermas. Essa característica foi discutida devido à influência genética que os brancos e negros exercem sobre os seus filhos, que determina um padrão facial, dentário e tegumentar variável.

Entretanto, a miscigenação entre os grupos étnicos desperta a necessidade de individualização do diagnóstico e plano de tratamento ortodôntico. Nesse sentido, o presente trabalho demonstrou a característica do posicionamento dentário em jovens brasileiros pardos ou mulatos na faixa etária de 12 a 14 anos de idade, com "oclusão normal". 


\subsection{Sugestões para trabalhos futuros}

-Comparar as variáveis cefalométricas dentárias em jovens brasileiros feodermas com jovens melanodermas, xantodermas e leucodermas, com "oclusão normal".

- Comparar as variáveis cefalométricas esqueléticas e tegumentares em jovens brasileiros feodermas com jovens melanodermas, xantodermas e leucodermas, com "oclusão normal". 


$$
\text { 7. CONCLUSÖES }
$$





\section{CONCLUSÕES}

- Baseado nos resultados obtidos e na metodologia empregada para determinação dos valores médios de normalidade para as variáveis cefalométricas dentárias, em jovens brasileiros feodermas com "oclusão normal", pode-se evidenciar que:

- a característica distinta observada nos padrões cefalométricos dos indivíduos feodermas difere das apresentadas na literatura para outros grupos étnicos, indicando a necessidade de análise específica ou diferenciada para o diagnóstico e plano de tratamento ortodôntico;

- não houve dimorfismo entre os gêneros analisados. 



$$
\text { ANEXOS }
$$



ANEXO-1

MODELO DO QUESTIONÁRIO: CLASSIFICAÇÃO DOS MULATOS (FEODERMAS).

\section{Universidade de São Paulo}

Faculdade de Odontologia de Bauru

Al. Dr. Octávio Pinheiro Brisolla 9-75-Bauru-SP-CEP 17012-901-C.P.73

PABX (0XX14)3235-8000-FAX (0XX14)3223-4679

CLASSIFICAÇÃO DO GRUPO ÉTNICO DO PAI:

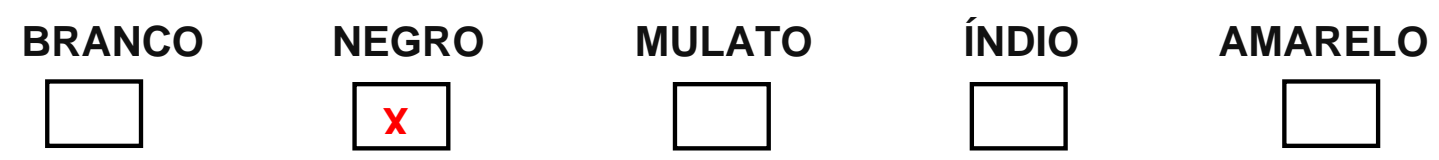

CLASSIFICAÇÃO DO GRUPO ÉTNICO DA MÃE:

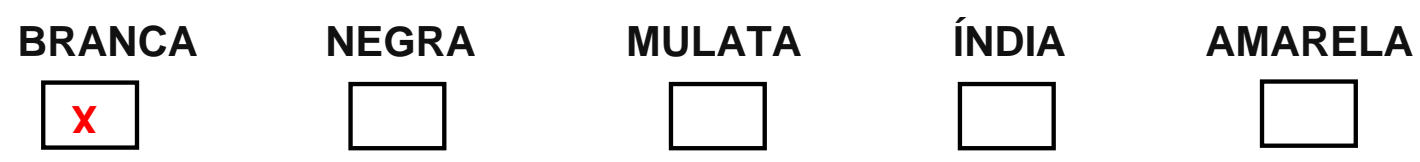

CLASSIFICAÇÃO DO GRUPO ÉTNICO DO ALUNO:

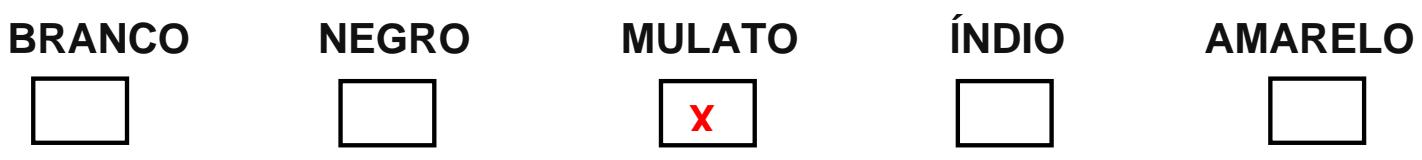

Eduardo Jacomino Franco

Ass: (Responsável); 



\section{REFERÊNCIAS BIBLIOGRÁFICAS}





\section{REFERÊNCIAS BIBLIOGRÁFICAS}

1. Aki, T; Nanda, RS; Currier, GF; Nanda, SK. Assesment of symphysis morphology as a predictor of the direction of mandibular growth. Am J Orthod Dentofacial Orthop. 1994; 106 (1):60-9.

2. Alcalde, RE; Jinno, T; Pogrel, MA; Matsumura, T. Cephalometric norms in Japanese adults. J Oral Maxillofac Surg. 1998; 56 (2):129-34.

3. Alexander, TL; Hitcock, HP. Cephalometric standards for American negro children. Am J Orthod. 1978; 74 (3):298-304.

4. Altemus, LA. A comparison of cephalofacial relationships. Angle Orthod. 1960; 30 (4):223-40.

5. Altemus, LA. Cephalofacial relationships. Angle Orthod. 1968; 38 (3):175-84.

6. Avila, JB. Antropologia Física. Rio de Janeiro: Agir, 1958.

7. Azevedo, T. Cultura e situação racial no Brasil. Rio de Janeiro: Civilização Brasileira, 1966.

8. Bacon, W; Girardin, P; Turlot, JC. A comparison of cephalometric norms for the African Bantu and a Caucasoid population. Eur J Orthod. 1983; 5 (3):233-40.

9. Behrents, RG. An Atlas of Growth in the Aging Craniofacial Skeleton. Michigan: 1985.

10. Bertoz, FA. Determinação da linha "I" em melanodermas brasileiros, masculinos de 12 a 17 anos, com oclusão normal. Dissertação (Mestrado) Faculdade de Odontologia de Bauru, Universidade de São Paulo, 1981.

11. Bishara, SE; Treder, JE; Jakobsen, JR. Facial and dental changes in adulthood. Am J Orthod Dentofacial Orthop. 1994; 106 175-86.

12. Bjork, A. Some biological aspects of prognathism and occlusion of the teeth. Acta Odont Scand. 1950; 9 (1):1-40. 
13. Bjork, A. Prediction of mandibular growth rotation. Am J Orthod. 1969; 55 (6):585-99.

14. Bjork, A; Skieller, V. Facial development and tooth eruption: an implant study at the age of puberty. Am J Orthod. 1972; 62 (4):339-83.

15. Briedenhann, SJ; Roos, EC. A cephalometric appraisal of the Hererospeaking negro male. J Dent Assoc S Afr. 1988; 43 (11):569-75.

16. Broadbent, $\mathrm{BH}$. A new X-ray technique and its application to orthodontia. Angle Orthod. 1931; 1 (2):45-66.

17. Brock, RAI; Taylor, RW; Buschang, PH; Behrentsd, RG. Ethnic differences in upper lip response to incisor retraction. Am $\mathrm{J}$ Orthod Dentofacial Orthop. 2005; 127 (6):683-91.

18. Brodie, AG. On the growth of the jaws and the eruption of the teeth. Angle Orthod. 1942; 12 (3):109-23.

19. Capelozza, LF. Diagnóstico em Ortodontia. Maringá: Dental Press, 2004.

20. Capelozza, LF; Cavassan, AO; Ozawa, TO. Alterações Verticais em Casos de Classe II Divisão 1 Dentária com Exodontias dos Quatro Primeiros Pré-molares. Rev Dent Press Ortod Ortop Facial. 2000; 5 (5):12-19.

21. Capelozza, LF; Fattori, L; Maltagliati, LA. Um novo método para avaliar as inclinações dentárias utilizando a tomografia computadorizada. Rev Dent Press Ortod Ortop Facial. 2005; 10 (5):23-29.

22. Carter, NE; Slattery, DA. Bimaxillary proclination in patients of AfroCaribbean origin. Br J Orthod. 1988; 15 (3):175-84.

23. Coben, SE. The integration of facial skeletal variants. Am J Orthod. 1955; 41 (6):407-34.

24. Connor, AM; Moshiri, F. Orthognathic surgery norms for American black patients. Am J Orthod. 1985; 87 (2):119-34. 
25. Cooke, MS; Wei, SH. A comparative study of southern Chinese and British Caucasian cephalometric standards. Angle Orthod. 1989; 59 (2):131-8.

26. Cotton, WN; Takano, WS; Wong, WM. The Downs analysis applied to three other ethnic groups. Angle Orthod. 1951; 21 (4):213-20.

27. Craven, $\mathrm{AH}$. A radiographic cephalometric study of the central australian aboriginal. Angle Orthod. 1958; 28 12-35.

28. Dahlberg, G. Statistical methods for medical and biological students. New York: Interscience, 1940.

29. Dandagena, TC; Nanda, RS. Bialveolar protrusion in a zimbabwean sample. Am J Orthod Dentofacial Orthop. 2003; 123 (2):133-37.

30. Dias, MCA; Pinzan, A; Henriques, JFC. Avaliação comparativa do crescimento maxilomandibular em crianças leucodermas brasileiras, com oclusão normal, utilizando as medidas Co-A, Co-Gn, AFAl e Dif. Mand./Max. da análise proposta por MCNAMARA JR. Ortodontia. 1993; 26 (1):14-37.

31. Downs, WB. Variations in facial relationship: their significance in treatment and prognosis. Am J Orthod. 1948; 34 (10):812-40.

32. Downs, WB. The role cephalometrics in orthodontic case analylis and diagnosis. Am J Orthod. 1952; 38 (3):162-82.

33. Downs, WB. Analysis of the dentofacial profile. Angle Orthod. 1956; 26 (4):191-212.

34. Drummond, RA. A determination of cephalometric norms for the Negro race. Am J Orthod. 1968; 54 (9):670-82.

35. Enlow, DH; Hans, MG. Essentials of facial growth. Philadelphia: W.B. Saunders, 1996.

36. Flynn, TR; Ambrogio, Rl; Zeichner, SJ. Cephalometric norms of orthognathic surgery in black American adults. J Oral Maxillofac Surg. 1989; 47 (1):30. 
37. Fonseca, RJ; Klein, WD. A cephalometric evaluation of American Negro women. Am J Orthod. 1978; 73 (2):152-60.

38. Gormley, MB; Carlo, JM; Reardon, JR. Cranio-skeletal morphology for a segment of the black urban population using sella nasion as a cranial base line. Quintessence International. 1975; 6 (3):67-70.

39. Gresham, H; Brown, T; Barrett, MJ. Skeletal and denture pattern in children from Yuendumu, Central Australia and Melbourne. Aust. dent. J. 1965; 10 (1):462-8.

40. Harris, JE; Kowalski, CJ; Walker, SJ. Distribuition of the mandibular incisor-mandibular plane angle in nubian schoolchildren. J. Dent.Res. 1975; 54 (3):699.

41. Houston, WJB. The analysis of errors in orthodontic measurements. Am J Orthod. 1983; 83 (5):382-90.

42. Hwang, HS; Kim, WS; McNamara, JA, Jr. Ethnic differences in the soft tissue profile of Korean and European-American adults with normal occlusions and well-balanced faces. Angle Orthod. 2002; 72 (1):72-80.

43. Interlandi, S. O cefalograma padrão do curso de pós-graduação de Ortodontia da Faculdade de Odontologia da USP. Rev Fac Odont Bauru. 1968; 6 (1):63-74.

44. Interlandi, S. Linha "I" na análise morfodiferencial para diagnóstico ortodôntico. Rev. Fac. Odont. Usp. 1971; 9 (2):289-310.

45. Interlandi, S. Orthodontia: Bases para a iniciação. São Paulo: Artes Médicas. Ed. da Univ. de São Paulo, 1977.

46. Isaacson, JR; Speidel, TM; Worms, FW. Extreme variation in vertical facial growth and associated variation in skeletal and dental relations. Angle Orthod. 1971; 41 (3):219-29.

47. Isaacson, R; Erdman, A; Hultgren, B. Facial and dental effects of mandibular rotation. In: Carlson, DS. Craniofacial biology. Ann Arbor Center for Human Growth and Development. University of Michigan., 1981. p.235-69. 
48. Isaacson, R; Zapfel, R; Worms, F; Erdman, JA. Effects of rotational jaw growth on the occlusion and profile. Am J Orthod. 1977; 72 (3):276-86.

49. Ishii, N; Deguchi, T; Hunt, NP. Morphological differences in the craniofacial structure between Japanese and Caucasian girls with Class II Division 1 malocclusions. Eur J Orthod. 2002; 24 (1):61-7.

50. Iwasawa, T; Moro, T; Nakamura, K. Tweed triangle and soft-tissue consideration of japonese with normal occlusion and good facial profile. Am J Orthod. 1977; 72 (2):119-27.

51. Jacobson, A. The craniofacial skeletal pattern of the South African Negro. Am J Orthod. 1978; 73 (6):681-91.

52. Jacobson, A; Oosthuizen, L. The craniofacial skeletal pattern of the south african bantu. J. dent. Ass. S. Afr. 1970; 25 (10):361-5.

53. Janson, GRP; Martins, DR. Estudo longitudinal e comparativo do crescimento facial - dos 13 aos 18 anos de idade em jovens brasileiros leucodermas, utilizando a análise cefalométrica de MCNAMARA JR. Ortodontia. 1992; 25 (3):4-18.

54. Janson, GRP; Metaxas, A; Woodside, DG. Variation in maxillary and mandibular molar and incisor vertical dimension in 12-year-old subjects with excess, normal, and short lower anterior face height. Am J Orthod Dentofacial Orthop. 1994; 106 (4):409-18.

55. Keene, HJ. Mesiodistal crown diameters of permanent teeth in male american negroes. Am J Orthod. 1979; 76 (1):95-9.

56. Kowalski, CJ; Nasjleti, CE; Walker, GF. Differencial diagnosis of adult male black and white population. Angle Orthod. 1974; 44 (4):346-50.

57. Krogman, WM; Sassouni, V. A syllabus in roentgenographic cephalometric. Philadelphia: College Offset, 1957.

58. Love, RJ. Facial growth in males 16 to 20 years of age. Am J Orthod. 1990; 97 (3):200-6.

59. Margolis, HI. Standartization X-ray cephalometrics. Am J Orthod. 1940; 26 (8):725-40. 
60. Margolis, HI. Composite X-ray photographs. Am J Orthod. 1941; 27 (12):717-22.

61. Margolis, HI. The axial inclination of the mandibular incisors. Am $\mathrm{J}$ Orthod. 1943; 29 (10):571-94.

62. Martins, DR. Estudo comparativo dos valores cefalométricos das análises de Downs, Tweed, Steiner e Alabama, com os adolescentes brasileiros, leucodermas, de origem mediterrânea. Tese (Livre Docência) Faculdade de Odontologia de Bauru, Universidade de São Paulo, 1979.

63. Martins, DR; Janson, GR; Pinzan, A; Freitas, MR; Henriques, JFC. Atlas de crescimento craniofacial. São Paulo: Ed. Santos, 1998.

64. Maruo, H. Tratamento de uma Classe II divisão 1 severa em paciente adulto: sucesso ou insucesso? Rev Dent Press Ortod Ortop Facial. 2001; 6 (3):65-72.

65. McNamara, JA, Jr. A method of cephalometric evaluation. Am J Orthod. 1984; 86 (6):449-69.

66. Medeiros, MAQB. Estudo cefalométrico do padrão dentário de jovens brasileiros melanodermas do sexo feminino com "oclusão normal". Ortodontia. 1988; 21 (1):18-33.

67. Miura, F; Inoue, N; Suzuki, K. Cephalometric standards for japanese according to the Steiner analysis. Am J Orthod. 1965; 51 (4):288-95.

68. Miyajima, K; McNamara, JA, Jr.; Kimura, T; Murata, S; lizuka, T. Craniofacial structure of Japanese and European-American adults with normal occlusions and well-balanced faces. Am J Orthod Dentofacial Orthop. 1996; 110 (4):431-8.

69. Montagu, A. Introdução à antropologia física. São Paulo: Cultrix, 1969.

70. Moraes, C; Freitas, MR; Henriques, JFC. Cefalometria - Determinação do padrão esquelético das adolescentes melanodermas brasileiras, com "oclusão normal". Ortodontia. 1988; 22 (4):4-14. 
71. Naidoo, LCD; Miles, LP. An evaluation of the mean cephalometric values for orthognathic surgery for black South Africa adults. Part II. J Dent Assoc S Afr. 1997; 52 (9):545-50.

72. Nanda, SK. Growth patterns in subjects with long and short faces. Am J Orthod Dentofacial Orthop. 1990; 98 (3):247-58.

73. Nouer, PRA; Nouer, DF; Garbui, IU; Miyamura, ZY; Tavano, O. Comparação entre análises de referência incisal em indivíduos jovens melanodermas brasileiros com oclusão normal. Rev Dent Press Ortod Ortop Facial. 2005; 10 (5):130-36.

74. Okuyama, CC. Preferência do perfil tegumentar em jovens melanodermas, leucodermas e xantodermas de ambos os sexos, avaliados por ortodontistas, leigos e artistas plásticos. Dissertação (Mestrado) Faculdade de Odontologia de Bauru, Universidade de São Paulo., 1995.

75. Oliveira, JN. Estudo longitudinal e comparativo da variação do pogônio com os incisivos inferiores, em relação à linha NB, em adolescentes brasileiros, leucodermas, de 12 aos 18 anos de idade, com "oclusão normal". Dissertação (Mestrado) Faculdade de Odontologia de Bauru, Universidade de São Paulo., 1977.

76. Pinzan, A. "Upgrade" nos conceitos da interpretação das medidas cefalométricas. In: Nova visão em ortodontia, ortopedia funcional dos maxilares. São Paulo: Santos, cap.4, 41-45, 2006.

77. Raddi, IMG; Henriques, JFC; Martins, DR. Determinação da linha "I" em xantodermas nipo-brasileiros, dos 12 anos aos 18 anos e 6 meses, com "oclusão normal". Ortodontia. 1989; 22 (3):24-32.

78. Ricketts, RMA. A foundation for cephalometric communication. Am J Orthod. 1960; 46 (5):330-57.

79. Riedel, RA. The relation of maxilary structures to cranium in maloclusion and in normal occlusion. Angle Orthod. 1952; 22 (3):142-5.

80. Rosa, RA; Arvystas, MG. An epidemiologic survey of malocclusions among American Negroes and American Hispanics. Am J Orthod. 1978; 73 (3):258-73. 
81. Schendel, SA. The long face syndrome: vertical maxillary excess. Am J Orthod. 1976; 70 (4):398-408.

82. Shishikura, K. The study on measurements of hard and soft tissues by cephalograms-particularly on normal and Class I occlusion among japonese adults. Nippon Kyosei Shika Gakkai Zasshi. 1969; 28 (2):2531.

83. Sinclair, PM; Little, RM. Dentofacial maturation of untreated normals. Am J Orthod. 1985; 88 (2):146-56.

84. Speidel, TD; Stoner, MM. Variation of mandibular incisor axis in adult "normal" occlusion. Am J Orthod. 1944; 30 (10):536-42.

85. Steiner, CC. Cephalometrics for you and me. Am J Orthod. 1953; 39 (10):729-55.

86. Subtelny, JD; Sakuda, M. Open bite: diagnosis and treatment. Am J Orthod. 1964; 50 (5):337-58.

87. Takahashi, R. Padrão cefalométrico FOB-USP para jovens nipobrasileiros com oclusão normal. Dissertação (Mestrado) Faculdade de Odontologia de Bauru, Universidade de São Paulo, 1998.

88. Takahashi, R. Determinação cefalométrica das alturas faciais anterior e posterior, em jovens brasileiros, descendentes de xandodermas e leucodermas, com oclusão normal. Tese (Doutorado) Faculdade de Odontologia de Bauru, Universidade de São Paulo., 2002.

89. Taylor, WH; Hitchcock, HP. The Alabama analysis. Am J Orthod. 1966; 52 (4):245-65.

90. Tweed, $\mathrm{CH}$. Indications for the extraction of teeth in orthodontic procedure. Am J Orthod. 1944; 30 (8):405-28.

91. Tweed, CH. A philosophy of orthodontic treatment. Am J Orthod. 1945; $31(2): 74-103$.

92. Tweed, $\mathrm{CH}$. The Francfort mandibular plane angle in orthodontic diagnosis, classification, treatment planning and prognosis. Am J Orthod. 1946; 32 (4):175-221. 
93. Tweed, $\mathrm{CH}$. Frankfort Mandibular Incisor Angle (FMIA) in diagnosis treatment planning and prognosis. Angle Orthod. 1954; 24 (3):121-69.

94. Uchiyama, LMAF. Estudo cefalométrico das alturas faciais anterior e posterior, em jovens brasileiros melanodermas, com "oclusão normal". Dissertação (Mestrado) Faculdade de Odontologia de Bauru. Universidade de São Paulo, 2005.

95. Van Der Linden, FPGM. Crescimento e Ortopedia Facial. São Paulo: Quintessence, 1990.

96. Vargas, JN; Henriques, JFC; Freitas, MR; Janson, GR; Almeida, RR. Avaliação Comparativa entre a Linha Sela-Násio e o Plano Horizontal de Francfort como Parâmetros para o Diagnóstico das Posições Ânteroposterior e Vertical das Bases Ósseas, em Jovens Brasileiros Leucodermas com Más Oclusões de Classe I e II de Angle*. Rev Dent Press Ortod Ortop Facial. 1999; 4 (2):13-22.

97. Vigorito, JW. Proposição de uma análise cefalométrica para o diagnóstico e plano de tratamento ortodôntico. ortodontia. 1974; 7 (2):141-52.

98. Wylie, WL. The relationship between ramus height, dental height and overbite. Am J Orthod. 1946; 32 (2):57-67.

99. Wylie, WL. Discussion of thel lower incisor, its influence on treatment and esthetics. Am J Orthod. 1959; 45 (1):50-54.

100. Yehezrel, S; Turley, PK. Changes in the African American female profile as depicted in fashion magazines during the 20th century. Am J Orthod Dentofacial Orthop. 2004; 125 (4):407-17. 



$$
\text { ABSTRACT }
$$





\section{ABSTRACT}

\section{CEPHALOMETRIC DENTAL PATTERN OF YOUNG BRAZILIAN AFRO- CAUCASIAN DESCENDENTS, WITH NORMAL OCCLUSION}

The purpose of this study was to present a specific cephalometric dental pattern for young Brazilian afrocaucasian descendents, by obtaining the mean values of some dental cephalometric variables, and to analyse the prevalence or absence of dimorphism between genders. The sample comprised 40 lateral cephalograms, 20 of male (mean age of 13.15 years) and 20 of female (mean age of 13.10 years) subjects. All subjects were offspring from the miscegenation of Brazilian African and Caucasian adults. All subjects presented permanent dentition in occlusion, except for the third molars, and had not received previous orthodontic treatment. Cephalometric dental measurements were performed following the analyses of DOWNS, STEINER, RIEDEL, TWEED, McNAMARA, RICKETTS. Comparison between genders was performed by the independent "t" test. Data obtained from this methodology confirmed the absence of dimorphism between genders. Additionally, protrusion and buccal tipping of maxillary and mandibular incisors were observed, thus evidencing the adoption of a specific cephalometric pattern for this population.

Key words: Ethnic groups, Cephalometry, Incisors. 




\section{APÊNDICES}

Apêndice 1- Refere-se a todos os valores cefalométricos individuais dos jovens brasileiros feodermas.

\begin{tabular}{|c|c|c|c|c|c|c|c|c|c|c|c|c|c|}
\hline$N^{0}$ & 1.NA & 1.PP & $1-P P$ & 1-PTV & 1-APerp & $1 . N B$ & 1-PM & 1-PTV & 1-NA & 1-NB & 1-APog & IMPA & Linha I \\
\hline 1 & 25.0 & 114.6 & 26.9 & 53.3 & 5.1 & 24.9 & 37.0 & 49.5 & 5.2 & 2.9 & 2.3 & 93.5 & -3.0 \\
\hline 2 & 26.4 & 119.8 & 27.0 & 57.8 & 8.1 & 33.4 & 38.7 & 52.3 & 7.4 & 5.8 & 4.0 & 103.0 & -5.2 \\
\hline 3 & 26.1 & 114.1 & 25.6 & 50.8 & 5.9 & 26.1 & 37.0 & 47.7 & 6.3 & 3.9 & 3.6 & 89.8 & -4.6 \\
\hline 4 & 32.3 & 118.2 & 29.9 & 56.2 & 7.5 & 30.5 & 40.4 & 51.4 & 9.1 & 6.1 & 5.3 & 100.1 & -5.8 \\
\hline 5 & 25.6 & 109.7 & 30.2 & 57.0 & 8.0 & 24.4 & 37.4 & 53.5 & 8.4 & 4.1 & 4.4 & 89.7 & -4.9 \\
\hline 6 & 31.7 & 120.0 & 25.7 & 58.0 & 11.5 & 29.9 & 38.0 & 53.8 & 11.5 & 4.8 & 5.7 & 99.5 & -7.1 \\
\hline 7 & 18.1 & 02.7 & 29.4 & 50.7 & 4.6 & 29.0 & 41.5 & 47.9 & 5.4 & 4.9 & 3.7 & 97.7 & -4.2 \\
\hline 8 & 26.5 & 111.4 & 27.2 & 42.3 & 5.3 & 30.0 & 40.3 & 38.9 & 7.4 & 6.8 & 5.5 & 98.0 & -5.4 \\
\hline 9 & 21.5 & 114.0 & 27.2 & 52.0 & 7.4 & 34.3 & 40.3 & 48.6 & 7.0 & 8.6 & 6.3 & 97.0 & -7.5 \\
\hline 10 & 17.6 & 111.1 & 27.7 & 51.6 & 6.3 & 33.4 & 39.3 & 47.9 & 4.6 & 7.3 & 4.6 & 95.1 & -5.9 \\
\hline 11 & 21.4 & 115.3 & 24.4 & 57.1 & 4.9 & 33.2 & 34.9 & 53.6 & 4.1 & 4.8 & 3.1 & 102.5 & -4.1 \\
\hline 12 & 29.6 & 118.3 & 24.6 & 51.6 & 5.6 & 26.1 & 38.3 & 48.8 & 6.8 & 4.4 & 4.4 & 89.7 & -5.2 \\
\hline 13 & 28.5 & 114.2 & 27.5 & 53.5 & 7.6 & 28.9 & 37.9 & 50.7 & 9.6 & 4.6 & 5.4 & 96.4 & -6.4 \\
\hline 14 & 25.0 & 111.9 & 27.3 & 56.2 & 7.5 & 26.7 & 40.1 & 52.0 & 7.2 & 0.9 & 5.4 & 90.7 & -5.9 \\
\hline 15 & 25.0 & 113.8 & 25.8 & 46.6 & 4.4 & 25.5 & 35.5 & 43.5 & 5.7 & 4.0 & 3.5 & 92.4 & -3.9 \\
\hline 16 & 23.5 & 120.9 & 25.6 & 53.8 & 7.8 & 31.6 & 39.2 & 49.9 & 6.4 & 6.2 & 4.1 & 95.8 & -4.1 \\
\hline 17 & 23.2 & 110.1 & 29.7 & 54.6 & 7.6 & 29.4 & 41.4 & 50.0 & 8.1 & 7.6 & 5.8 & 94.1 & -5.7 \\
\hline 18 & 23.5 & 117.0 & 26.2 & 66.3 & 9.1 & 34.5 & 43.8 & 61.5 & 7.1 & 5.4 & 4.0 & 102.4 & -5.4 \\
\hline 19 & 25.1 & 112.1 & 28.5 & 45.0 & 4.2 & 26.6 & 41.3 & 42.7 & 7.1 & 3.3 & 3.9 & 93.3 & -4.0 \\
\hline 20 & 14.8 & 1.4 & 26.7 & 46.2 & 2.0 & 19.9 & 36.2 & 43.0 & 3.3 & & 0.4 & 90.0 & -0.5 \\
\hline 21 & 22.1 & 117.0 & 22.5 & 47.7 & 3.2 & 23.8 & 37.5 & 44.9 & 4.1 & $4 .{ }^{2}$ & 2.6 & 88.4 & -3.7 \\
\hline 22 & 23.9 & 112.9 & 24.9 & 48.5 & 3.8 & 24.0 & 36.7 & 44.6 & 5.0 & 4.2 & 2.9 & 91.2 & -3.1 \\
\hline 23 & 20.8 & 115.1 & 22.6 & 48.5 & 3.9 & 22.5 & 35.9 & 45.5 & 3.6 & 4.5 & 2.8 & 87.0 & -3.0 \\
\hline 24 & 20.9 & 112.0 & 26.1 & 46.8 & 2.2 & 26.3 & 39.0 & 43.4 & 3.0 & 4.3 & 2.1 & 95.1 & -2.4 \\
\hline 25 & 22.3 & 114.5 & 29.7 & 53.6 & 5.8 & 33.1 & 42.6 & 49.1 & 6.3 & 7.0 & 4.8 & 100.7 & -6.0 \\
\hline 26 & 22.5 & 108.0 & 25.0 & 56.4 & 7.7 & 35.7 & 36.5 & 52.7 & 6.7 & 6.7 & 5.1 & 105.3 & -5.8 \\
\hline 27 & 33.4 & 121.6 & 27.8 & 55.2 & 7.3 & 33.6 & 40.9 & 50.5 & 9.3 & & 5.4 & 103.1 & -6.7 \\
\hline 28 & 26.6 & 108.4 & 30.2 & 46.0 & 3.2 & 23.8 & 40.7 & 42.8 & 7.4 & 3.5 & 3.7 & 94.0 & -3.2 \\
\hline 29 & 20.3 & 110.3 & 26.2 & 51.6 & 4.9 & 28.1 & 40.3 & 47.9 & 4.9 & 8.5 & 5.3 & 97.3 & -7.4 \\
\hline 30 & 24.3 & 112.6 & 26.0 & 55.1 & 6.9 & 24.9 & 37.5 & 51.1 & 6.7 & 4.4 & 3.7 & 90.2 & -4.1 \\
\hline 31 & 33.0 & 117.6 & 30.3 & 58.0 & 10.5 & 36.8 & 40.7 & 55.2 & 12.6 & 7.2 & 7.9 & $\begin{array}{ll}101.7 \\
\end{array}$ & -9.7 \\
\hline 32 & 18.0 & 110.8 & 26.6 & 55.5 & 5.2 & 29.1 & 41.9 & 52.2 & 4.5 & 6.7 & 3.9 & 93.3 & -4.6 \\
\hline 33 & 17.4 & 111.8 & 27.3 & 54.0 & 5.2 & 36.0 & 40.2 & 50.7 & 3.6 & 6.9 & 4.1 & 100.3 & -5.6 \\
\hline 34 & 19.8 & 110.2 & 23.8 & 53.3 & 3.1 & 17.9 & 36.2 & 49.7 & 3.4 & 1. & 0.8 & 88.9 & -1.0 \\
\hline 35 & 28.5 & 114.8 & 29.3 & 51.7 & 6.7 & 22.9 & 38.6 & 49.5 & 7.2 & 4.1 & 4.5 & 84.1 & -5.8 \\
\hline 36 & 23.2 & 114.9 & 21.2 & 55.8 & 3.5 & 13.1 & 36.2 & 53.0 & 4.0 & 1.6 & 1.6 & 80.5 & -1.8 \\
\hline 37 & 29.4 & 124.1 & 22.7 & 60.7 & 8.8 & 33.0 & 36.9 & 56.9 & 7.6 & 7.5 & 5.8 & 91.2 & -7.2 \\
\hline 38 & 26.5 & 118.0 & 26.9 & 58.5 & 6.3 & 29.2 & 42.8 & 54.7 & 6.2 & 9.2 & 6.1 & 91.1 & -6.8 \\
\hline 39 & 24.7 & 110.1 & 26.0 & 52.3 & 6.3 & 29.7 & 36.6 & 48.1 & 6.9 & 5.1 & 4.1 & 97.7 & -4.5 \\
\hline 40 & 21.2 & 109.3 & 25.0 & 48.4 & 3.4 & 22.3 & 36.9 & 45.2 & 5.3 & 1.2 & 1.5 & 93.7 & -1.7 \\
\hline
\end{tabular}


Apêndice 2- Refere-se aos valores cefalométricos individuais dos jovens brasileiros feodermas do gênero masculino.

\begin{tabular}{c|c|c|c|c|c|c|c|c|c|c|c|c|c}
\hline $\boldsymbol{N}^{\text {O }}$ & 1.NA & 1.PP & 1-PP & 1-PTV & 1-APerp & 1.NB & 1-PM & 1-PTV & 1-NA & 1-NB & 1-APog & IMPA & Linha I \\
\hline Masc. 1 & 25.0 & 114.6 & 26.9 & 53.3 & 5.1 & 24.9 & 37.0 & 49.5 & 5.2 & 2.9 & 2.3 & 93.5 & -3.0 \\
\hline Masc. 2 & 18.1 & 102.7 & 29.4 & 50.7 & 4.6 & 29.0 & 41.5 & 47.9 & 5.4 & 4.9 & 3.7 & 97.7 & -4.2 \\
\hline Masc. 3 & 29.6 & 118.3 & 24.6 & 51.6 & 5.6 & 26.1 & 38.3 & 48.8 & 6.8 & 4.4 & 4.4 & 89.7 & -5.2 \\
\hline Masc. 4 & 28.5 & 114.2 & 27.5 & 53.5 & 7.6 & 28.9 & 37.9 & 50.7 & 9.6 & 4.6 & 5.4 & 96.4 & -6.4 \\
\hline Masc. 5 & 23.5 & 120.9 & 25.6 & 53.8 & 7.8 & 31.6 & 39.2 & 49.9 & 6.4 & 6.2 & 4.1 & 95.8 & -4.1 \\
\hline Masc. 6 & 23.2 & 110.1 & 29.7 & 54.6 & 7.6 & 29.4 & 41.4 & 50.0 & 8.1 & 7.6 & 5.8 & 94.1 & -5.7 \\
\hline Masc. 7 & 23.5 & 117.0 & 26.2 & 66.3 & 9.1 & 34.5 & 43.8 & 61.5 & 7.1 & 5.4 & 4.0 & 102.4 & -5.4 \\
\hline Masc. 8 & 25.1 & 112.1 & 28.5 & 45.0 & 4.2 & 26.6 & 41.3 & 42.7 & 7.1 & 3.3 & 3.9 & 93.3 & -4.0 \\
\hline Masc. 9 & 20.9 & 112.0 & 26.1 & 46.8 & 2.2 & 26.3 & 39.0 & 43.4 & 3.0 & 4.3 & 2.1 & 95.1 & -2.4 \\
\hline Masc. 10 & 22.3 & 114.5 & 29.7 & 53.6 & 5.8 & 33.1 & 42.6 & 49.1 & 6.3 & 7.0 & 4.8 & 100.7 & -6.0 \\
\hline Masc. 11 & 33.4 & 121.6 & 27.8 & 55.2 & 7.3 & 33.6 & 40.9 & 50.5 & 9.3 & 6.4 & 5.4 & 103.1 & -6.7 \\
\hline Masc. 12 & 26.6 & 108.4 & 30.2 & 46.0 & 3.2 & 23.8 & 40.7 & 42.8 & 7.4 & 3.5 & 3.7 & 94.0 & -3.2 \\
\hline Masc. 13 & 20.3 & 110.3 & 26.2 & 51.6 & 4.9 & 28.1 & 40.3 & 47.9 & 4.9 & 8.5 & 5.3 & 97.3 & -7.4 \\
\hline Masc. 14 & 24.3 & 112.6 & 26.0 & 55.1 & 6.9 & 24.9 & 37.5 & 51.1 & 6.7 & 4.4 & 3.7 & 90.2 & -4.1 \\
\hline Masc. 15 & 33.0 & 117.6 & 30.3 & 58.0 & 10.5 & 36.8 & 40.7 & 55.2 & 12.6 & 7.2 & 7.9 & 101.7 & -9.7 \\
\hline Masc. 16 & 18.0 & 110.8 & 26.6 & 55.5 & 5.2 & 29.1 & 41.9 & 52.2 & 4.5 & 6.7 & 3.9 & 93.3 & -4.6 \\
\hline Masc. 17 & 19.8 & 110.2 & 23.8 & 53.3 & 3.1 & 17.9 & 36.2 & 49.7 & 3.4 & 1.7 & 0.8 & 88.9 & -1.0 \\
\hline Masc. 18 & 23.2 & 114.9 & 21.2 & 55.8 & 3.5 & 13.1 & 36.2 & 53.0 & 4.0 & 1.6 & 1.6 & 80.5 & -1.8 \\
\hline Masc. 19 & 29.4 & 124.1 & 22.7 & 60.7 & 8.8 & 33.0 & 36.9 & 56.9 & 7.6 & 7.5 & 5.8 & 91.2 & -7.2 \\
\hline Masc. 20 & 21.2 & 109.3 & 25.0 & 48.4 & 3.4 & 22.3 & 36.9 & 45.2 & 5.3 & 1.2 & 1.5 & 93.7 & -1.7 \\
\hline
\end{tabular}


Apêndice 3- Refere-se aos valores cefalométricos individuais dos jovens brasileiros feodermas do gênero feminino.

\begin{tabular}{l|c|c|c|c|c|c|c|c|c|c|c|c|c}
\hline Fem. 1 & 26.4 & 119.8 & 27.0 & 57.8 & 8.1 & 33.4 & 38.7 & 52.3 & 7.4 & 5.8 & 4.0 & 103.0 & -5.2 \\
\hline Fem. 2 & 26.1 & 114.1 & 25.6 & 50.8 & 5.9 & 26.1 & 37.0 & 47.7 & 6.3 & 3.9 & 3.6 & 89.8 & -4.6 \\
\hline Fem. 3 & 32.3 & 118.2 & 29.9 & 56.2 & 7.5 & 30.5 & 40.4 & 51.4 & 9.1 & 6.1 & 5.3 & 100.1 & -5.8 \\
\hline Fem. 4 & 25.6 & 109.7 & 30.2 & 57.0 & 8.0 & 24.4 & 37.4 & 53.5 & 8.4 & 4.1 & 4.4 & 89.7 & -4.9 \\
\hline Fem. 5 & 31.7 & 120.0 & 25.7 & 58.0 & 11.5 & 29.9 & 38.0 & 53.8 & 11.5 & 4.8 & 5.7 & 99.5 & -7.1 \\
\hline Fem. 6 & 26.5 & 111.4 & 27.2 & 42.3 & 5.3 & 30.0 & 40.3 & 38.9 & 7.4 & 6.8 & 5.5 & 98.0 & -5.4 \\
\hline Fem. 7 & 21.5 & 114.0 & 27.2 & 52.0 & 7.4 & 34.3 & 40.3 & 48.6 & 7.0 & 8.6 & 6.3 & 97.0 & -7.5 \\
\hline Fem. 8 & 17.6 & 111.1 & 27.7 & 51.6 & 6.3 & 33.4 & 39.3 & 47.9 & 4.6 & 7.3 & 4.6 & 95.1 & -5.9 \\
\hline Fem. 9 & 21.4 & 115.3 & 24.4 & 57.1 & 4.9 & 33.2 & 34.9 & 53.6 & 4.1 & 4.8 & 3.1 & 102.5 & -4.1 \\
\hline Fem. 10 & 25.0 & 111.9 & 27.3 & 56.2 & 7.5 & 26.7 & 40.1 & 52.0 & 7.2 & 6.9 & 5.4 & 90.7 & -5.9 \\
\hline Fem. 11 & 25.0 & 113.8 & 25.8 & 46.6 & 4.4 & 25.5 & 35.5 & 43.5 & 5.7 & 4.0 & 3.5 & 92.4 & -3.9 \\
\hline Fem. 12 & 14.8 & 101.4 & 26.7 & 46.2 & 2.0 & 19.9 & 36.2 & 43.0 & 3.3 & 1.2 & 0.4 & 90.0 & -0.5 \\
\hline Fem. 13 & 22.1 & 117.0 & 22.5 & 47.7 & 3.2 & 23.8 & 37.5 & 44.9 & 4.1 & 4.3 & 2.6 & 88.4 & -3.7 \\
\hline Fem. 14 & 23.9 & 112.9 & 24.9 & 48.5 & 3.8 & 24.0 & 36.7 & 44.6 & 5.0 & 4.2 & 2.9 & 91.2 & -3.1 \\
\hline Fem. 15 & 20.8 & 115.1 & 22.6 & 48.5 & 3.9 & 22.5 & 35.9 & 45.5 & 3.6 & 4.5 & 2.8 & 87.0 & -3.0 \\
\hline Fem. 16 & 22.5 & 108.0 & 25.0 & 56.4 & 7.7 & 35.7 & 36.5 & 52.7 & 6.7 & 6.7 & 5.1 & 105.3 & -5.8 \\
\hline Fem. 17 & 17.4 & 111.8 & 27.3 & 54.0 & 5.2 & 36.0 & 40.2 & 50.7 & 3.6 & 6.9 & 4.1 & 100.3 & -5.6 \\
\hline Fem. 18 & 28.5 & 114.8 & 29.3 & 51.7 & 6.7 & 22.9 & 38.6 & 49.5 & 7.2 & 4.7 & 4.5 & 84.1 & -5.8 \\
\hline Fem. 19 & 26.5 & 118.0 & 26.9 & 58.5 & 6.3 & 29.2 & 42.8 & 54.7 & 6.2 & 9.2 & 6.1 & 91.1 & -6.8 \\
\hline Fem. 20 & 24.7 & 110.1 & 26.0 & 52.3 & 6.3 & 29.7 & 36.6 & 48.1 & 6.9 & 5.1 & 4.1 & 97.7 & -4.5 \\
\hline
\end{tabular}


Apêndice 4- Refere-se aos valores das idades individuais dos jovens brasileiros feodermas do gênero masculino.

\begin{tabular}{c|c|c}
\hline IDADES & RAÇA & GÊNERO \\
\hline 14,3 anos & Feod. & Masc. \\
\hline 13,2 anos & Feod. & Masc. \\
\hline 13,5 anos & Feod. & Masc. \\
\hline 12,2 anos & Feod. & Masc. \\
\hline 13,3 anos & Feod. & Masc. \\
\hline 12,5 anos & Feod. & Masc. \\
\hline 13,1 anos & Feod. & Masc. \\
\hline 13,5 anos & Feod. & Masc. \\
\hline 12,1 anos & Feod. & Masc. \\
\hline 13,3 anos & Feod. & Masc. \\
\hline 13,2 anos & Feod. & Masc. \\
\hline 12,3 anos & Feod. & Masc. \\
\hline 14,1 anos & Feod. & Masc. \\
\hline 13,3 anos & Feod. & Masc. \\
\hline 14,2 anos & Feod. & Masc. \\
\hline 13,4 anos & Feod. & Masc. \\
\hline 13,1 anos & Feod. & Masc. \\
\hline 13,0 anos & Feod. & Masc. \\
\hline 12,3 anos & Feod. & Masc. \\
\hline 12,2 anos & Feod. & Masc. \\
\hline & & \\
\hline
\end{tabular}


Apêndice 5- Refere-se aos valores das idades individuais dos jovens brasileiros feodermas do gênero feminino.

\begin{tabular}{c|l|l}
\hline IDADES & RAÇA & GÊNERO \\
\hline 12,0 anos & Feod. & Fem. \\
\hline 13,2 anos & Feod. & Fem. \\
\hline 14,2 anos & Feod. & Fem. \\
\hline 12,2 anos & Feod. & Fem. \\
\hline 12,1 anos & Feod. & Fem. \\
\hline 13,5 anos & Feod. & Fem. \\
\hline 12,4 anos & Feod. & Fem. \\
\hline 13,6 anos & Feod. & Fem. \\
\hline 13,2 anos & Feod. & Fem. \\
\hline 12,8 anos & Feod. & Fem. \\
\hline 13,7 anos & Feod. & Fem. \\
\hline 12,1 anos & Feod. & Fem. \\
\hline 12,1 anos & Feod. & Fem. \\
\hline 12,3 anos & Feod. & Fem. \\
\hline 13,4 anos & Feod. & Fem. \\
\hline 12,8 anos & Feod. & Fem. \\
\hline 13,9 anos & Feod. & Fem. \\
\hline 12,3 anos & Feod. & Fem. \\
\hline 12,6 anos & Feod. & Fem. \\
\hline 13,9 anos & Feod. & Fem. \\
\hline
\end{tabular}

